\title{
Investigation of Correlation between Remotely Sensed Impervious Surfaces and Chloride Concentrations
}

by

\section{Faranak Amirsalari}

\author{
A thesis \\ presented to the University of Waterloo \\ in fulfillment of the \\ thesis requirement for the degree of \\ Master of Environmental Studies
}

in

Geography

Waterloo, Ontario, Canada, 2007

(C) Faranak Amirsalari 2007 


\section{AUTHOR'S DECLARATION}

I hereby declare that I am the sole author of this thesis. This is a true copy of the thesis, including any required final revisions, as accepted by my examiners.

I understand that my thesis may be made electronically available to the public. 


\begin{abstract}
Water quality and nonpoint source (NPS) pollution are important issues in many areas of the world, including the Greater Toronto Area where urban development is changing formerly rural watersheds into impervious surfaces. Impervious surfaces (i.e. roads, sidewalks, parking lots, strip malls, building rooftops, etc.) made out of impenetrable materials directly impact hydrological attributes of a watershed. Therefore, understanding the degree and spatial distribution of impervious surfaces in a watershed is an important component of overall watershed management.
\end{abstract}

According to Environment Canada's estimates, road salts, also considered nonpoint source pollutants, represent the largest chemical loading to Canadian surface waters. The main objective of this study is to verify the often assumed correlation between impervious surfaces and chlorides that result from the application of road salts, focusing on a case study in the selected six major watersheds within the Greater Toronto Area.

In this study, Landsat-5 TM images from 1990, 1995, 2000, and 2005 were used in mapping urban impervious surface changes within the study area. Pixel-based unsupervised classification technique was utilized in estimation of percentage impervious surface coverage for each watershed. Chloride concentrations collected at Water Quality Monitoring Stations within the watersheds were then mapped against impervious surface estimates and their spatiotemporal distribution was assessed. In a GIS environment, remotely sensed impervious surface maps and chloride maps were overlaid for the investigation of their potential correlation. 
The main findings of this research demonstrate an average of $12.9 \%$ increase in impervious surface areas as well as a three-fold increase in chloride concentrations between 1990 and 2005. Water quality monitoring stations exhibiting the highest amounts of chloride concentrations correspond with the most impervious parts of the watersheds. The results also show a correlation (coefficient of determination of 0.82) between impervious surfaces and chloride concentrations. The findings demonstrate that the increase in imperviousness do generate higher chloride concentrations. Correspondingly, the higher levels of chloride can potentially degrade quality of surface waters in the region. Through an innovative integrated remote sensing approach, the study was successful in identifying areas most vulnerable to surface water quality degradation by road salts. 


\section{ACKNOWLEDGEMENTS}

I would like to give my sincere thanks to my supervisor Dr. Jonathan Li for his kind guidance and excellent supervision skills. His supervision has meant an incredible amount to me. Special thanks for all of his fruitful discussions and critical remarks. I would also like to thank him for his enduring efforts to ensure my financial support throughout my master's study.

I would like to give heartfelt thanks to my committee member Dr. Bill Booty for providing me the amazing opportunity to work with him. Special thanks for all his invaluable suggestions. His guidance and insight into water quality information management has been truly inspirational. I would also like to thank my readers Dr. Claude Duguay and Dr. Alex Brenning for their time and effort.

Special thanks go to Anne Grant for her technical assistance to solve remote sensing and GIS-related problems and to Lynn Finch for her administrative support. Many thanks are also extended to Ram Yerubandi, Oscar Resler, Tom Kralidis, and Yao Lu for their patience and enduring assistance. Special thanks go to Gloria Ichim for her formatting assistance, friendship and thought provoking conversations. Thanks also go to Yipeng Yuan for his companionship and encouragement.

Last, but not least, I wish to express my sincere appreciation to my parents, Fahimeh Azarian and Cyrous Amirsalari, who provided unwavering encouragement and support, particularly my dad for his inspiring and thought provoking conversations, and to my fiancé Hossein Rhanama for his love, patience and understanding. I would never have been able to succeed in my master's studies without their generous support. 


\section{TABLE OF CONTENTS}

AUTHOR'S DECLERATION......................................................

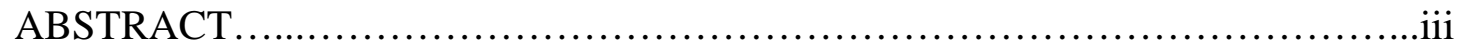

ACKNOWLEDGEMENTS.......................................................

TABLE OF CONTENTS ....................................................

LIST OF FIGURES....................................................viii

LIST OF TABLES............................................................

LIST OF ABBREVIATIONS ................................................

Chapter 1 Introduction........................................................

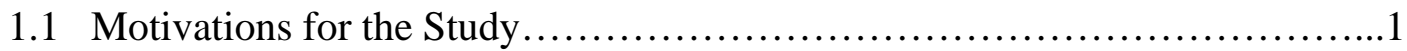

1.2 Objectives of the Study....................................................

1.3 Organization of the Thesis............................................ 7

Chapter 2 Impervious Surface Estimation and Water Quality Evaluation: An

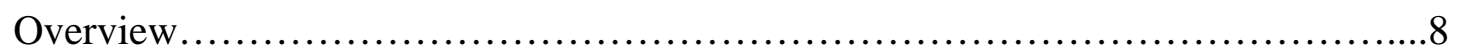

2.1 Introduction.............................................................

2.2 Importance of Impervious Surface Estimation.............................9

2.2.1 Hydrologic Impacts of Impervious Surfaces.............................9

2.2.2 Remote Sensing of Impervious Surfaces.............................12

2.3 Surface Water Contamination by Road Salts.............................. 15

2.3.1 History of Road Salt Contamination................................. 15

2.3.2 Surface Water Contamination by Salts..............................17

2.4 Challenging Issues with Existing Studies................................19

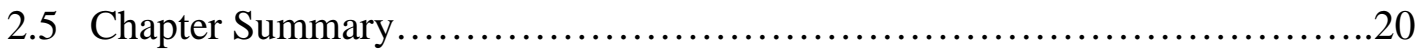

Chapter 3 A Satellite-based Approach for Impervious Surface Estimation Towards

Water Quality Assessment.................................................22

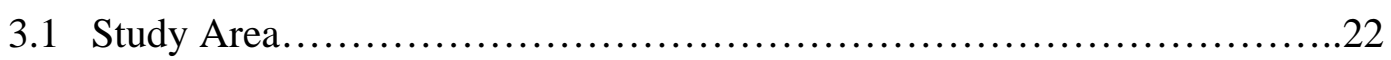

3.2 Physical Characteristics of the Watersheds............................25

3.2.1 Humber River Watershed....................................25

3.2.2 Credit River Watershed.........................................27

3.2.3 Etobicoke and Mimico Creek Watersheds...........................29

3.2.4 Don River Watershed..............................................30

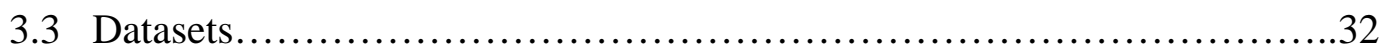

3.3.1 Remote Sensing Data Selection................................32 
3.3.2 Surface Water Quality Data Selection..............................38

3.4 Research Method.....................................................40

3.4.1 Impervious Surface Estimation Method............................40

3.4.2 Chloride Concentration Mapping................................44

3.4.3 Integrating of Remote Sensing and Chloride Data...................44

3.5 Chapter Summary .................................................46

Chapter 4 Chloride and Impervious Surface Trend Analysis: Results and Discussion.............................................................. 47

4.1 Impervious Surface Maps.........................................47

4.1 .1 Introduction.................................................47

4.1.2 Impervious Surface Classification Results........................50

4.1.3 Impervious Surface Growth Analysis............................61

4.2 Accuracy Assessment of Classification.................................62

4.3 Mapping Chloride Concentrations in Watersheds..........................67

4.3.1 Spatial and Temporal Variations.................................67

4.3.2 The Role of Weather Conditions and Salt Usage on Chloride Concentrations..................................................74

4.4 Integration of Impervious Surface Data with Chloride Data................75

4.5 Statistical Analysis................................................80

4.6 Chapter Summary..................................................83

Chapter 5 Conclusions and Recommendations................................84

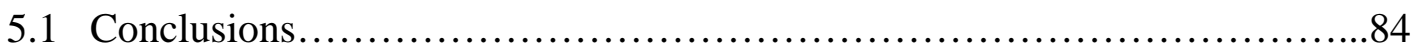

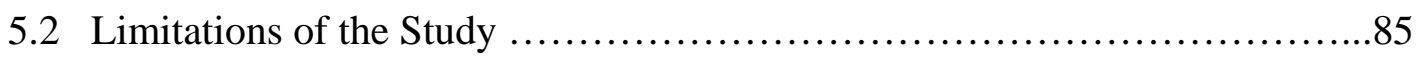

5.3 Recommendations for Water Resource Planners...........................87

5.4 Directions for Future Research........................................90

REFERENCES........................................................ 


\section{LIST OF FIGURES}

Figure 2.1 Hydrologic impact of urbanization. Gray boxes identify direct impacts of impervious surfaces

Figure 2.2 Flow chart showing supervised vs. unsupervised classification methodology

Figure 3.1 The Study Area Watersheds.......................................24

Figure 3.2 Seasonal distribution of rain events in the GTA......................25

Figure 3.3 Humber River Watershed..........................................26

Figure 3.4 Credit River watershed..........................................27

Figure 3.5 Etobicoke and Mimico Creek watersheds...............................29

Figure 3.6 Boundary of Don River Watershed................................. 31

Figure 3.7 Water quality monitoring stations in the GTA........................39

Figure 3.8 Overall research methodology....................................45

Figure 4.1 Landsat-5 TM images of the study area: (A) 1990, (B) 1995, (C) 2000, and

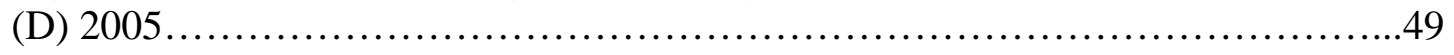

Figure 4.2 Impervious Surface Map of Credit River Watershed.....................52

Figure 4.3 Impervious Surface Map of Etobicoke Creek Watershed.................53

Figure 4.4 Impervious Map of Main Humber Watershed..........................54

Figure 4.5 Impervious Surface Map of Mimico Creek Watershed....................55

Figure 4.6 Impervious Surface Map of West Humber Watershed.....................56

Figure 4.7 Impervious Surface Map of Don River Watershed.....................57

Figure 4.8 Impervious Surface Map of the Entire Study Area Watersheds............59

Figure 4.9 Overall impervious surface changes between 1990 and $2005 . \ldots \ldots \ldots \ldots . .60$

Figure 4.10 Average and median dry season chloride concentrations (mg/L) between

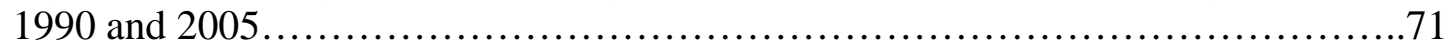

Figure 4.11 Average and median wet season chloride concentrations (mg/L) between 1990 and 2005. 
Figure 4.12 Temporal variations in chloride concentrations between base-flow and dry season conditions at each monitoring station................................. 73

Figure 4.13 Temporal variations in chloride concentrations between base-flow and wet season conditions at each monitoring station.............................73

Figure 4.14 Impervious surface map of 1990, 1995, 2000 and 2005 overlaid on top of chloride map

Figure 4.15 Linear regressions of chloride concentrations and impervious surfaces

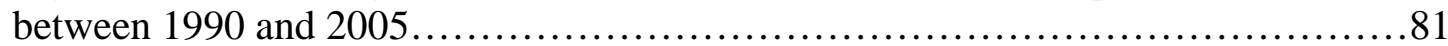

Figure 4.16 Linear regression plot of chloride as a function of impervious surface for all four dates combined........................................................ 82

Figure 4.17 Non-linear correlation between chloride (dry season) and impervious surfaces in six selected watersheds by year. .83 


\section{LIST OF TABLES}

Table 3.1 Comparison of sensor's spatial, spectral, radiometric, and temporal resolution, as well as their coverage area.

Table 3.2 Summary of the approximate cost per $120 \mathrm{~km}^{2}$ area using different remote sensing data sources.

Table 3.3 Selected Landsat TM images used in this study....

Table 3.4 Attributes of selected water quality monitoring stations within the Greater

Toronto Area watersheds.

Table 4.1 Overall impervious surfaces in each watershed between 1990 and 2005...60

Table 4.2 Accuracy Assessment Report. 62

Table 4.3 Total salt usage of cities........................................... 74

Table 4.4 Total amount of snow fall in 1990, 1995, 2000 and 2005................75

Table 4.5 Significance of linear regression between chloride (dry season) and impervious surface by year. 


\section{LIST OF ABBREVIATIONS}

CVC Credit Valley Conservation

DEM Digital Elevation Model

ETM+ Enhanced Thematic Mapper Plus

GIS Geographical Information System

GTA Greater Toronto Area

HRV High Resolution Visible

IR Infra-Red

ISODATA Iterative Self-Organizing Data Analysis Technique

LULC Land Use and Land Cover

MSS Multi-Spectral Scanner

NASA National Aeronautics and Space Administration

ORM Oak Ridges Moraine

PWQMN Provincial Water Quality Monitoring Network

PWQMS Provincial Water Quality Monitoring Station

TM Thematic Mapper

TRCA Toronto and Region Conservation Authority

UTM Universal Transverse Mercator

VHR Very High Resolution

WGS84 World Geodetic System 1984 


\section{CHAPTER 1}

\section{INTRODUCTION}

\subsection{Motivations for the Study}

The phenomenon of urbanization of rural lands is an important problem in growing cities. Growing cities often signify a strong economy, however, as they expand, the stress exerted on natural environments and resources becomes greater (Weng, 2001). Urbanization has substantial influence on different aspects of the quality of life and has brought the extensive attention of researchers, urban planners, ecologists, policymakers and politicians.

During the past 30 years, the Greater Toronto Area (GTA), Ontario has been identified as one of the fastest growing industrial areas of the Great Lakes Basin. As North America's fifth most populated city, serious questions are being raised regarding the environmental sustainability of the urban growth around the GTA. With this urbanization comes a major increase in the amount of impervious surfaces.

Impervious surfaces are defined as any material covering the ground that prohibits the infiltration of water into the soil. Most of these surfaces are man-made surfaces made out of materials such as asphalt and concrete; however, there are some that are natural surfaces that are so heavily compacted that function as impervious. Examples of these are compacted soil in construction areas, dirt roads, and bedrock close to the surface (Arnold and Gibbons, 1996; Schueler, 1994). In this study, impervious surface is defined as human structures that have the potential to prevent infiltration of water 
into the soil. These include building rooftops and patios; transportation-related impervious surface such as highways and roads, strip malls, parking lots and sidewalks; as well as recreational surface such as swimming pools and tennis courts.

Over time, the rapid and uncontrolled conversion of agricultural and rural lands will have a profound impact on the physical and hydrological cycle as well as the chemical and biological quality of water resources (Howard and Maier, 2006). Impervious surfaces influence hydrology in a number of ways. Impervious surfaces prevent precipitation and melt water from infiltrating soils and are likely to generate more runoff during wet seasons and less groundwater discharges to streams during dry seasons (Bowen and Hinton, 1998; Barnes et al., 2001; Shuster et al., 2005). The reduced stream flow and more extreme stream temperatures will stress aquatic ecosystems, therefore disrupting and degrading aquatic habitats (Krause et al., 2004). The increased runoff rate presents a greater potential for degrading stream channels and banks and damaging vegetation around it. As stream banks erode, more sediments, toxic contaminants, and nonpoint source pollutants are carried into the streams from surrounding lands (Herlihy et al., 1998; Booth and Reinfelt, 1993; Shuster et al., 2005; Gibson et al., 2005). All these changes have an adverse impact on the chemical water quality. It has been well-documented that the amount of urban runoff and its impact on surface water quality are strongly correlated to the percentage of impervious surfaces within a watershed (Schueler, 1994; Arnold and Gibbons, 1996; Clausen et al., 2003). 
In the GTA, chloride concentrations have been rising across a majority of urbanized watersheds over the past three decades. The rise in chloride levels is attributed mainly to the increase in road salt applications. Growing sprawl of the urban areas along with the decline in the use of winter tires with the promotion of all-season tires has all led to ever increasing dumping of salts onto our highways, roads, parking lots and sidewalks. Road salts, particularly sodium chloride $(\mathrm{NaCl})$, represent the largest chemical loading to the Canadian surface waters (Environment Canada, 2001). According to an assessment by Environment Canada, an estimated 6.8 million tones of road salts were sold for highway deicing in 2003. There are field and laboratory data showing rapid decline in rainbow trout population after a week's exposure to concentrations of above $1,000 \mathrm{mg} / \mathrm{L}$ of chloride as well as damage to vegetations as far as 50 meters from roadways treated with road salts (Environment Canada, 2001). The trouble is, once the salt dissolves, it washes into streams, enters the drainage system or underlying soil and is forgotten (Kaushal et al., 2005).

This study is mainly motivated by the following:

Firstly, it is evident that high levels of impervious covers will have greater nonpoint source pollutant loads available for transport directly into receiving waters (Todd et al., 1989; Stocker et al., 1999; Snodgrass and D’Andrea, 1993). Surface water quality degradation by road salt is a major concern as there is little evidence that salt loadings can be significantly reduced, and there are no cost effective alternatives to these salts for large scale use at the moment (Howard and Maier, 2006). Recognizing this is crucial to effectively monitor and protect water resources. Therefore, fully understanding the urban growth in the GTA along with its associated increase in 
chloride levels would enhance future decision-making and the protection of surface water quality in the study area.

There are a number of standard physical and chemical parameters used in water quality assessment, such as dissolved oxygen, turbidity, total suspended solids, $\mathrm{pH}$, fecal coliform bacteria, phosphorus, nitrogen and chloride (Hurd and Civco, 2004; Boyer et al., 2002). Selection of chloride as a water quality indicator was a challenge. Among these conventional parameters, chloride is most attributed to urbanization and the consequent increase in imperviousness and therefore is selected to be examined in this study. Also, in 2001, concerns over contamination of surface waters by road salts and its effects on freshwater organisms lead to the inclusion of "road salts" on the second Priority Substances List under the Canadian Environmental Protection Act (CEPA). A detailed report by Environment Canada concluded that road de-icing chemicals containing inorganic chloride salts have serious adverse impacts on the aquatic environment and are therefore toxic (Environment Canada, 2001). One of the most important implications of being classified as "CEPA Toxic" is the need to develop and implement measures that will reduce the impact of road salts on the environment. Accurate and up-to-date information on impervious surface covers and chloride concentrations can help to quantify the current chloride contamination in surface water resources and predict future water quality trends.

Secondly, despite accumulating evidence in recent years of the irreversible damage caused to surface waters by road salts, many case studies focused mainly on estimating groundwater contamination (Pilon and Howard, 1987; Bowen and Hinton, 1998; Williams et al., 2000), while most of the research efforts on the remote sensing 
side are put towards addressing the technical land use and land cover (LULC) classification deficiencies (Wang et al., 2000; Flanagan and Civco, 2001; Wu and Murray, 2003). This study is an attempt to fill in this gap in literature through development of an integrated methodology combining remote sensing and Geographical Information Systems (GIS) with hydrological studies.

Accordingly, the ultimate goal of this study is to make use of digital satellite remote sensing data and geographic information systems (GIS) to develop a fast and reliable solution to estimate the amount of imperviousness with acceptable level of consistency and accuracy, to confirm the connection between chloride and impervious surfaces, and to predict areas most vulnerable to water quality degradation in the future.

\subsection{Objectives of the Study}

This study contributes to the field of hydrology and water resource management by extending the literature on the potential correlation between increased chloride concentrations as a result of increased impervious surfaces and potential water quality impacts in the GTA using satellite remote sensing techniques.

The primary objectives of the study are to map out chloride concentrations at the selected Provincial Stream Water Quality Monitoring Network Stations within six watersheds in the GTA during a 15-year period (1990, 1995, 2000 and 2005), to generate improved and consistent impervious surface estimates for the four separate dates of image data, and to identify the relationship between increased watershedbased impervious surfaces and decreased water quality over time. 
Overall, this study provides a spatiotemporal measure of an important environmental indicator of a rapidly expanding region in Canada by adopting an integrated remote sensing and GIS approach, which may then be applied to other regions as a preliminary step in water quality monitoring and protection.

The following specific tasks are conducted on this study:

1) Generate impervious surface maps using multitemporal Landsat-5 TM data by means of a post-classification approach for four separate dates spanning a 15 year period (1990, 1995, 2000, and 2005).

2) Identify the two land cover types of "green" and "impervious" and to calculate the amount of impervious and to determine areas of increased impervious surfaces through comparison of classified land cover maps in different dates.

3) Relate historical chloride information for selected water quality monitoring stations across study area watersheds to the four date impervious surface estimates to determine, preliminarily, if a relationship between increased impervious surfaces and increased chloride contamination can be identified over time.

4) Integrate maps of chloride concentrations and impervious surfaces in a GIS environment to validate further the adverse effect of impervious surfaces on water quality. 


\subsection{Organization of the Thesis}

The rest of this thesis is organized as follows:

Chapter 2 examines the current literature in the fields of remote sensing of impervious surfaces and advantages of using satellite remote sensing in water quality monitoring and assessment of surface water chloride contamination. It also addresses the current gap in literature that exists in fields of remote sensing and hydrology.

Chapter 3 describes physiological characteristics of the six watersheds in the study area and the data sets used. Then, a comparison of different remote sensing data sources is presented. A detailed explanation of the ISODATA unsupervised classification method used in impervious surface estimation is presented and parameter setting for the test of object-oriented classification approach is also described.

Chapter 4 presents the impervious surface estimation results derived from Landsat TM image classification and its strong correlation with increased chloride concentrations. Accuracy assessment results for unsupervised classification, estimation of correlation coefficient between the two variables, and the results of the integration of remote sensing data with chloride maps in a GIS environment are given and discussed.

Finally, Chapter 5 provides a summary of the study findings including the strong correlation between imperviousness and chloride concentrations. The implications of study’s major findings as well as directions for future research are provided. 


\section{CHAPTER 2}

\section{IMPERVIOUS SURFACE ESTIMATION AND WATER QUALITY EVALUATION: AN OVERVIEW}

This chapter begins with an overview of the hydrological impacts caused by increased urbanization and impervious surfaces in Section 2.1. Section 2.2 discusses the importance of impervious surface estimation, techniques used in impervious surface estimation including conventional remote sensing techniques. A brief overview of road salt contamination in Canada is presented in Section 2.3, followed by the current state of research on surface water contamination by chloride salts. Finally, Section 2.4 discusses gaps found in the literature: lack of attention to surface water contamination by salts, and hardly any study combining remote sensing and surface water quality.

\subsection{Introduction}

Urban water systems are in a period of stress and vulnerability, and will experience rapid and significant changes in the coming decades. Increased impervious surfaces due to urban sprawl negatively impact water quality and can lead to impaired human health and socio-economic decline. Recent studies on the effects of impervious surfaces on surface water quality have concluded that the percent of impervious surface in an urban watershed is a good environmental indicator of potential water quality impacts (Arnold and Gibbons, 1996). Many scientists have identified a positive correlation among percentage of urban land and select water quality parameters (Brabec et al., 2002; Clausen et al., 2003; Roy et al., 2003; Hurd and Civco, 2004). Thus understanding the location and spatial distribution of impervious surfaces is fundamental for urban watershed planning and management. 
Although many scientific discoveries have dramatically advanced our understanding of the ecosystem processes, predicting it with an acceptable degree of certainty is still a challenge (Lunetta and Elvidge, 1998). GIS and satellite remote sensing technologies are valuable tools for understanding change and planning strategies. Multispectral and multitemporal Landsat TM satellite images have been shown to provide accurate, reliable and detailed information of urban environments in terms of spatial coverage and revisit capability (Lillesand et al., 2004). This chapter summarizes the remote sensing techniques used for impervious surface estimation and the advantages of using remotely sensed impervious surfaces in water quality monitoring and assessment of surface water chloride contamination.

\subsection{Importance of Impervious Surface Estimation}

\subsubsection{Hydrologic Impacts of Impervious Surfaces}

Impervious surfaces influence hydrology of a region by preventing infiltration, interception and evapotraspiration. An increase in imperviousness is directly related to increase in the volume and intensity of stormwater runoff (Booth and Reinfelt, 1993). The strong relationship between urban runoff and imperviousness implies impervious surfaces are an important indicator of water quality.

Also, with more impervious surfaces comes a corresponding increase in nonpoint source pollution generation. The nonpoint source pollutants are contaminants of surface and subsurface soils and waters (e.g., fertilizers, pesticides, and salts) that are generally the direct result of human activities. They depend on the routes of the 
hydrological cycle to transport them into the receiving water bodies such as streams and lakes. Another important attribute of nonpoint source pollutants is that they are diffuse in nature (Todd et al., 1989; Arnold and Gibbons, 1996; Corwin and Wagenet, 1996).

Increases in imperviousness and runoff results in more impermeable surfaces and less area for water to drain into soil, thus leading to direct transport of elevated amounts of nonpoint source pollutants including pathogens, nutrients, toxic contaminants, and sediment into receiving waters (Snodgrass and D'Andrea, 1993; D'Andrea and Anderton, 1996; Boyer et al., 2002). The hydrological impacts of impervious surfaces are illustrated in Figure 2.1.

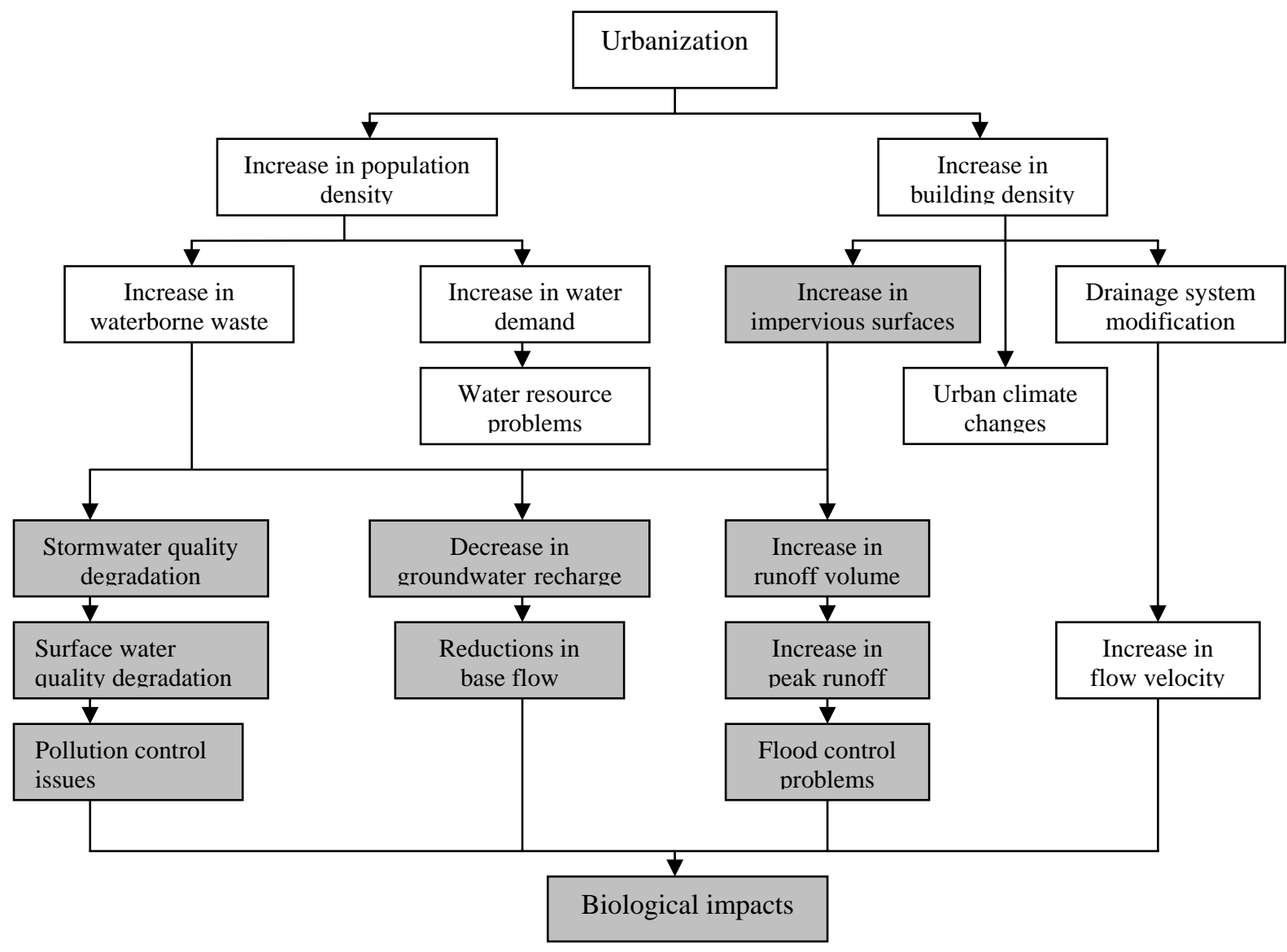

Figure 2.1 Hydrologic impact of urbanization. Gray boxes identify direct impacts of impervious surfaces (Source: Hall, 1984). 
Nonpoint source pollutants cannot be correlated to a single point location and this makes it difficult to monitor, estimate, map or model them. Direct point-based measurement methods of estimating nonpoint source pollutants are limited in that due to cost and logistical considerations, only a portion of the total nonpoint source load could be effectively monitored (Loague et al., 1998). With the launch of medium to high-resolution satellites and the availability of multi-spectral and multi-temporal land cover data sets, our understanding of the intricate relationships between land cover and nonpoint source pollution as well as the effects of land management on water quality has tremendously increased.

Impervious surface maps are useful in monitoring urban sprawl which is an indication of increases in conversion of rural and agricultural lands for development construction. This phenomenon is of growing concern to citizens, those who are responsible for sustainable management of land resources, urban planners, as well as water quality monitoring agencies. Urban growth needs to be monitored regularly since the accumulation of irregular environmental change and the accompanying loss of agricultural lands, forests and wetlands can lead to pollution issues and degrade the overall quality of life (Bauer et al., 2002; Forsythe and Du, 2006).

Satellite remote sensing has the advantage of indirectly measuring continuous realtime environmental impacts of nonpoint source pollutants over large geographic areas in a cost effective and timely manner. PC-based GIS software packages are also needed to efficiently manipulate, store, recover, view, and display the vast volumes of spatial data. 
Accurate maps of impervious surfaces can depict which areas are affected, or will potentially be affected by polluted storm water runoffs so that preventative measures can be put in place. Therefore, understanding the degree of imperviousness and quantifying the spatial coverage of these surfaces provides urban and watershed planners with a crucial component of overall management and gives them a better understanding of how precipitation runoff over these surfaces directly impact regional water quality.

\subsubsection{Remote Sensing of Impervious Surfaces}

For many years, interpretations from aerial photographs have been an important source for land use-land cover mapping. Although accurate for impervious surface delineation, the cost of aerial photography acquisition and interpretation is extremely expensive for large geographic regions. Also, this process is very time-consuming, requires expensive equipment, and expertise of a professional photogrammetrist (Stocker, 1998). Past change detection efforts have been hindered by inconsistent methods and outdated or unavailable data. Today, these expensive and lengthy procedures are being replaced with faster and more economical methods of remote sensing technology capable of automatically and accurately mapping urban environments from digital satellite imagery such as the Landsat Thematic Mapper (TM) or Enhanced Thematic Mapper Plus (ETM+).

With the launch of medium to high-resolution satellites and the availability of multispectral and multi-temporal land cover data sets, our understanding of the intricate 
relationships between land cover and nonpoint source pollution as well as the effects of land management on water quality has tremendously increased.

Despite recent advances in algorithms and methodologies developed for quantification of impervious surfaces (i.e. spectral mixture analysis, artificial neural networks, advanced machine learning algorithms, etc.), the conventional classification techniques have proven effective at estimating impervious surfaces with acceptable accuracy (Jensen, 2005; Campbell, 2002). These pixel-based classification techniques include supervised and unsupervised classifications. Figure 2.2 shows the supervised and unsupervised classification procedures.
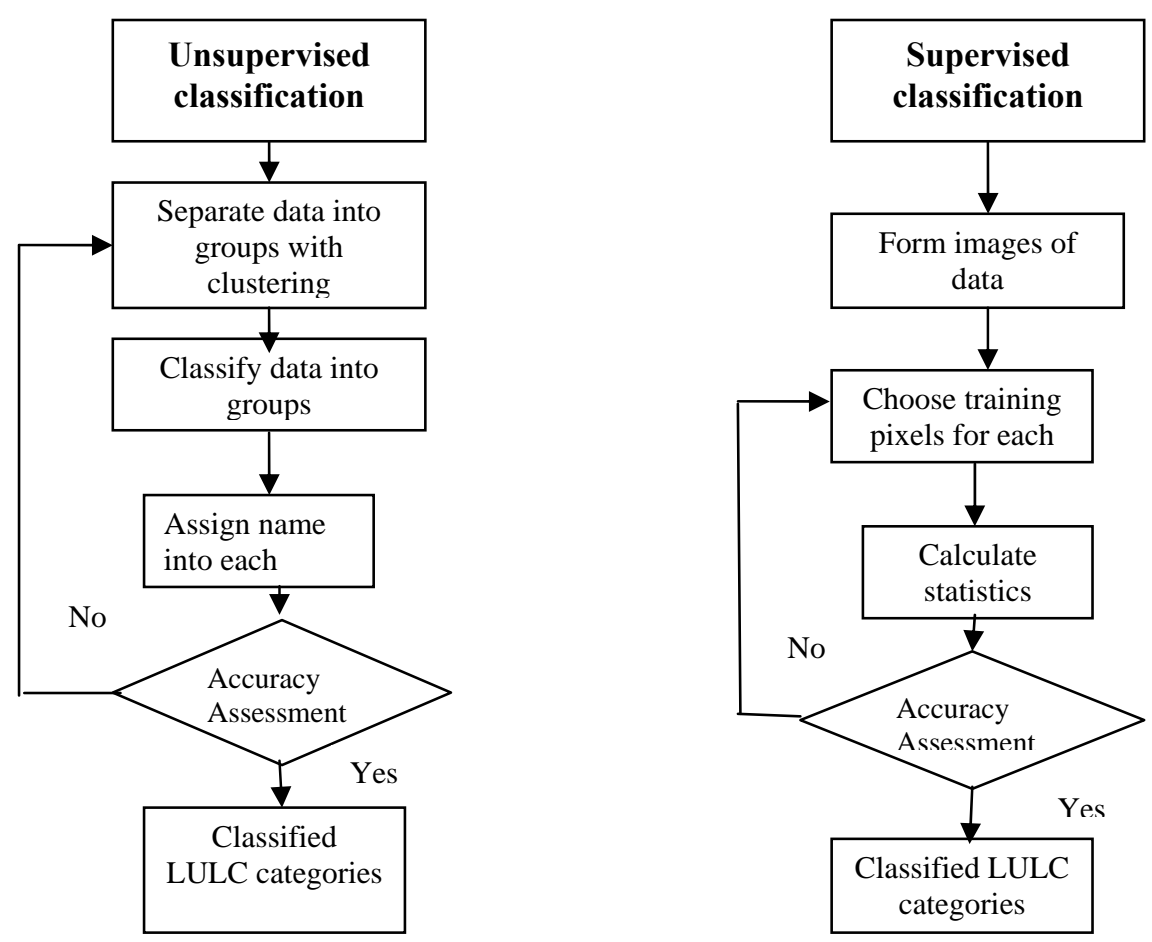

Figure 2.2 Flow chart showing supervised vs. unsupervised classification methodology.

Supervised classification relies on the a priori knowledge of the location and attributes of land cover types present in the image. This can be achieved through field 
work and collection of ground samples, use of aerial photographs or other independent sources of information. Therefore, training areas are used to "train" the classification algorithm and distinguish land cover classes according to their spectral signature. After selection of training areas for each of the land cover classes, statistics are calculated for them, image pixels are assigned to a land cover class, and the accuracy of the classification is assessed. Factors that can influence the training signature of the land cover classes include soil type variations, soil moisture levels, and vegetation health among other environmental factors. Since these factors are very difficult to satisfy for a priori ground sampling, the reverse method of unsupervised classification has gained notice (Mokken, 1995).

In unsupervised classification each individual pixel is compared to each discrete cluster or natural grouping to see which one it is most likely to belong to (Lillesand et al., 2004). This map is then interpreted manually by the user to assign the proper meaning to corresponding classes that are actually present in the real world scene; this requires some knowledge of the scene’s features from general experience or personal familiarity with the area.

The algorithms used in classification of multispectral satellite imagery are pixel-based classifiers which classify the image based on spectral information, such as clustering, parallelepiped, minimum distance, ISODATA, maximum likelihood and Baysian (Jensen, 2005; Campbell, 2002). With both supervised and unsupervised classification techniques, the conventional practice has been based on standard statistical methods: Supervised classification can be based on linear analyses, using standard distributional assumptions (i.e. normal distribution), Bayesian a posteriori 
distribution, or standard maximum likelihood methods, while unsupervised classification can be based on various methods of cluster analysis with similar assumptions (Mokken, 1995).

\subsection{Surface Water Contamination by Road Salts}

\subsubsection{History of Road Salt Contamination}

Road salts, mainly sodium chloride $(\mathrm{NaCl})$, are any salt applied to transportation related surfaces mainly as anti-icing chemicals and have been used in Canada since the 1940’s (Perchanok et al., 1991). Organic salts are not used in Canada or are used in specific circumstances, such as airport runways (Mayer et al., 1999), and are not considered in this study. Sodium chloride is composed of $40 \%$ sodium and $60 \%$ chloride and is released to the environment both naturally and through anthropogenic causes. Natural sources of chloride include rock and soil erosion, atmospheric precipitation, and groundwater discharge (Mayer, 1999). Anthropogenic sources of inorganic chloride salts include direct applications of salt to urban and rural roadways, household waste (Sonzogni et al., 1983), and effluent from the chemical and petrochemical industry (Johnson and Kauss, 1991).

According to Environment Canada's estimates about 4.9 million tonnes of road salts were released to the environment every year during the late 90's, accounting for over 3.0 million tonnes of chloride, to make city driving and pedestrian walking conditions safe. Salting generally begins in mid November and ends in late March. The highest annual loadings of road salt are recorded in the provinces of Ontario and Quebec (Environment Canada, 2001). In the past, the general assumption has been that most 
of the applied salt is flushed into drainage ditches through overland flow and that the environmental impact is minimal. We now know that chloride circulates in the hydrologic system and pass readily though soil, enter groundwater and eventually drain into surface waters.

Road salts can enter the hydrologic system via three sources: release of salt from snow storage areas, snow disposal sites for salt-contaminated snow, and salt applied to roadways and pavements as a de-icing agent. However, salt applied to roadways represents by far the largest and most damaging source of anthropogenic salt contamination (Perchanok et al., 1991). The circulation of inorganic sodium chloride road salt through the water pathways is due mostly to its persistence and very high solubility in water. Because chloride ions are persistent in the hydrological cycle, all chloride applied to roadways as road salts or released from snow disposal sites can be expected to be ultimately found in surface waters (Mayer et al.,1999; Environment Canada, 2001). Once salts reach surface waters, there are no major mechanisms (i.e. biodegradation, evaporation, oxidation, etc.) to remove them from surface waters.

In Canada, natural chloride concentrations in non-bedrock aquifers are generally no more than a few milligrams per liter, with some local or regional exceptions of higher natural salinity. Higher chloride levels are typically associated with road salt applications; for example, chloride concentrations over 18,000 mg/L were observed in runoff from roads and up to $82,000 \mathrm{mg} / \mathrm{L}$ in runoff from uncovered salt piles in a storage yard. Adjacent to storage yards, chloride concentrations have been measured as high as $2800 \mathrm{mg} / \mathrm{L}$ in groundwater, $4000 \mathrm{mg} / \mathrm{L}$ in ponds and wetlands, $4300 \mathrm{mg} / \mathrm{L}$ in watercourses, $2000-5000 \mathrm{mg} / \mathrm{L}$ in urban lakes and $150-300 \mathrm{mg} / \mathrm{L}$ in rural lakes 
(Environment Canada, 2001). The highest concentrations are often associated with winter or spring thaws, although high concentrations can also be seen in the summer, as a result of the travel time to surface waters and the reduced water overland flows in the summer.

\subsubsection{Surface Water Contamination by Salts}

Throughout North America, even within the GTA alone, there are numerous studies of groundwater contamination (Pilon and Howard, 1987; Pollock, 1992; Howard and Haynes, 1993; Snodgrass and D’Andrea, 1993; Gerber and Howard, 1997; Williams et al., 2000; Howard and Livingstone, 2000; Howard and Maier, 2006) with only a few case studies in surface water contamination by road salts. This gap in the literature is further discussed in Section 2.4.

In one of the earliest studies in Canada, Sibul et al. (1977) discovered that one third of groundwater samples collected in the Duffins Creek and Rouge River drainage basins, in the Eastern GTA, contained total dissolved solids in excess of the $500 \mathrm{mg} / \mathrm{L}$ drinking water quality guidelines. Later, Paine (1979) performed a chloride mass balance on the Don River watershed in Toronto, Ontario, and discovered that only nearly half of the salt applied to the watershed was being removed by surface water flow, with the rest infiltrating in groundwater. Frost et al (1981) estimated that $20 \%$ of the highway de-icing salts applied in Massachusetts re-entered surface waters through the groundwater system. In a more recent study by Environment Canada (2001), it has been estimated that $10 \%$ to $60 \%$ of the salt applied to roads infiltrates the groundwater. 
A local study within the GTA, detected chloride levels as high as $14,000 \mathrm{mg} / \mathrm{L}$ in shallow groundwater next to a salted highway in Toronto. Also evident from this study was the appearance of road salt contamination even at distances up to $100 \mathrm{~m}$ from major urban roads (Pilon and Howard, 1987). In another case study, Locat and Gelinas (1989) observed chloride concentrations of over $800 \mathrm{mg} / \mathrm{L}$ in a salt lens that had formed beneath a highway near Trois-Rivieres-Ouest, Quebec as a result of road de-icing application. Later, a survey of 23 springs in the GTA demonstrated chloride concentrations exceeding 1,200 mg/L as a result of road salt applications (Williams et al., 2000).

A comprehensive U.S. study by Kaushal et al. (2005) documented increased chloride concentrations in seven streams and rivers in Maryland, New York, and New Hampshire. The long-term nature of their dataset is important as they analyzed chloride concentrations for a period of 20-40 years showing a steady increase over time. Their results suggested that if salinity were to increase at its present rate, many rural streams in the Northeast would have salt levels of above $250 \mathrm{mg} / \mathrm{L}$, which is the accepted threshold for drinking water and a tolerance level at which chronic toxicity occurs for many freshwater species. Similarly, in Canada, this federally recognized threshold is set at $200 \mathrm{mg}$ sodium/L and $250 \mathrm{mg}$ chloride/L (Canadian Council of Ministers of Environment, 1998). According to estimates by Kaushal et al., surface waters in the Northeastern U.S. could become detrimental to human consumption as well as to quality of freshwater life in the next century.

Another important aspect of Kaushal et al. (2005) study is their intensive focus on streams in the greater Baltimore area, a rapidly urbanizing region. Based on their 
observations, the mean annual chloride concentrations in the urbanized streams increased in relation to the level of impervious surface coverage in the watershed. At above $15 \%$ impervious cover, chloride concentrations were strong enough to damage some plants, and, above $40 \%$, the streams surpassed the threshold of $250 \mathrm{mg} / \mathrm{L}$ chloride. Not surprisingly, the data of Kaushal et al. showed strong seasonal effects, with the highest concentrations in winter (i.e. reaching over 4,600 mg/L). More surprisingly however, chloride concentrations in the rural streams did not return to baseline levels during summer months, even when no salt was being applied. One reason explained was that salt concentrations build up over many years and remain high in the soil and groundwater (Kaushal et al., 2005).

\subsection{Challenging Issues with Existing Studies}

There are some issues facing urban remote sensing studies as well as water quality related studies which are addressed here:

(1) With urbanization and subsequent increases in imperviousness, water that would previously infiltrate into the soil and eventually reach the groundwater table now flows over concrete land and quickly reaches other receiving bodies of water including larger streams and lakes that directly or indirectly sustain our lives (D’Andrea and Anderton, 1996; Mayer et al., 1999). Review of the existing literature in this field showed that in recent years much research has focused on the impacts of road salts on groundwater systems. This study fills in the gap in the surface water literature that has received much less attention. 
(2) Many urban remote sensing studies tend to focus on technical issues in data assembly and physical image classification rather than on the use of the mapped byproducts in the spatiotemporal analysis of urban regions. In this regard, this research focuses on a comprehensive understanding of the relationship between regional impervious surface coverage and water quality impacts by analyzing the data generated with proven remote sensing classification methods such as conventional pixel-based unsupervised classification technique.

Today, there are continued research efforts focusing on improved impervious surface estimation using advanced algorithms and techniques (Wang et al., 2000; Flanagan and Civco, 2001; Wu and Murray, 2003). Although the impact that the location of impervious surfaces has on the water quality of the region will be analyzed as one of the main objectives of this study, improving classification algorithm and accuracy is beyond its scope; this research is using remote sensing as a tool and is aiming at showing the suitability and applicability of this tool to be integrated with other disciplines (i.e. hydrological studies, nonpoint source pollutant impact assessment, watershed planning, watershed management, etc.).

\subsection{Chapter Summary}

Economic development and growth in the GTA continues with each passing year and is characterized by the transformation of rural and agricultural lands into residential and commercial centers. One of the more serious consequences of this growth has been reduced stream water quality and loss of aquatic habitat caused by application of road salts on these paved surfaces. 
GIS and satellite remote sensing technologies are valuable tools in mapping and determining the extent of impervious surfaces within urban watersheds. Through the interpretation and analysis of impervious surfaces derived from digital satellite imagery, the potential impact of road salts on surface waters can be indirectly assessed. Land use-land cover (LULC) map, including impervious surface map, is one of the most important end-products of image interpretation which is obtained from digital image classification process. The process of satellite image classification is described in detail in Chapter 3. The following chapter also presents the designed research methodology and the advantages of using simple but proven remote sensing techniques in preliminary water quality assessment. 


\section{CHAPTER 3}

\section{A Satellite-based Approach for Impervious Surface Estimation towards Water Quality Assessment}

Based on the previous literature review, it has been recognized that impervious surfaces are a key indicator that reflects a number of environmental factors. Increased imperviousness and the consequent increase in chloride levels is an indicator of habitat loss which influences surface water quality. Therefore, setting up a simple, applicable and feasible approach to identify these two indicators is of high importance.

This chapter provides a conceptual framework adopted in this study. Section 3.1 provides a brief overview of the study area. A concrete description of the study area's major watersheds is given in Section 3.2. Section 3.3 describes the required data sources and how they were selected. Section 3.4 presents the research methodology flow chart and detailed explanation of classification, mapping and data integration techniques. Section 3.5 is the summary of this chapter.

\subsection{Study Area}

The GTA in southern Ontario is Canada's largest metropolitan area, with a population of over 5 million (City of Toronto, 2007). In this study, the investigation of chloride levels in relation to impervious surfaces has focused on six watersheds in total: five of which are administered by the Credit Valley Conservation (CVC) and one (Don River) managed by Toronto and Region Conservation Authority (TRCA). The CVC 
watersheds are Credit River, Etobicoke Creek, Mimico Creek, West Humber River, and Main Humber River.

These watersheds are located in a hydrologically sensitive area, bordering the Oak Ridges Moraine (ORM) and the Niagara Escarpment from the north and Lake Ontario from the south (see Figure 3.1). The Regional Municipality of Peel, the second-largest municipality in Ontario after Toronto, occupies the majority of the study area. With an area of approximately $1,242 \mathrm{~km}^{2}$, it encompasses the City of Mississauga, the City of Brampton, and the Town of Caledon. The study area watersheds include a diversity of land cover classes and reflect a range of land use, geology and soils settings. High density urban development characterizes the southern half, while several rural land uses, including agricultural fields, wetlands and forests are dispersed across the upper (north) portion of the region. It is estimated that over $80 \%$ of the population lives in the lower (south) half of this region. In 2001 the population of the Peel Region was 988,948. The population increased at a rate of 17.2\% between 2001 and 2006 (1.16 million) with much growth occurring in the cities of Mississauga and Brampton (Region of Peel, 2007).

Watersheds selected for this research are unique in that some fall entirely in urbanized landscapes whereas the majority of other watersheds are located in rural lands. Therefore, the effects of varying perviousness on how nonpoint source pollutants will be transported can be clearly analyzed (Clausen et al., 2003; Coulter et al., 2004). The diversity of land cover types, combined with the urbanization of the GTA, makes it a near ideal area to evaluate the potential of Landsat TM data for monitoring land change dynamics with respect to water quality. 
Although the topography of the region is not remarkably hilly, elevation differences ranging from $75 \mathrm{~m}$ above-sea-level at the Lake Ontario shore to $270 \mathrm{~m}$ above mean sea level (MSL) in the region's north end can be found. The average elevation at Toronto’s Lester B. Pearson International Airport is 170m above MSL (Environment Canada, 2004).

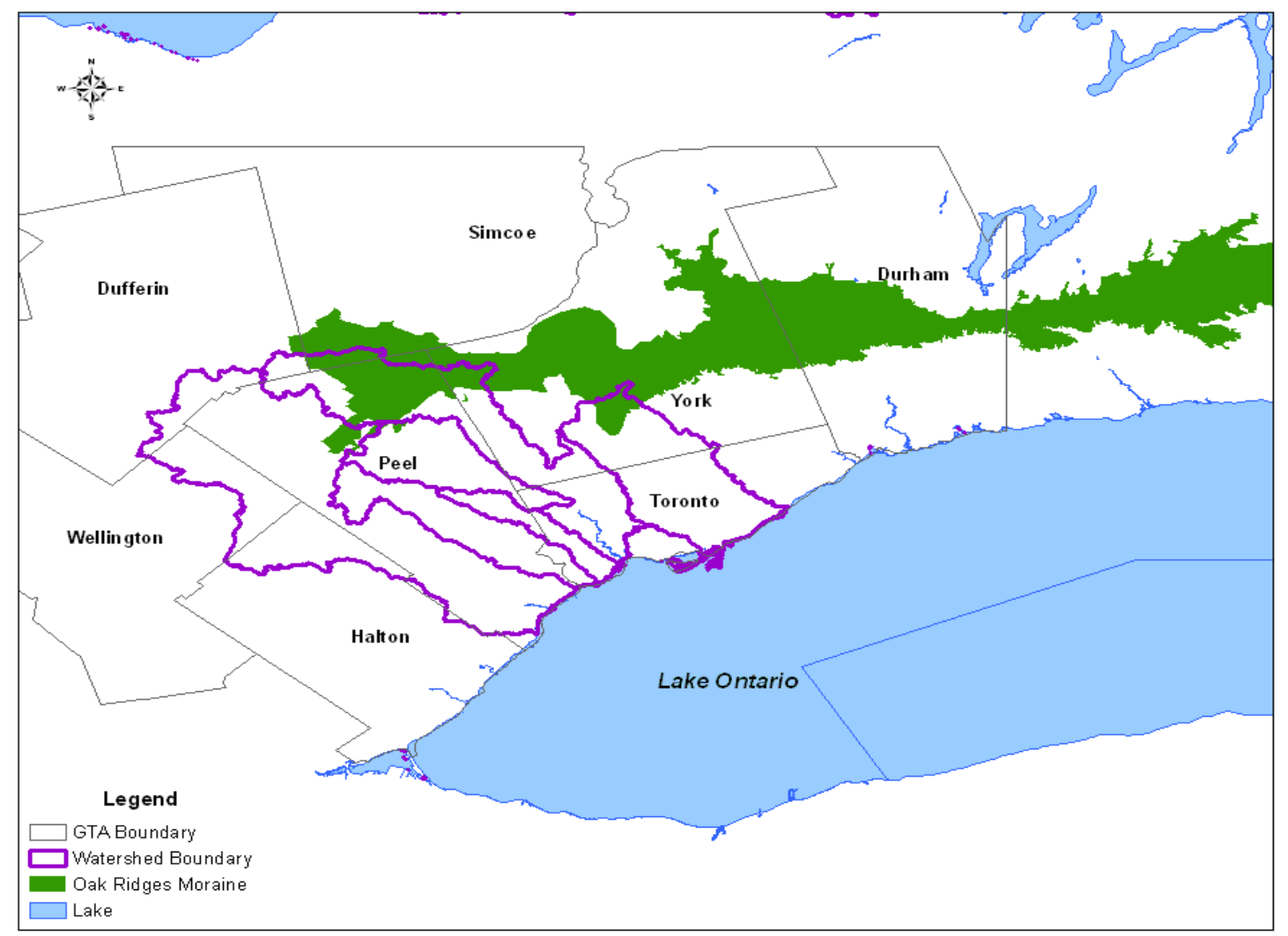

Figure 3.1 Selected watersheds in the study area.

The local climate in the study area is highly influenced by the Oak Ridges Moraine from the north and Lake Ontario in the south. An examination of the seasonal distribution of rain storm events in the GTA has shown that the highest amounts of seasonal rain precipitation takes place between the months of May and November (Figure 3.2). From Figure 3.2 it is evident that the maximum number of monthly rain events generally does not exceed three, with September scoring the highest number of rain events. Observations from the Ontario Chapter of the Soil and Water 
Conservation Society also indicate that one or two rain events each year are responsible for generating over $90 \%$ of the annual pollutant load to Lake Ontario.

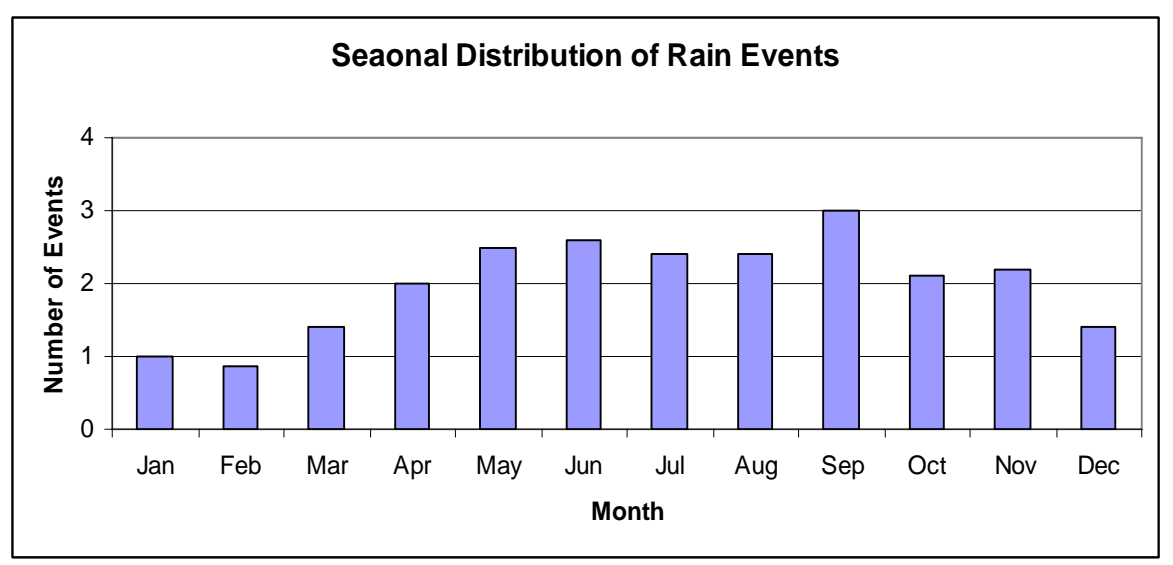

Figure 3.2 Seasonal distribution of rain events in the GTA, Ontario, Canada (Source: Soil and Water Conservation Society, 2007).

\subsection{Physical Characteristics of Selected Watersheds}

At a basic level, five variables control stream hydrology and function: climate, geology, soils, land use, and vegetation (Brabec et al., 2002). The shape of the land, determined by geology and weather, greatly influences vegetation and drainage patterns. Soil types and structures are also dependent on the underlying geologic formations. Soil texture determines moisture holding capacity and that coupled with local topography determine the vulnerability of land to erosion. The following sections briefly describe these physical characteristics within the study area watersheds.

\subsubsection{Humber River Watershed}

The Humber River Watershed occupies the northeast corner of the Peel Region (Figure 3.3). Approximately 27\% of the watershed consists of urban land use, with $40 \%$ in rural use and 32\% under natural covers (i.e. forest, wetlands) (TRCA, 2007). 


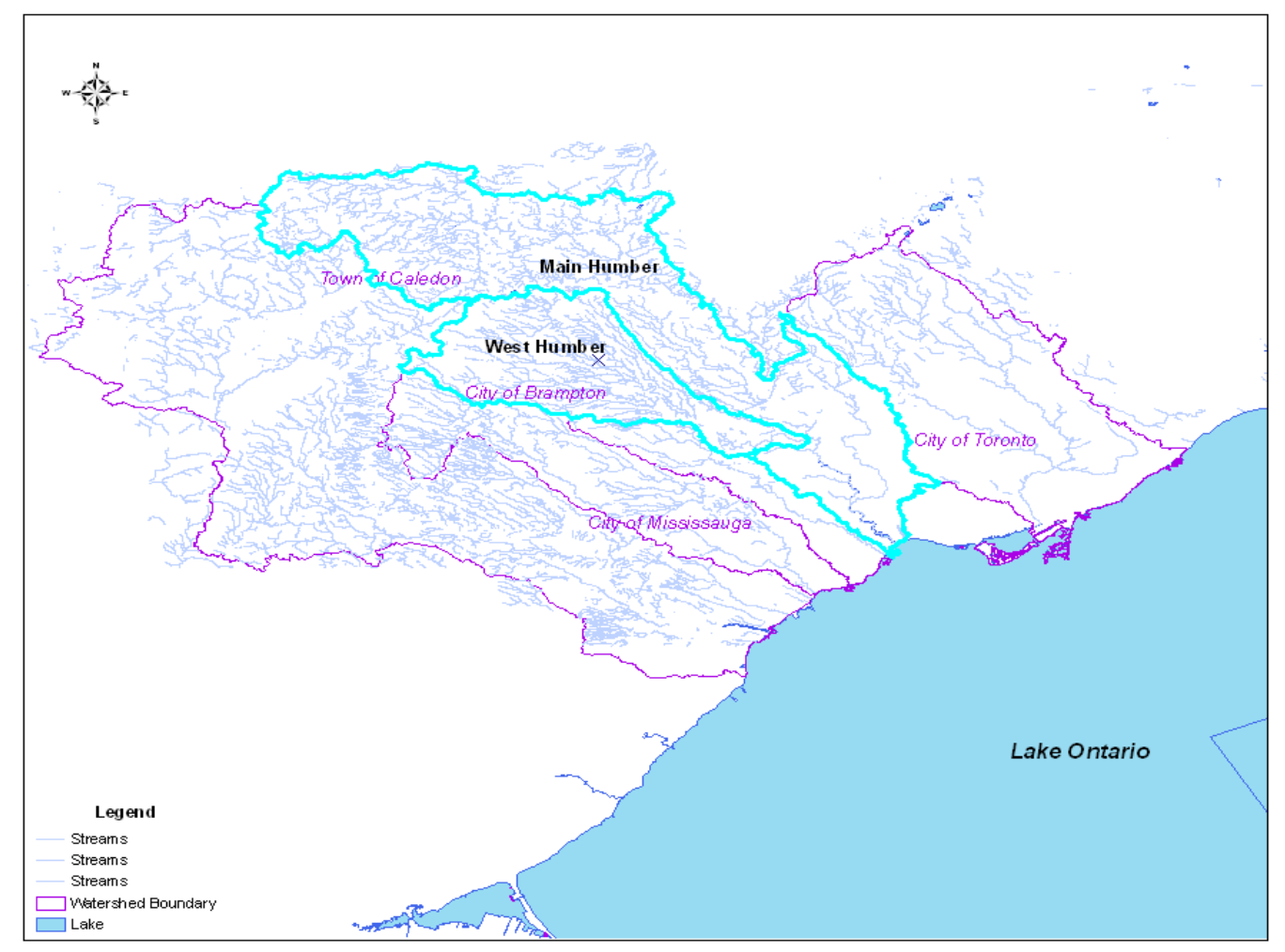

Figure 3.3 Humber River watershed.

The major physiographic formations in the Humber watershed include Niagara Escarpment, Oak Ridges Moraine, South Slope, and Peel Plain. The bedrock in most of the Humber watershed is made up of shale of the Georgian Bay Formation Shale. Limestone bedrock, which can store large amounts of ground water, is only found in the upper reaches of the Main Humber subwatershed above the Niagara Escarpment. In the Oak Ridges Moraine, soils are mostly characterized by sand and gravel, whereas silty clay soils are found in the Peel Plain (Humber River Watershed Plan, 2007).

Of the four subwatersheds across the Humber River watershed, the Main Humber and West Humber subwatersheds are the only two that fall within the boundary of the Peel Region. Most people live in the highly developed areas of the West Humber in the City of Brampton and in northern parts of the City of Mississauga. 
The head waters of the West Humber are located in the South Slope, with the rest of the subwatershed lying in the Peel Plain. The lower reaches of streams in the West Humber with its clay soils, lower groundwater discharges and urbanized landscape exhibit the poorest overall water quality in the Humber river watershed. The upper half of the Main Humber subwatershed within the Town of Caledon remains largely agricultural, with significant natural covers.

\subsubsection{Credit River Watershed}

The majority of the Peel Region is occupied by the Credit River watershed. This watershed is naturally divided into three distinct zones: the upper, middle (also known as the Niagara Escarpment) and lower watersheds (see Figure 3.4).

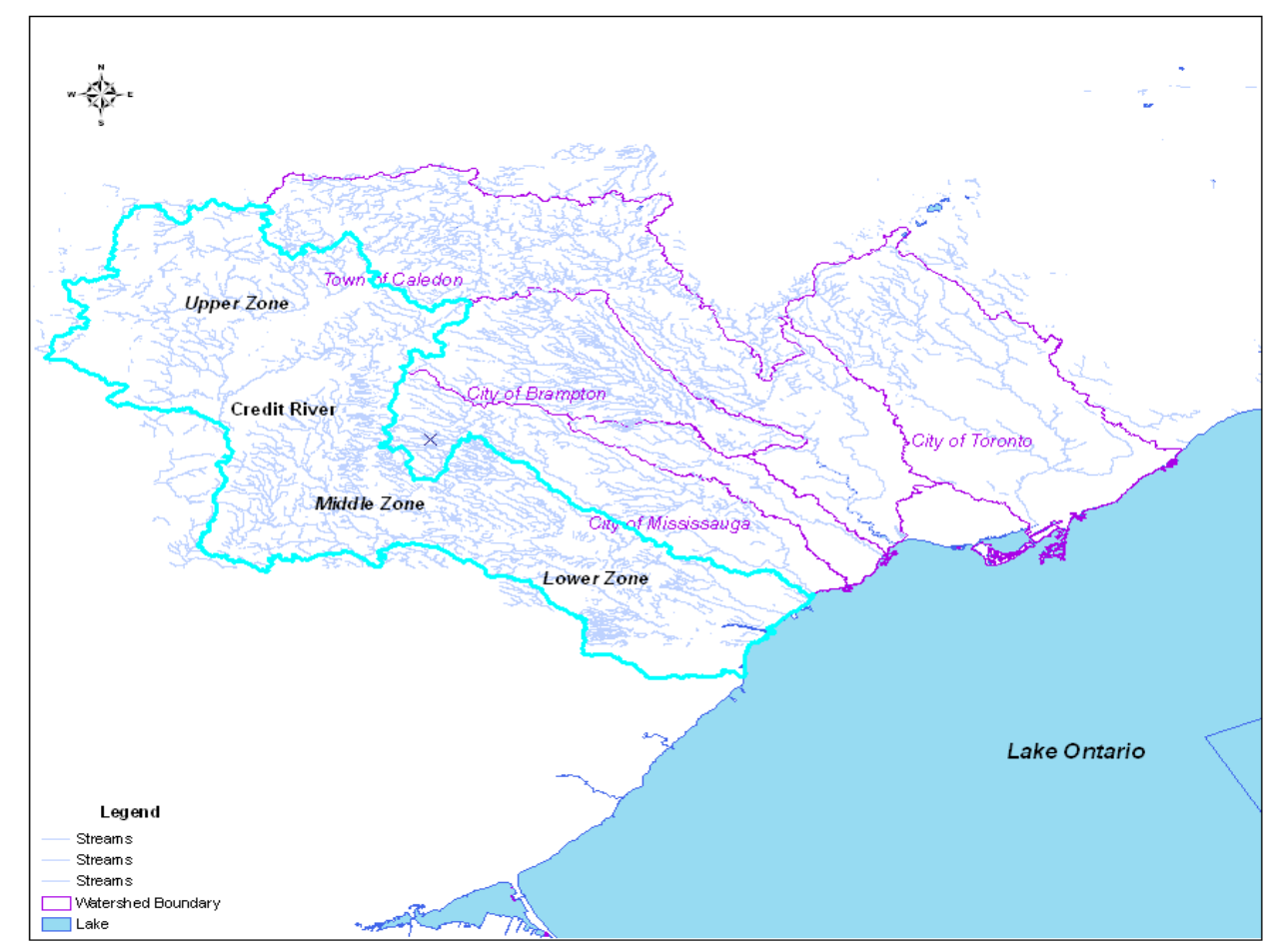

Figure 3.4 Credit River watershed. 
The upper watershed lies above the Niagara Escarpment and has soils that are more coarse-grained and permeable than elsewhere in the watershed. Because of the elevation and the soils, there is significant infiltration of water into the ground. With vegetation cover types such as forests, wetlands and open space areas, Caledon West contains the majority of natural areas in the upper watershed. These natural covers play a vital role in promoting evapotranspiration and groundwater recharge in the lower reaches of the Credit River (CVC, 2005). Unmanaged open space areas that are available in the upper watershed zone can be targeted for future restoration and rehabilitation activities.

Portions of the Oak Ridges Moraine and Niagara Escarpment are located in the middle zone of the Credit River watershed. The Oak Ridges Moraine is characterized by hummocky hills of fine grained sand. Thin soils, steep slope and large areas of rock outcrops characterize the Niagara Escarpment. This topography leads to relatively high runoff volumes and velocities; however, the high percentage of forest cover tends to act against this influence by slowing runoff and increasing infiltration of water into the ground (CVC, 2005).

The lower watershed is comprised of two primary formations, Peel Plain and Iroquois Plain. In comparison to the upper watershed, both of these formations are characterized by low infiltration and relatively flat topography, leading to longer runoff times. The lower watershed includes portions of the City of Brampton and the City of Mississauga. The lower watershed is predominantly made up of urbanized areas with a high level of imperviousness, resulting in higher peak flows. 


\subsubsection{Etobicoke and Mimico Creek Watersheds}

The Etobicoke and Mimico Creek watersheds are situated in the southern half of the Peel Region and include portions of the City of Toronto, City of Mississauga, City of Brampton and the Town of Caledon within their boundaries (Figure 3.5). Toronto's Lester B. Pearson International Airport is the largest single land use lies in the centre of the two watersheds.

The Etobicoke and Mimico Creek watersheds are two of the most highly urbanized watersheds in Ontario. A report by Toronto and Region Conservation Authority (2006) revealed that impervious areas have increased from 10\% in 1947 to 66\% in 2006. While Environment Canada's target for riparian cover within a watershed is 75\%, currently less than 20\% of Etobicoke Creek and only 16\% of Mimico Creek is forest cover (TRCA, 2006).

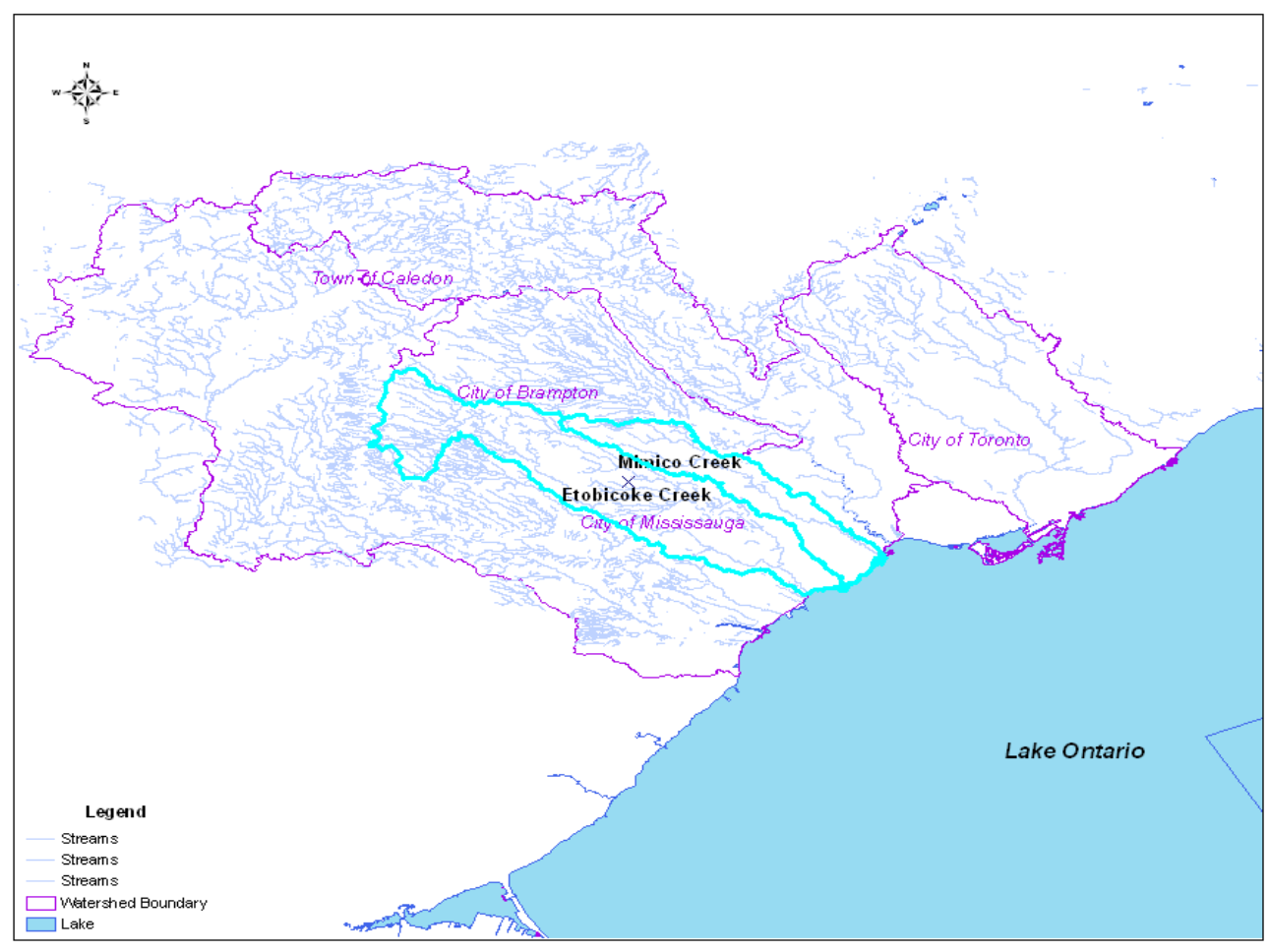

Figure 3.5 Etobicoke and Mimico Creek watersheds. 
Both subwatersheds are similar in surface geology, geomorphology and climatic conditions. Typically the difference between the southern and northern regions of the watersheds is a slightly longer growing season, more precipitation, and warmer summers in the southern areas. The presence of Lake Ontario and the greater extent of urbanization have moderated the climate in the lower portions of the watersheds.

Similar to the Credit River watershed, the major landforms within the Etobicoke and Mimico Creek watersheds include the south slope, Peel Plain and the Iroquois Plain. These plains are characterized by flat to gently sloping topography. Fine clay soils are found on the Peel Plain. As a result, the infiltration is low and groundwater supply is limited as more precipitation runs on the surface, or is lost through evaporation. The South Slope and Iroquois Plain are mainly characterized by sands, gravels, and clay soils. The large deposits of sand and gravel associated with ancient Lake Iroquois are highly permeable and may contribute baseflow to steams flowing through the area (TRCA, 2006). However, impermeable surfaces such as asphalt and concrete have hindered infiltration and reduced baseflow discharges.

\subsubsection{Don River Watershed}

The Don River is formed from two rivers (East Don and West Don) that meet $7 \mathrm{~km}$ north of Lake Ontario and similar to other major streams flows southward into Lake Ontario. Figure 3.6 shows the boundaries of the Don River watershed. This river drains a large part of the GTA covering two regions, Toronto and York, as well as eight local municipalities within these regions: Toronto, East York, North York, York, Scarborough, Markham, Vaughan, and Richmond Hill. 
The eastern most part of the East Don River originates from the Oak Ridges Moraine, flowing south-east through ravine forests in municipality of Richmond Hill. The headwaters area of the East Don in the City of Vaughan are still undeveloped, however, the greater part of the Don River watershed is paved over for residential and commercial use. Flowing through the heart of City of Toronto, the Don River is one of Canada's most polluted urban rivers. Its $360 \mathrm{~km}^{2}$ of land is over $80 \%$ urbanized and houses over 800,000 people (TRCA, 2006).

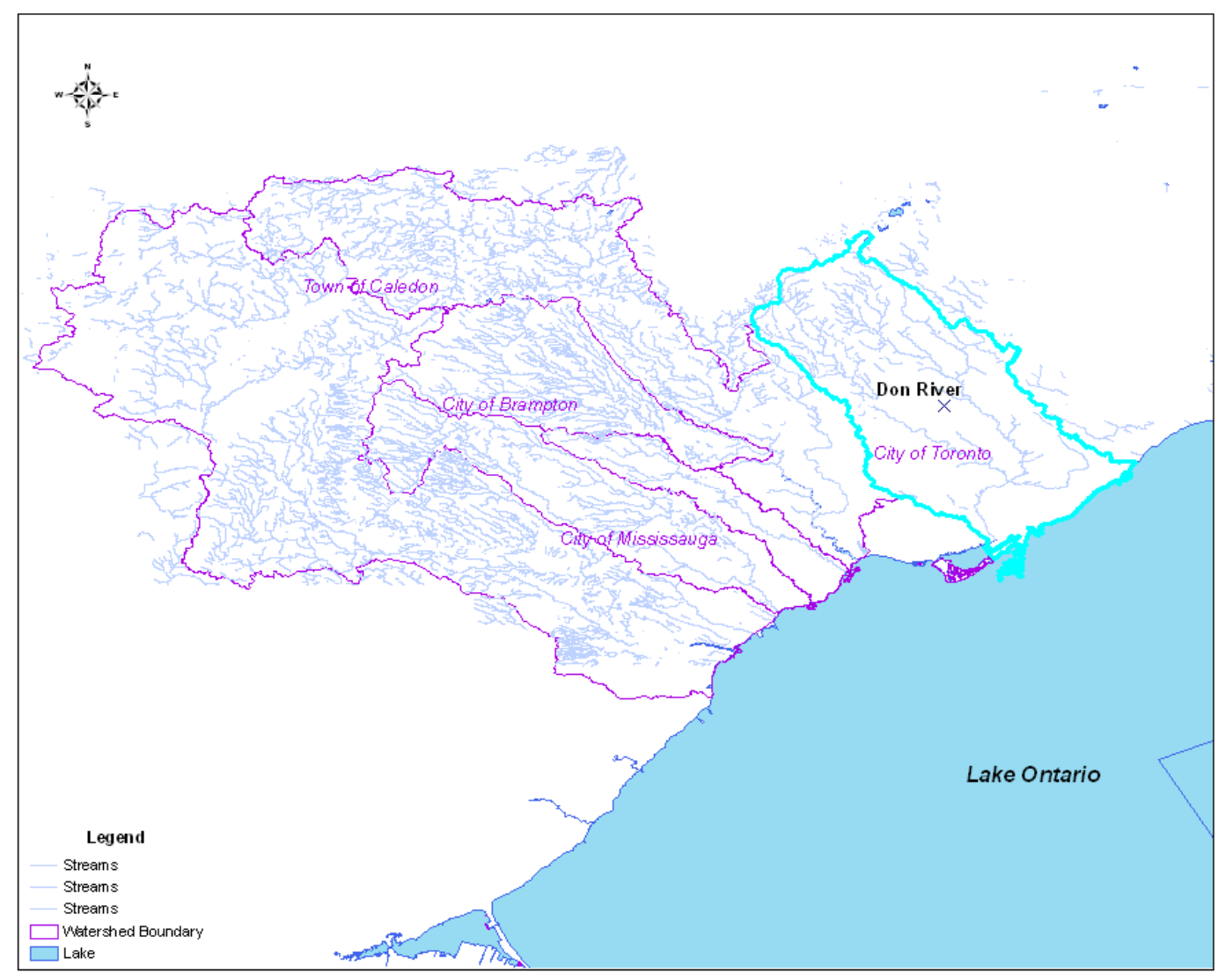

Figure 3.6 Don River watershed. 


\subsection{Datasets Used in the Study}

\subsubsection{Satellite Image Data}

The selection of sensible and practical data sources is important to ensure the proper execution of the study objectives. The following sections briefly describe different data sources available for impervious surface estimation along with their advantages and disadvantages.

\section{Comparison of Different Remote Sensing Data Sources}

Early impervious surface estimation using remotely sensed data were mainly conducted through the interpretation of aerial photographs. This procedure is very time consuming and costly when applied over large areas. In addition, aerial photographs were collected on different dates and at varying scales, therefore the adjustment, correction and digitization of the images were generally required. Later, digital satellite imagery began to provide a synoptic view of the Earth's surface by producing fast and repeatable digital maps. With the advent of new remote sensing techniques, the amount of labor necessary for impervious surface estimation was significantly reduced; therefore results comparable to aerial photo interpretation could be obtained in considerably less time and with significant reduction in costs (Donnay et al., 2001).

The year of 1972 marks the launch of the world's first Earth Resources Technology Satellite (ERTS-1), later called Landsat-1, by NASA. Since then, the spatial resolution of satellites have continuously improved from coarse spatial resolution Landsat Multispectral Scanner (MSS), Landsat Thematic Mapper (TM), to medium 
resolution Enhanced Thematic Mapper Plus (ETM+) series, SPOT High Resolution Visible (HRV) series, and to high-resolution IKONOS and QuickBird commercial satellites.

Landsat satellites have been operational for environmental and natural resources mapping since the early 1980s. A big advantage of Landsat images is that satellite sensors have spectral bands that match the spectral reflectance of certain land covers (Lillesand et al., 2004). Whereas colour and colour-infrared aerial photography is limited to three spectral bands, and black and white photographs have only one band which provides even less information. The Landsat TM sensor records the visible (band 1, 2, 3), near-IR (band 4 and 5), mid-IR (band 7) and thermal (band 6) part of the electromagnetic spectrum in seven bands of data as opposed to the four bands of data collected from the Landsat MSS sensor.

In addition to having three more bands, the TM data can be viewed at a much higher resolution compared with MSS. Bands 1-5 and 7 each have a spectral resolution of 30m while the MSS is only offered in $79 \mathrm{~m}$ and $82 \mathrm{~m}$ resolutions. Band 6 (thermal IR) has a maximum spatial resolution of $120 \mathrm{~m}$. Of all satellites of the Landsat program, today, only Landsat-5 (launched in March 1, 1984) and Landsat-7 (launched in April 15, 1999) are still functioning, both of which operate in a sun-synchronous orbit that visits the same location on the Earth every 16 days. Landsat 7 ETM+ data are essentially the same as Landsat 5 TM data, except it has a new panchromatic band at $15 \mathrm{~m}$ and a thermal IR band (band 6) with an increased resolution of 60m from previous 120m (Satellite Imaging Corporation, 2007). 
The French Earth Observation System SPOT is another provider of medium-to-high resolution satellite imagery. The first SPOT imaging satellite was launched in early 1986 and there have been five SPOT satellites launched, providing image data of the earth's surface over the visible (green and red) to near infrared portion of the electromagnetic spectrum (CRISP, 2007). SPOT has several advantages over Landsat: it has higher spatial resolution, a valuable aid in classification since smaller features can be better identified by shape characteristics. SPOT also has off-nadir capabilities and has the ability to produce stero pair for DEM generation and is able to revisit the same area every 5 days. However, SPOT scene sizes are smaller than Landsat $(60 \mathrm{~km}$ vs. $185 \mathrm{~km}$ ). Landsat has more spectral bands and produces larger images. In fact, Landsat 7 ETM + provides nine times the coverage of a 10m panchromatic SPOT scene.

There are, however, some limitations in using Landsat TM imagery: The image resolution is low when compared to large scale aerial photography. Users of aerial photography are accustomed to very high resolution (VHR) images with typical ground sample sizes of $15-20 \mathrm{~cm}$, which satellite imagery cannot match at present. However, availability and access to recent aerial photographs is often limited and new aerial surveys are time consuming, costly and difficult to arrange. Although Landsat TM's ability to provide fine detailed maps is limited, its resolution is fine enough to differentiate land-cover properties with differing levels of imperviousness.

In September 1999, the world's first VHR commercial imaging satellite, IKONOS-2, was launched. With a swath width of $11 \mathrm{~km}$ at nadir, IKONOS sensor records 4 channels of multispectral data at $4 \mathrm{~m}$ resolution and one panchromatic channel with 
$1 \mathrm{~m}$ resolution. Another new generation of high-resolution commercial imaging satellite, QuickBird, was later launched in October 2001. QuickBird offers $0.6 \mathrm{~m}$ resolution panchromatic and $2.4 \mathrm{~m}$ multispectral imagery. At $0.6 \mathrm{~m}$ resolution, impervious surfaces such as houses, buildings, roads, bridges, etc. become clearly visible. This is currently the highest spatial and radiometric (11 bit) available in a commercial imaging satellite (GeoCommunity, 2007). While spatial resolution of a sensor refers to the size of the smallest possible feature that can be detected, the radiometric resolution describes its ability to discriminate very slight differences in energy (see Table 3.1). The drawback in using VHR satellite imagery such as IKONOS and Quickbird is no longer the spatial resolution but is the cost, especially for mapping large regional areas.

Table 3.1 Characteristics of satellite image.

\begin{tabular}{|c|c|c|c|c|c|}
\hline Sensor & $\begin{array}{l}\text { Spectral } \\
\text { resolution } \\
(\mu \mathrm{m})\end{array}$ & $\begin{array}{l}\text { Spatial } \\
\text { resolution } \\
\text { (m) }\end{array}$ & $\begin{array}{l}\text { Temporal } \\
\text { resolution } \\
\text { (day) }\end{array}$ & $\begin{array}{l}\text { Radiometric } \\
\text { resolution } \\
\text { (bit) }\end{array}$ & $\begin{array}{c}\text { Coverage/ } \\
\text { swath } \\
\left(\mathbf{k m}^{2}\right)\end{array}$ \\
\hline $\begin{array}{l}\text { Landsat (1- } \\
\text { 4) MSS }\end{array}$ & $\begin{array}{l}\text { 1) } 0.45-0.52 \\
\text { 2) } 0.52-0.60 \\
\text { 3) } 0.63-0.69 \\
\text { 4) } 0.76-0.90\end{array}$ & 79 & 16 & $\begin{array}{l}6 \text { (64 gray } \\
\text { levels) }\end{array}$ & $185 \times 185$ \\
\hline $\begin{array}{c}\text { Landsat-4/5 } \\
\text { TM }\end{array}$ & $\begin{array}{l}\text { 1) } 0.45-0.52 \\
\text { 2) } 0.52-0.60 \\
\text { 3) } 0.63-0.69 \\
\text { 4) } 0.76-0.90 \\
\text { 5) } 1.55-1.75 \\
\text { 6) } 10.4-12.5 \\
\text { 7) } 2.08-2.35 \\
\text { Pan) } 0.52-0.90\end{array}$ & 120(band 6) & 16 & $\begin{array}{c}8 \text { (256 gray } \\
\text { levels) }\end{array}$ & $185 \times 185$ \\
\hline $\begin{array}{l}\text { Landsat-7 } \\
\text { ETM+ }\end{array}$ & $\begin{array}{l}\text { 1) } 0.45-0.52 \\
\text { 2) } 0.52-0.60 \\
\text { 3) } 0.63-0.69 \\
\text { 4) } 0.76-0.90 \\
\text { 5) } 1.55-1.75 \\
\text { 6) } 10.4-12.5 \\
\text { 7) } 2.08-2.35 \\
\text { Pan) } 0.52-0.90\end{array}$ & $\begin{array}{c}\text { 30/15 (pan) } \\
60 \\
\text { 120(band 6) }\end{array}$ & 16 & $\begin{array}{c}8 \text { (256 gray } \\
\text { levels) }\end{array}$ & $185 \times 185$ \\
\hline SPOT 1-4 & 1) $0.50-0.59$ & 20/10 (pan) & 26 (nadir) & 8 (256 gray) & $60 \times 60$ \\
\hline
\end{tabular}




\begin{tabular}{|c|c|c|c|c|c|}
\hline & $\begin{array}{l}\text { 2) } 0.61-0.68 \\
\text { 3) } 0.79-0.89 \\
\text { 4) } 1.58-1.73 \\
\text { (SPOT 4) }\end{array}$ & & $\begin{array}{c}1-3 \text { (off } \\
\text { nadir) }\end{array}$ & levels) & \\
\hline SPOT 5 & $\begin{array}{l}\text { 1) } 0.50-0.59 \\
\text { 2) } 0.61-0.68 \\
\text { 3) } 0.78-0.89 \\
\text { 4) } 1.58-1.75 \\
\text { pan) } 0.48-0.71\end{array}$ & 10/5 (pan) & 5 & $\begin{array}{c}8 \text { (256 gray } \\
\text { levels) }\end{array}$ & $60 \times 60$ \\
\hline IKONOS & $\begin{array}{ll}\text { 1) } & 0.45-0.52 \\
\text { 2) } & 0.52-0.60 \\
\text { 3) } & 0.63-0.69 \\
\text { 4) } & 0.76-0.90 \\
\text { Pan) } & 0.45-0.90 \\
\end{array}$ & 4/1 (pan) & 3 & $\begin{array}{c}11 \text { (2048 gray } \\
\text { levels) }\end{array}$ & $11 \times 11$ \\
\hline QuickBird & $\begin{array}{ll}\text { 1) } & 0.45-0.52 \\
\text { 2) } & 0.52-0.60 \\
\text { 3) } & 0.63-0.69 \\
\text { 4) } & 0.76-0.90 \\
\text { Pan) } & 0.45-0.90\end{array}$ & $\begin{array}{l}2.44 / 0.61 \\
\text { (pan) }\end{array}$ & 3 & $\begin{array}{c}8 \& 16 \\
\text { (multispectral } \\
\text { ) } \\
11 \text { bit (pan) }\end{array}$ & $16 \times 16$ \\
\hline
\end{tabular}

Table 3.2 Summary of the approximate cost per $120 \mathrm{~km}^{2}$ area using different remote sensing data sources.

\begin{tabular}{|c|c|c|c|c|}
\hline Data Source & Product & Resolution & Product Type & $\begin{array}{l}\text { Unit Cost } \\
\text { US\$/120 km² }\end{array}$ \\
\hline $\begin{array}{l}\text { Aerial Photo } \\
\text { (non-rectified) }\end{array}$ & 9-inch & $1 \mathrm{~m}$ & Colour & $4-5,000$ \\
\hline $\begin{array}{l}\text { Aerial Photo } \\
\text { (orthorectified) }\end{array}$ & 9-inch & $1 \mathrm{~m}$ & Colour & $10-15,000$ \\
\hline Landsat-5 TM & Georeferenced & $30 \mathrm{~m}$ & MS & 1.6 \\
\hline $\begin{array}{l}\text { Landsat-7 } \\
\text { ETM+ }\end{array}$ & Georeferenced & 30/15 (pan) & $\begin{array}{l}\text { MS \& } \\
\text { Pan }\end{array}$ & 2.5 \\
\hline SPOT-5 & Georeferenced & $10 / 5$ (pan) & $\begin{array}{l}\text { MS \& } \\
\text { Pan }\end{array}$ & 0.70 \\
\hline \multirow[t]{2}{*}{ IKONOS } & Reference & $1 \mathrm{~m}$ & $\begin{array}{l}\text { MS \& } \\
\text { Pan }\end{array}$ & 5,300 \\
\hline & $\begin{array}{l}\text { Precision } \\
\text { Orthorectified }\end{array}$ & $1 \mathrm{~m}$ & $\begin{array}{l}\text { MS \& } \\
\text { Pan }\end{array}$ & 10,000 \\
\hline \multirow[t]{2}{*}{ QuickBird } & Standard & $0.61 \mathrm{~m}$ & $\begin{array}{l}\text { MS \& } \\
\text { Pan }\end{array}$ & 3,600 \\
\hline & Orthorectified & $0.61 \mathrm{~m}$ & $\begin{array}{l}\text { MS \& } \\
\text { Pan }\end{array}$ & 7,800 \\
\hline
\end{tabular}


Aside from data quality and availability, the cost of data acquisition plays a major part in urban change detection applications. Remote sensing data acquisition costs vary dramatically on a per unit basis. Table 3.2 presents a cost comparison of different remotely sensed data sources. Generally speaking, the older the data, the lower the per unit cost of acquisition will be (Lunetta, 1999). The cost estimates are for simple general comparisons.

Although the exact costs for remote sensing data acquisitions have fluctuated over the past decades, some relative cost relationships have remained consistent. Generally, higher resolution more detailed images cost more to purchase per unit area of coverage. Aerial photographs and ground survey involve more manpower, consequently costing more than digital satellite data.

Today, Landsat-5 TM, Landsat-7 ETM+ and SPOT-5 satellites are the major providers of remote sensing imagery used in urban change detection and impervious surface mapping. Taking into account data spatial resolution, availability and cost factors, the medium resolution satellite data are the most suitable for regional scale urban land cover due to their low cost, long-term data series and timely update availability. Therefore, four cloud-free Landsat-5 TM images covering the GTA were selected and used in this study (see Table 3.3).

Table 3.3 Selected Landsat TM images used in this study.

\begin{tabular}{|l|l|l|l|l|}
\hline Sensor & Date & Georeference & Resolution & Bands \\
\hline Landsat-5 TM & August 5, 1990 & UTM, zone 18, WGS84 & $30 \mathrm{~m}$ & $1-5,7$ \\
\hline Landsat-5 TM & July 19, 1995 & UTM, zone 18, WGS84 & $30 \mathrm{~m}$ & $1-5,7$ \\
\hline Landsat-5 TM & August 20, 2000 & UTM, zone 18, WGS84 & $30 \mathrm{~m}$ & $1-5,7$ \\
\hline Landsat-5 TM & September 3, 2005 & UTM, zone 18, WGS84 & $30 \mathrm{~m}$ & $1-5,7$ \\
\hline
\end{tabular}


These Landsat images were acquired in late summer and early fall, when the land is fully covered by vegetation, as this is the preferred season for land use and land cover analysis. In order to avoid radiometric differences, the attempt was made to select the acquisition dates as close to each other as possible. The goal is to distinguish the change in two major land cover features, namely "green" and "impervious", and, thereafter, to derive a correlation between "impervious" areas and chloride levels as an indicator of water quality degradation by means of integration in a GIS environment.

\subsubsection{Surface Water Quality Data}

Surface water quality data in Ontario are collected by individual conservation authorities. These data however are the property of Ontario Ministry of Environment that is responsible for testing, analyzing and monitoring data. Water samples and readings of water quality at the monitoring stations are taken using portable, handheld equipment. At each Provincial Water Quality Monitoring Network (PWQMN) station a standard set of water quality indicators are collected once a month on the major tributaries of watersheds. These indicators include chloride, nutrients, suspended solids, trace metals and other general chemistry parameters (Ontario Ministry of Environment, 2007). Basically, data from near the mouth of each watershed are used to provide estimates of the concentration for the entire watershed. This information provides the core data for surface water quality assessments, determines the location and causes of water quality degradation, and measures the effectiveness of water management programs (TRCA, 1998). 
Figure 3.7 shows the location of water quality monitoring stations within the Peel and Toronto Region while Table 3.4 lists their site specific attributes. The amount of data is varied, ranging from many stations with monthly sampling interval to some watersheds with only intermittent samples. In each watershed only a hand full of WQMS (Water Quality Monitoring Stations) contained continuous historic data. These particular stations (Figure 3.7) were chosen because they have long periods of continuous records required for this study.

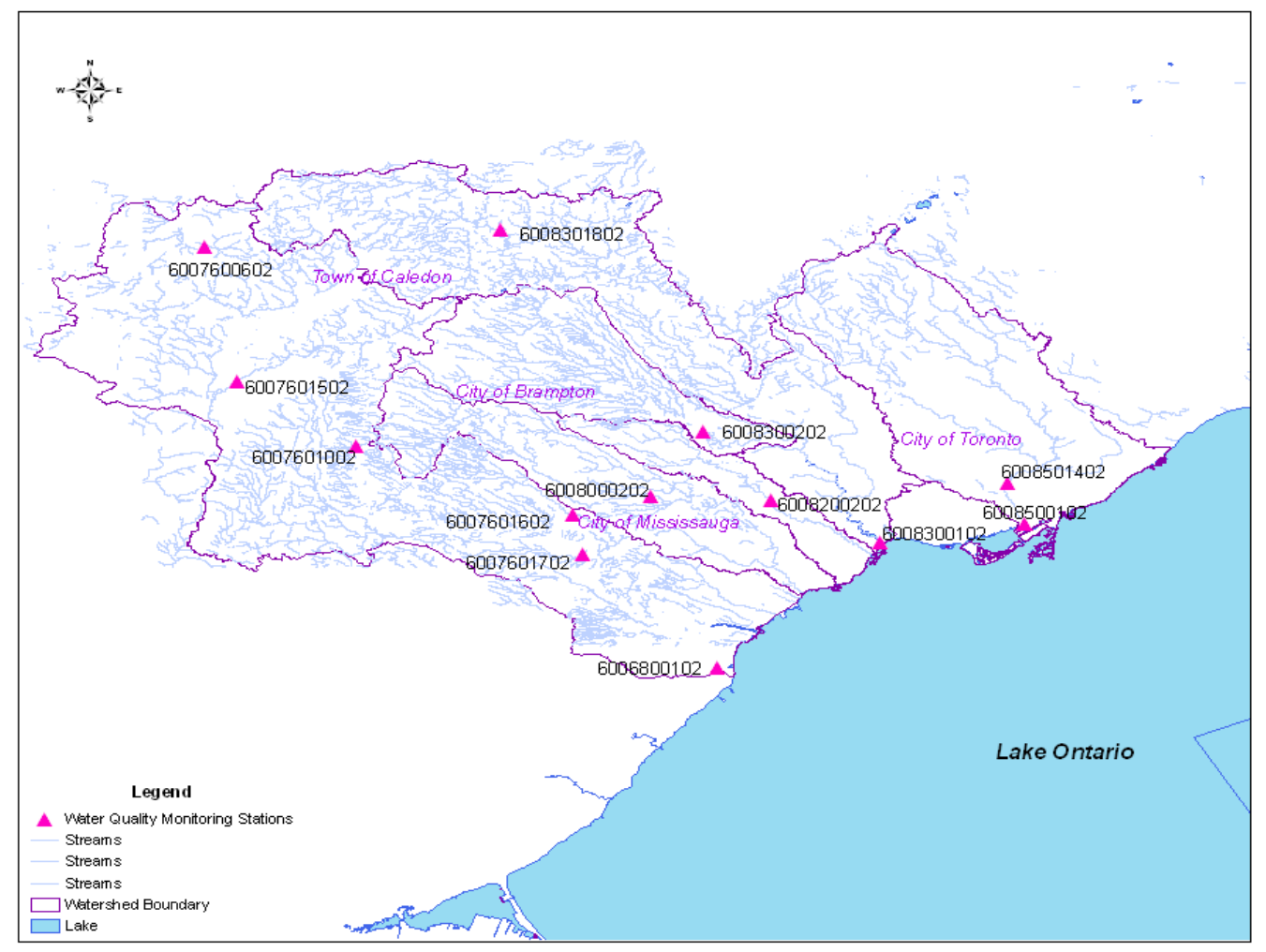

Figure 3.7 Water quality monitoring stations in the GTA.

Table 3.4 Attributes of selected water quality monitoring stations within the GTA watersheds.

\begin{tabular}{|l|l|l|l|l|l|}
\hline Station No & Station Name & Address & Authority & Longitude & Latitude \\
\hline 6006800102 & Sheridan Creek & $\begin{array}{l}\text { Rattray Marsh, Meadow } \\
\text { Wood Rd, Clarkson }\end{array}$ & Credit & -79.61543248170 & 43.51593351370 \\
\hline 6007600602 & Credit River & $\begin{array}{l}\text { Hwy 10, dwnstrm } \\
\text { Orangeville, 1st crossing }\end{array}$ & Credit & -80.06325348210 & 43.90965438900 \\
\hline 6007601002 & Credit River & Heritage Rd and King St. & Credit & -79.93099773200 & 43.72381351390 \\
\hline 6007601502 & West Credit & Winston Churchill Blvd, & Credit & -80.03480098210 & 43.78373676390 \\
\hline
\end{tabular}




\begin{tabular}{|l|l|l|l|l|l|}
\hline & River & dwnstrm Erin & & & \\
\hline 6007601602 & $\begin{array}{l}\text { Fletchers } \\
\text { Creek }\end{array}$ & $\begin{array}{l}\text { Steeles Ave W, } \\
\text { Brampton }\end{array}$ & Credit & -79.74145535680 & 43.65858538880 \\
\hline 6007601702 & Credit River & $\begin{array}{l}\text { Old Derry Rd, W of Hwy } \\
10\end{array}$ & Credit & -79.73326498180 & 43.62214888880 \\
\hline 6008501402 & Don River & Pottery Rd., Toronto & Toronto & -79.36213573150 & 43.68847163880 \\
\hline 6008500102 & Don River & Lakeshore Rd., DVP & Toronto & -79.34726573150 & 43.65075276380 \\
\hline 6008000202 & $\begin{array}{l}\text { Etobicoke } \\
\text { Creek West }\end{array}$ & $\begin{array}{l}\text { Derry Rd, E of Dixie Rd, } \\
\text { Mississauga }\end{array}$ & Toronto & -79.67343810680 & 43.67603001380 \\
\hline 6008301802 & Humber River & $\begin{array}{l}\text { Old Church Rd, dwnstrm } \\
\text { Albion Hills CA }\end{array}$ & Toronto & -79.80458748190 & 43.92582576400 \\
\hline 6008200202 & Mimico Creek & Eglinton Ave W & Toronto & -79.56929498170 & 43.67286488880 \\
\hline $\begin{array}{l}6008300202 \\
6008300102\end{array}$ & $\begin{array}{l}\text { Humber West } \\
\text { Humber River }\end{array}$ & $\begin{array}{l}\text { Claireville dam outlet } \\
\text { Lakehore Blvd, South } \\
\text { Kingsway }\end{array}$ & $\begin{array}{l}\text { Toronto } \\
\text { Toronto }\end{array}$ & -79.62831823170 & 43.73686613890 \\
& & & & 43.63304563880 \\
\hline
\end{tabular}

\subsection{Research Methodology}

The objective of this part of the study is to distinguish changes of two land cover types, namely “impervious” and "green”, and, thereafter, to assess the quality of water at select monitoring stations by means of integration with GIS techniques. The methodology scheme adopted in this study is outlined in the following sections.

\subsubsection{Impervious Surface Estimation Method}

The pixel-based unsupervised classification method was employed to detect urban land cover changes during the last 15 years (1990-2005) using 30m resolution multitemporal Landsat-5 TM data. Unsupervised classification is a method which examines a large number of unknown pixels by dividing them into a number of classes based on spectral similarities. The basic principle behind this technique is that values within a given land cover type should have similar gray levels, whereas data in different classes should have comparatively different gray levels (Lillesand and Kiefer, 2000). 
In the PC-based environment of PCI Geomatica V10.0.3, all four multitemporal Landsat-5 TM images were classified using unsupervised approach known as ISODATA (Iterative Self-Organizing Data Analysis Technique) clustering to generate impervious surface estimates. The ISODAT classifier utilizes the minimum distance method to identify similar spectral clusters according to the number of clusters specified (Jensen, 2005). The ISODATA technique has proven to be one of the most efficient and accurate approach to identifying spectral clusters of an image (Qiu et al., 2003).

\section{Parameter Setting}

To achieve more accurate results, the parameter setting was changed to: 25 classes, 25 maximum iterations, and 0.95 convergence threshold. The threshold specifies that as soon as $95 \%$ or more of the pixels stay in the same cluster between iterations, the utility should stop processing. This threshold prevents the ISODATA utility from running indefinitely. The classification scheme of 25 classes is based on the study's interest which focuses on the identification of built-up (urban) and non-built land features. Following the creation of 25 spectral clusters, each class was labeled into general categories of urban, agriculture, forest, water, wetland, and barren and then aggregated into two major classes labeled as “green” and “impervious” for long-term impervious surface change analysis. Later, the classification accuracy is evaluated through visual comparison of corresponding classified maps with reference data. The percentage of imperviousness for each map is then calculated based on statistics provided in the classification report generated by the classification process. 


\section{Accuracy Assessment}

The purpose of classification accuracy assessment is to determine the agreement between the selected reference data and the classified data. The "stratified random" function of PCI Geomatica is used to create sample points for all classified images. For this purpose 50 random pixels in each watershed are selected and their agreement with reference data is analyzed. The evaluation results are presented in two reports: the classification error matrix (also called confusion matrix) and the accuracy report (see Chapter 4). The error matrix simply compares the reference points to the classified points in an $n \times n$ matrix, where $\mathrm{n}$ is the number of classes. The accuracy report calculates statistics of the percentages of accuracy, based upon the results of the error matrix.

The Kappa statistics measures the difference between the actual agreement between reference data and an automated classifier as well as the change agreement between the reference data and a random classifier. Thus, it indicates the extent to which the percentage correct values of an error matrix are due to the "true" agreement versus the “change" agreement. For instance, a Kappa value of 0.80 implies that the classification is $80 \%$ better than results based on chance (Lillesand et al., 2004).

\section{Examination of Object-Oriented Classification}

The classical unsupervised classification method was chosen in this study because it is a simple automated method that produces extremely fast results and requires little in the nature of operational parameters. This procedure can provide a remarkably rapid means of producing quality land cover data on a continuing basis that also meets map accuracy standards. 
However, throughout the course of the study, a new and promising classification approach called "object-oriented" was also tested on a number of images using the trial version of the eCognition software. Object-oriented image analysis is divided into three general steps: segmentation, creation of general classes, and classification rules. Segmentation is the first and most important phase of the object-oriented classification. The aim of segmentation is to create meaningful image objects. Through a “trial and error” process, segmentation parameters were defined and image segments were calculated. The scale parameter is an abstract value to determine the maximum possible change of heterogeneity cause by fusing several objects. Colour is the pixel value, while shape includes compactness and smoothness (the two geometric features that can be used as “evidence”). Smoothness describes the similarity between the image object borders, whereas compactness explains the "closeness" of pixels clustered in an object (Oruc et al., 2004; Qian et al., 2007).

Originally, the scale parameter was set to 300 and three big segments were created. The scale parameter was then reduced to 40 for each of these big segments in order to separate them into smaller more precise segments. Shape factor was set to 0.1 , colour to 0.9 , and compactness and smoothness to 0.5. After defining these parameters, eCognition produced a new image with the new groupings of pixels. The next step included creating and defining classes. Six classes were created and given different colour schemes to represent various land covers. In order to define the six classes, training sites of known areas from the image could be selected. After the training sites were selected, the image could be classified by the classes defined using the standard nearest neighbor classifier. 


\subsubsection{Chloride Concentration Mapping}

The mean and median total chloride concentrations of samples collected from May to October (dry season) as well as November to April (wet season) at monitoring stations in the Peel and Toronto Region watersheds are compiled for years 1990, 1995, 2000 and 2005. The chloride values are added as layers in the ArcGIS V9.2 environment. The chloride layers are georeferenced using World Geodetic System 1984 (WGS84) projection so they can later be overlaid on top of impervious surface maps for further investigation of the correlation between the two variables. Different colour schemes are applied to years 1990 (pink), 1995 (yellow), 2000 (green) and 2005 (red) to differentiate between separate dates. The "graduated symbols" are chosen to show a more visually enhanced map of chloride quantities in watersheds.

\subsubsection{Integration of Remote Sensed Impervious Surfaces and Chloride Data}

The interrelationship between impervious surface estimates and water quality degradation is widely recognized and has been the focus of many studies (Arnold and Gibbons, 1996; Bowen and Hinton, 1998; Boyd, 1999; Mayer et al., 1999; Howard and Livingstone, 2000; Clausen et al., 2003; Roy et al., 2003; Groffman et al., 2004; Shuster et al., 2005). However, hardly any study looked at the integration of remotely sensed data with chloride concentrations in assessing regional water quality as it relates to chloride contamination. Overlay of impervious surface estimates with water quality indicator data (i.e. chloride levels) can provide a simple, quick and inexpensive overview of areas more prone to water quality degradation in a regional level over time. The data overlay puts variables in context by giving the audience a quantitative measure that is also enhanced visually. 
The integration of the impervious surface estimates with maps of chloride concentrations in a GIS environment is the final step in the methodology and is performed in the environment of ArcMap V9.2. The flow chart of proposed methodology used in this study is shown in Figure 3.8.

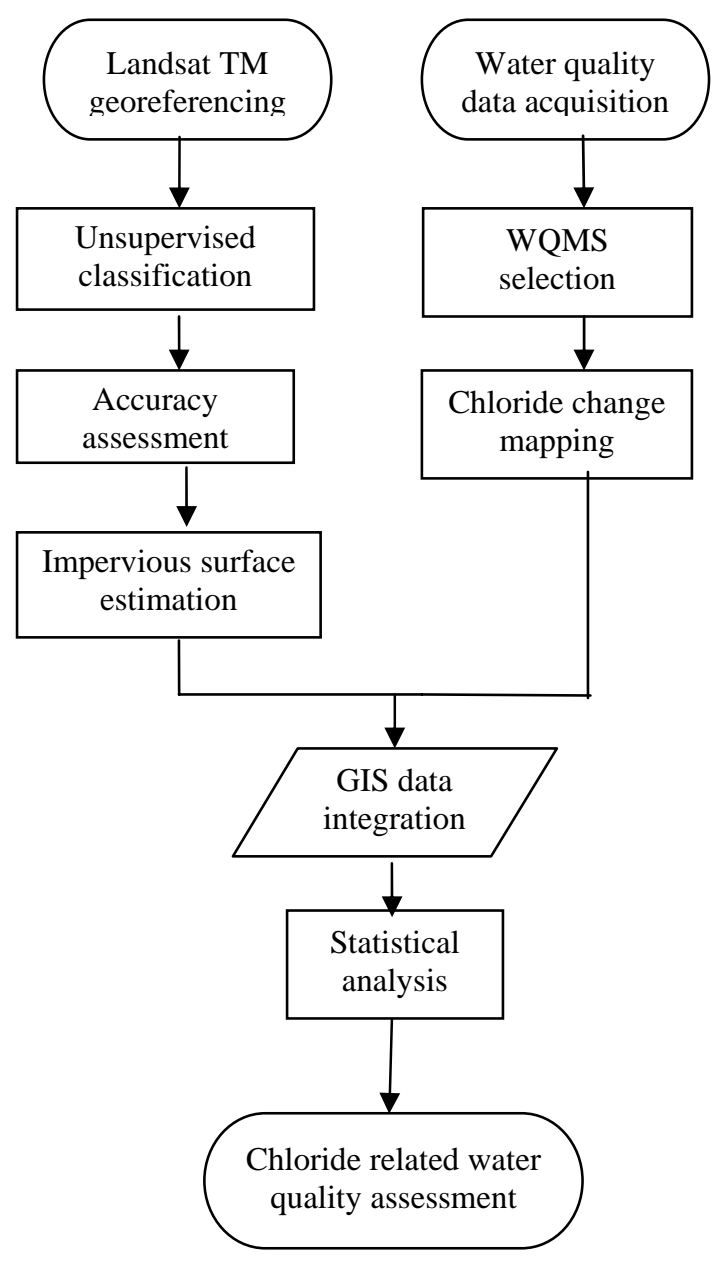

Figure 3.8 Overall research methodology. 


\subsection{Chapter Summary}

Based on the literature review and following the objectives of the study, an integrated remote sensing and GIS solution will be presented in the following chapter in order to obtain reliable and accurate impervious surface estimates. The impervious surfaces and their changes over time extracted from Landsat-5 TM images are then combined with chloride concentrations in a GIS environment for preliminary assessment of current and future surface water contamination due to increased imperviousness. The experimental results obtained using the designed methodology will be presented and discussed in Chapter 4. 


\section{CHAPTER 4}

\section{CHLORIDE AND IMPERVIOUS SURFACE TREND ANALYSIS: RESULTS}

\section{AND DISCUSSION}

The designed study framework is implemented in the following six major watersheds: Credit River, Main Humber, West Humber, Etobicoke Creek, Mimico Creek, and Don River. The corresponding results obtained from the analysis of these watersheds are presented in this chapter. Section 4.1 introduces the subset of the area of interest, illustrates the layout of the classified impervious surface maps and depicts the impervious surface change detection over a 15-year period, respectively. Accuracy assessment of classification is given in Section 4.2. The results of chloride concentration maps including spatial and temporal variations in addition to the role of weather conditions in chloride levels are presented in Sections 4.3. The results by integrating impervious surface maps with chloride maps and the corresponding statistical analyses are illustrated in Sections 4.4 and 4.5. A summary of this chapter is included in Section 4.6.

\subsection{Impervious Surface Maps}

\subsubsection{Introduction}

The Landsat-5 TM images, acquired in 1990, 1995, 2000, and 2005, of the study area watersheds in true-colour (band 3, 2, 1) are shown in Figure 4.1. From these images, the urban sprawl, particularly in the cities of Mississauga and Brampton, for each 5year time interval can visually be identified. 

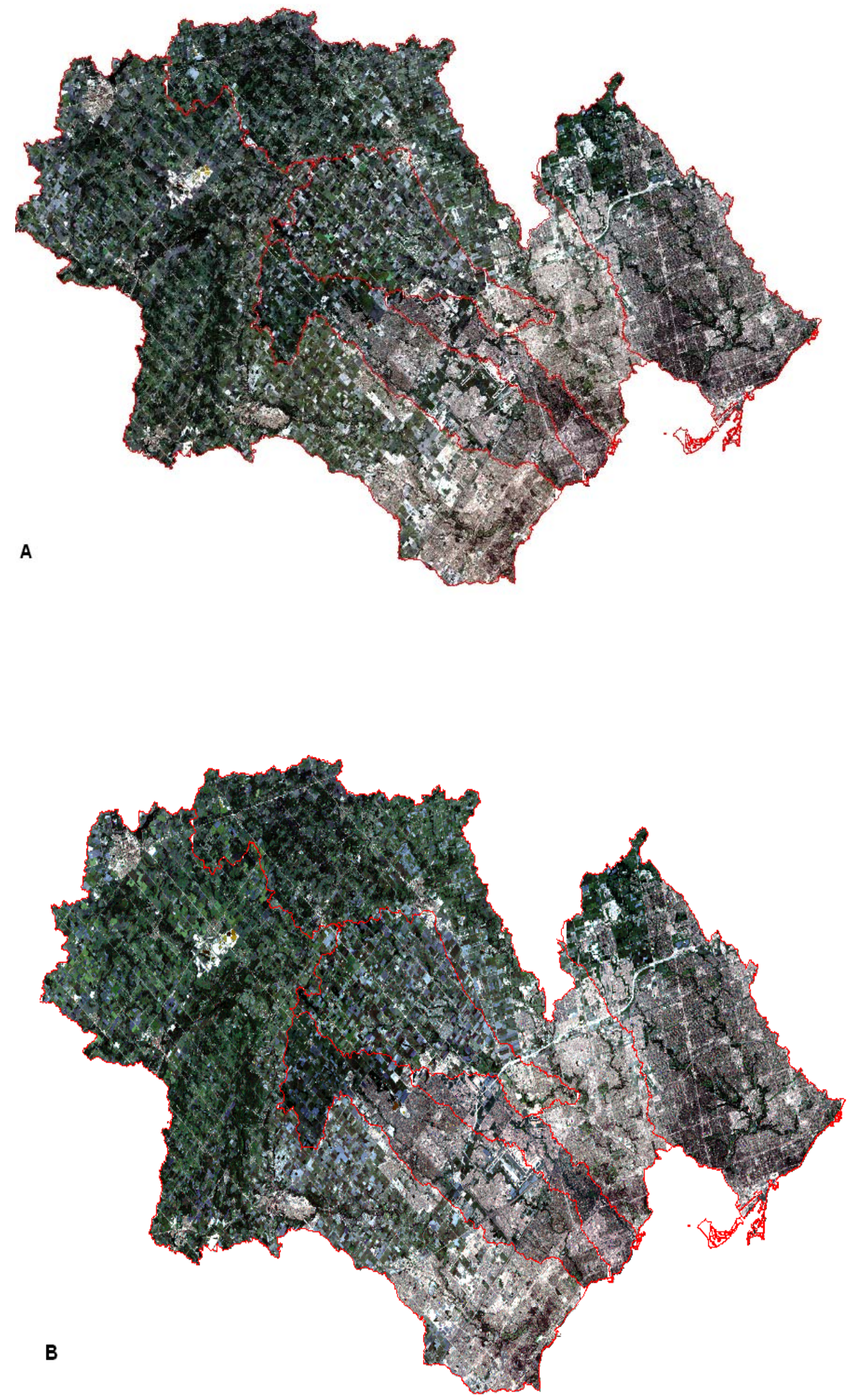

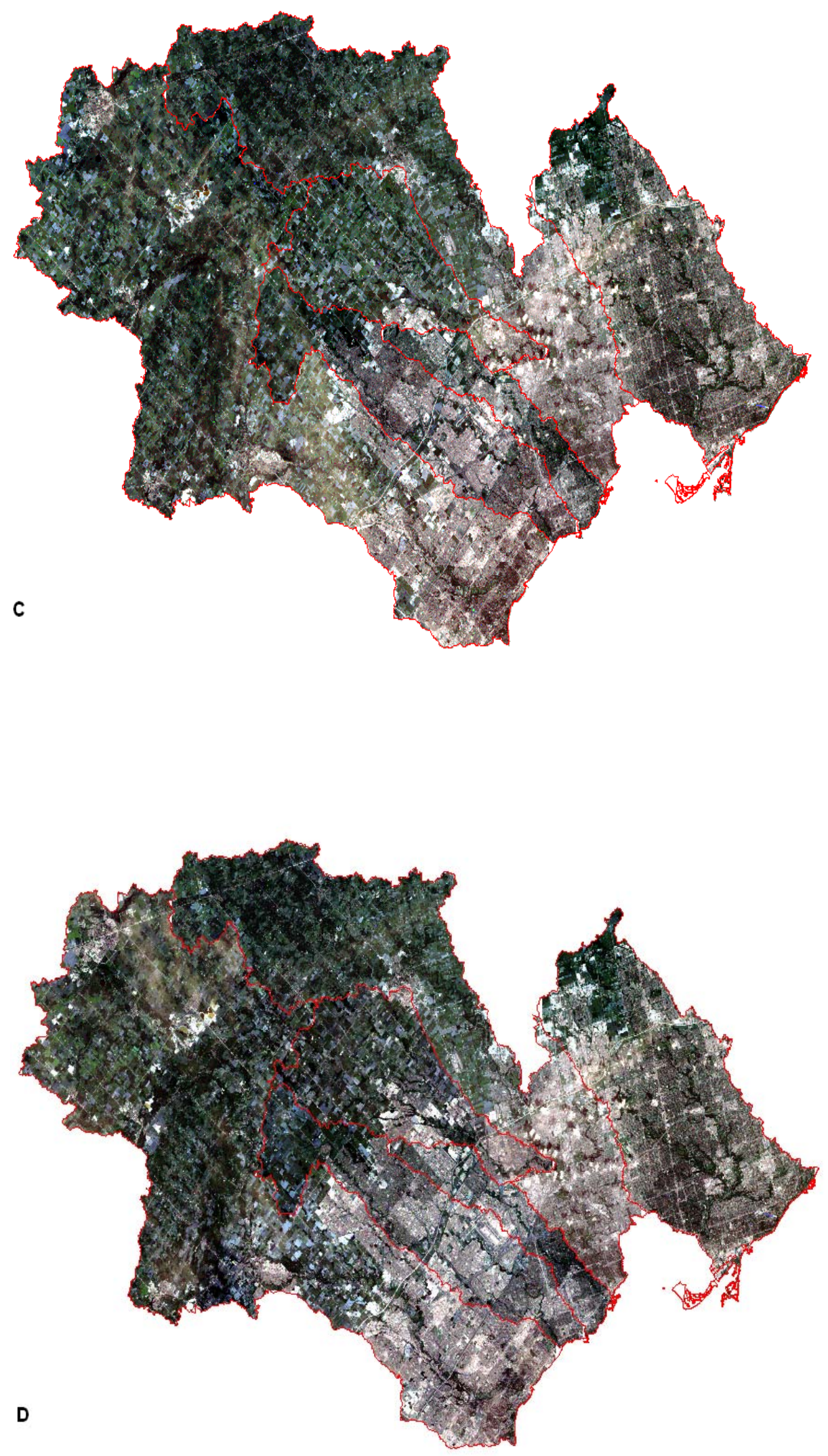

Figure 4.1 Landsat-5 TM images covering the entire study area: (A) 1990, (B) 1995, (C) 2000, and (D) 2005. 


\subsubsection{Impervious Surface Classification Results}

As mentioned in Chapter 3, Object-oriented classification, a new and promising classification approach, was tested in this research. At the time of this study only the trial version of eCognition software was available for the object-oriented classification test. Therefore, final accuracy assessment could not be performed.

Despite this limitation, according to the preliminary results, proper segmentation of image objects on medium resolution imagery (i.e. Landsat TM) proved to be very difficult and rather inaccurate. Therefore, the utilization of object-oriented classification technique on medium resolution Landsat TM imagery resulted in overestimation of impervious surfaces compared to conventional pixel-based unsupervised classification technique.

The preliminary results indicated that the object-oriented approach appears to work best on high-resolution imagery (i.e. QuickBird, IKONOS) where image objects can be easily recognized and segmented. For this reason, further application of this technique in impervious surface estimation using Landsat imagery was disregarded.

Therefore, the ISODATA (Iterative Self-Organizing Data Analysis Technique) classifier, an unsupervised classification approach available with the commercial PCI Geomatica Version 10.0.3 software package, is used for classification of impervious surfaces. According to reference data $(61 \mathrm{~cm}$ digital orthophotos) and visual interpretation of spectral properties of true-colour images, 25 classified spectral clusters for each image are assigned to appropriate land cover classes, such as agricultural lands, golf courses, residential areas, industrial zones, road networks, 
wetlands, and alike. These classes are then grouped into two composite classes referred to as impervious and pervious for long-term urban change analysis.

Figures 4.2 through 4.7 display the classified impervious surface maps of the six study area watersheds between 1990 and 2005 with a 5-year time interval, respectively. The gray area represents impervious surfaces while yellow represents pervious areas including vegetation, soil, agricultural lands, open space, etc. The classified impervious surface maps reflect the overall urban-related land uses within the study area which has markedly changed during the 15-year period (see Figure 4.8). 

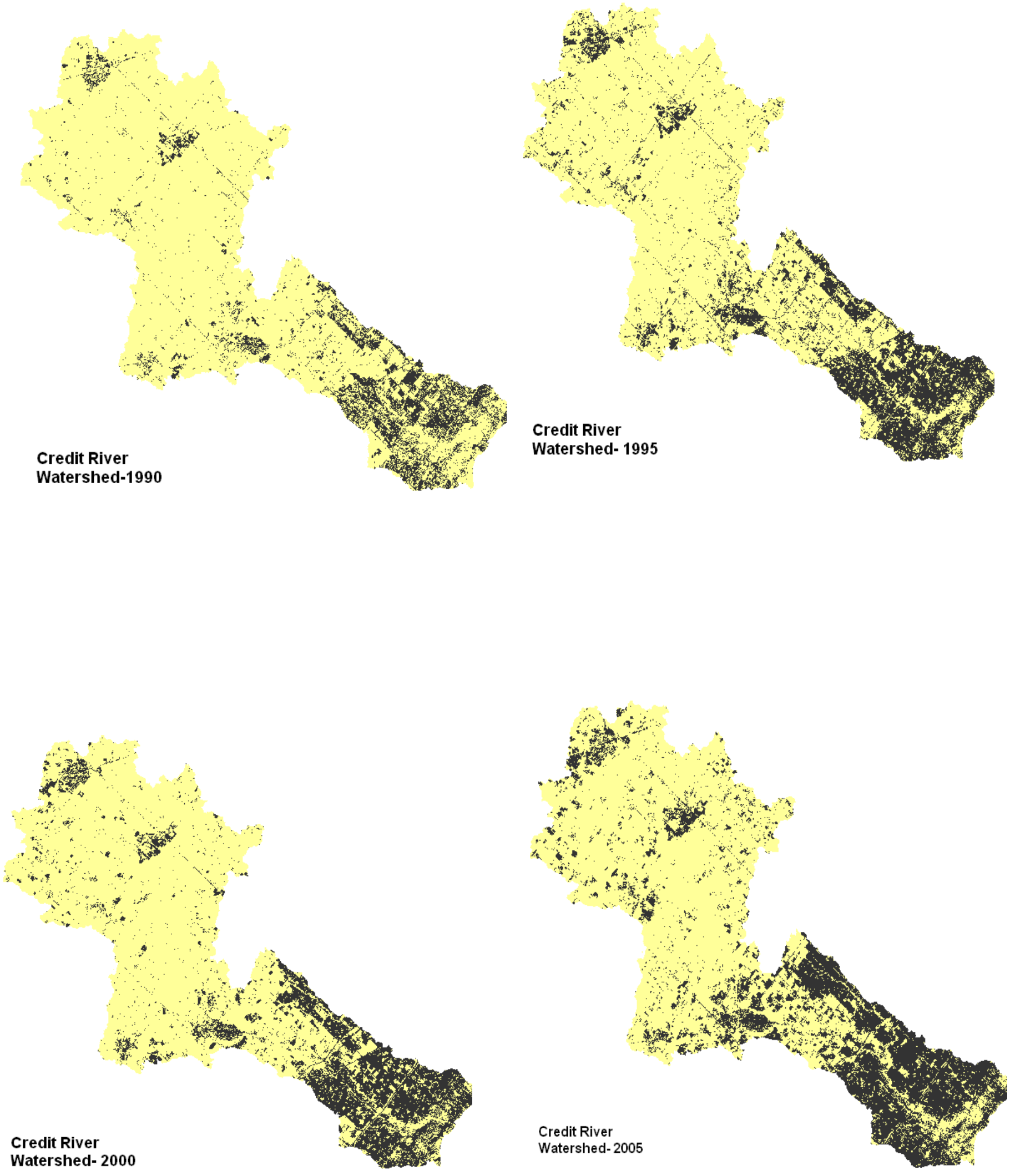

Figure 4.2 Impervious surface map of Credit River watershed. 

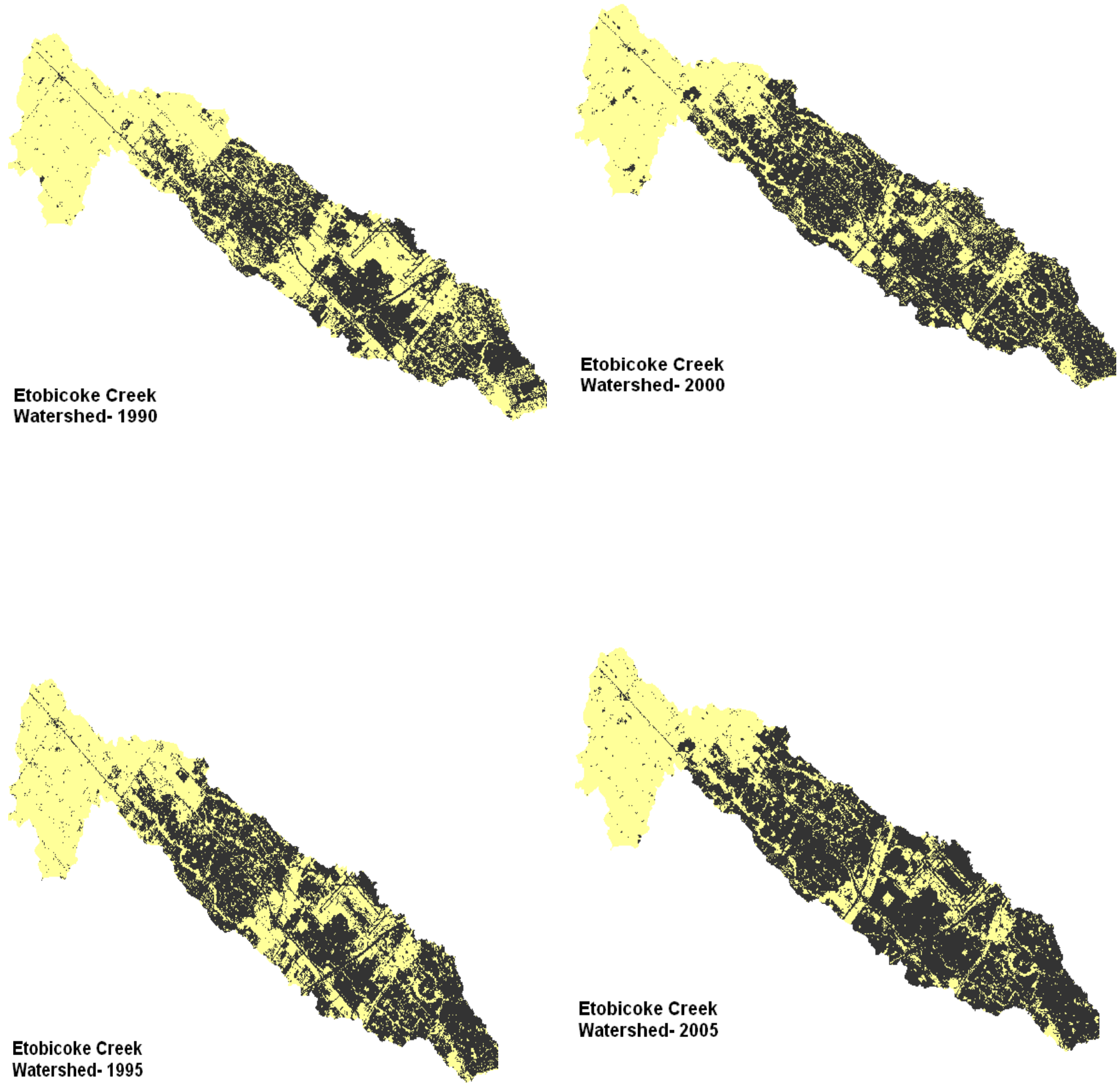

Figure 4.3 Impervious surface map of Etobicoke Creek watershed. 

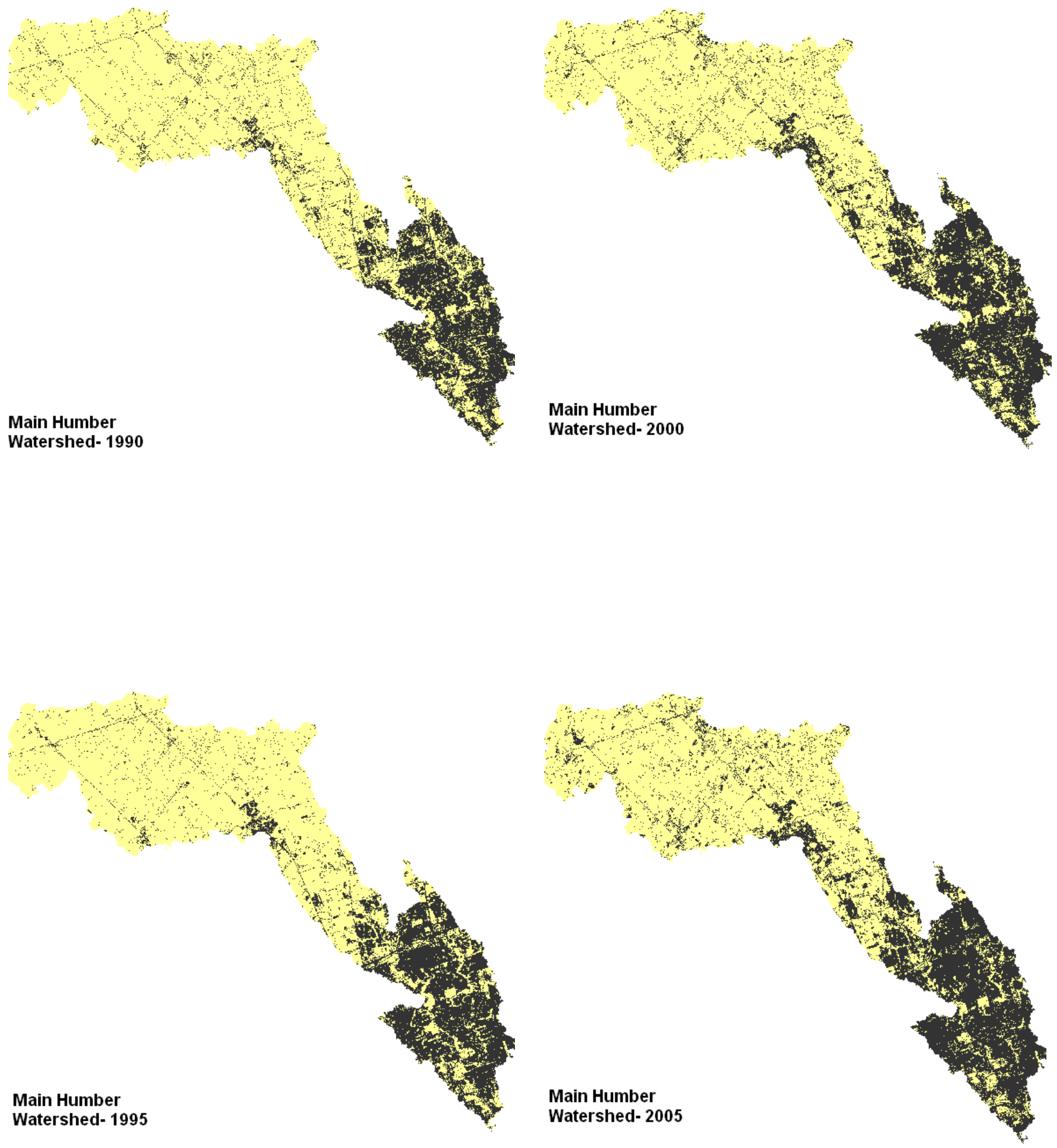

Figure 4.4 Impervious map of Main Humber watershed. 


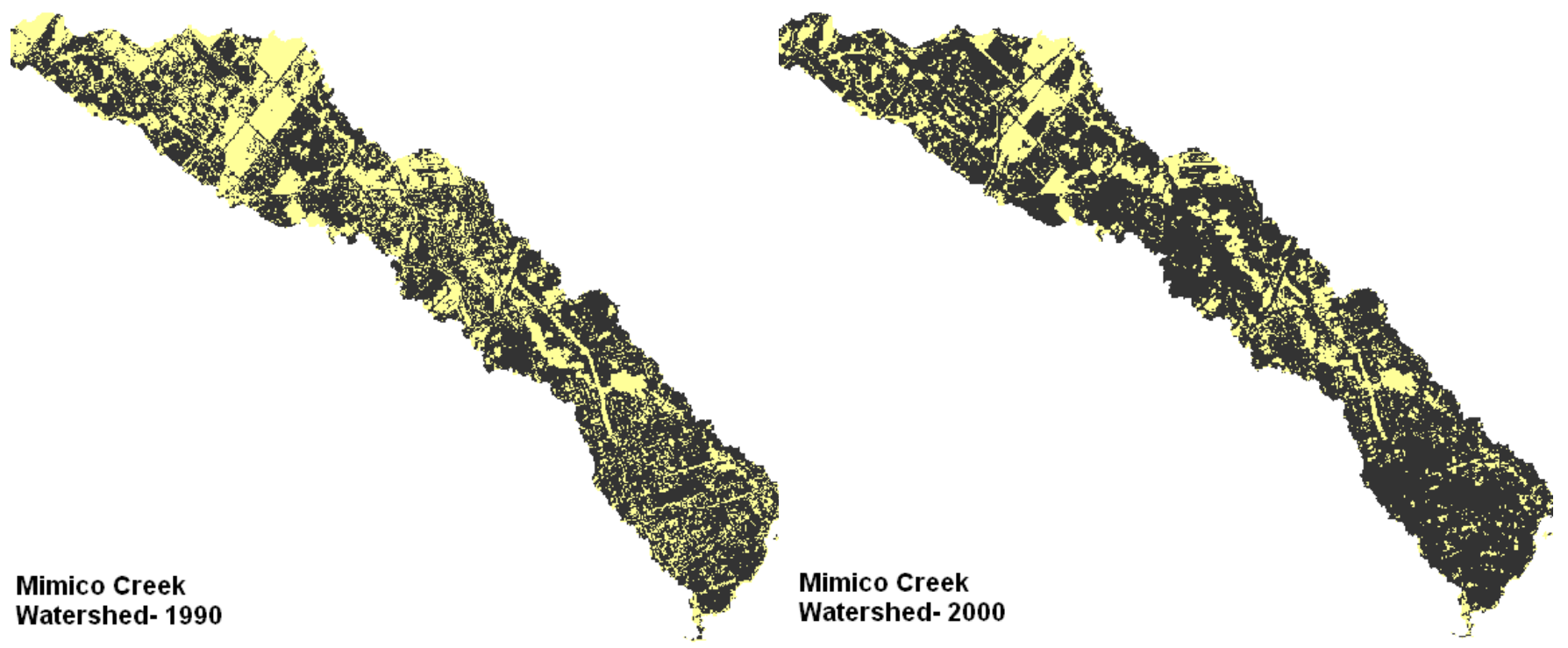

Mimico Creek

Watershed- 1995

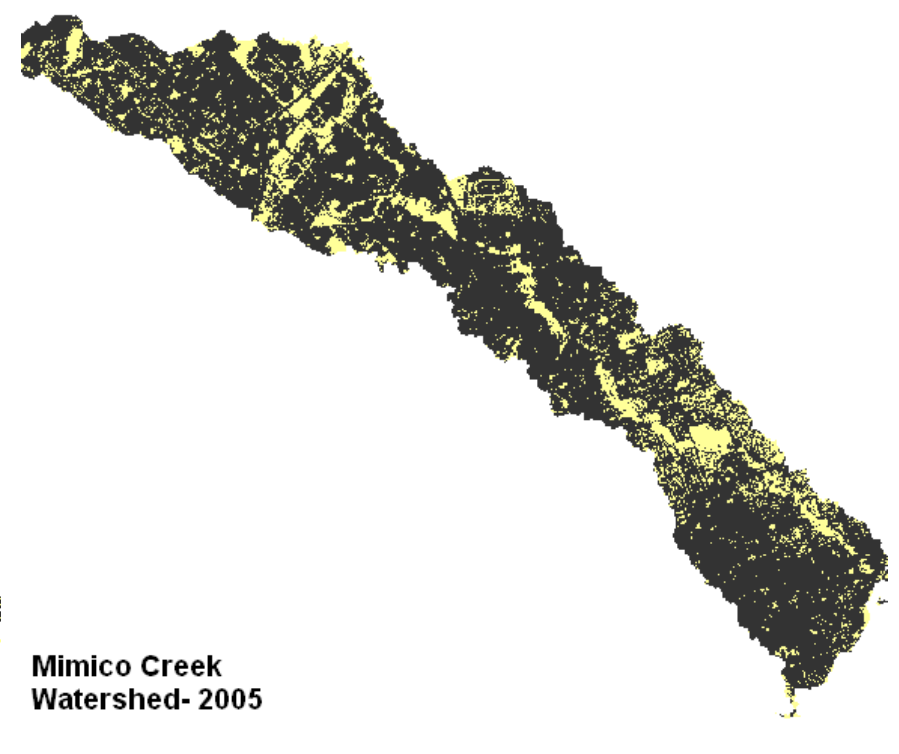

Figure 4.5 Impervious surface map of Mimico Creek watershed. 

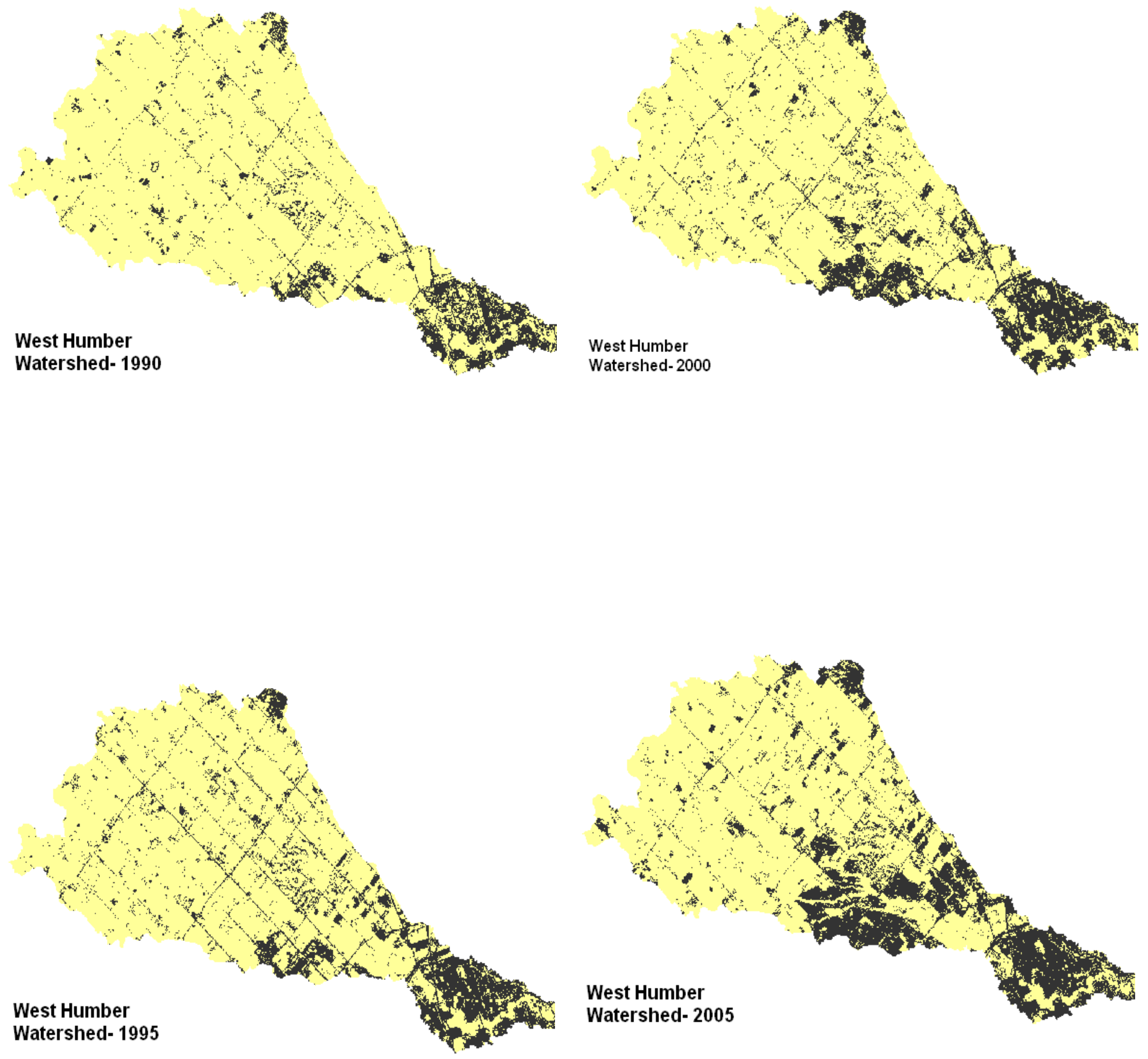

Figure 4.6 Impervious surface map of West Humber watershed. 

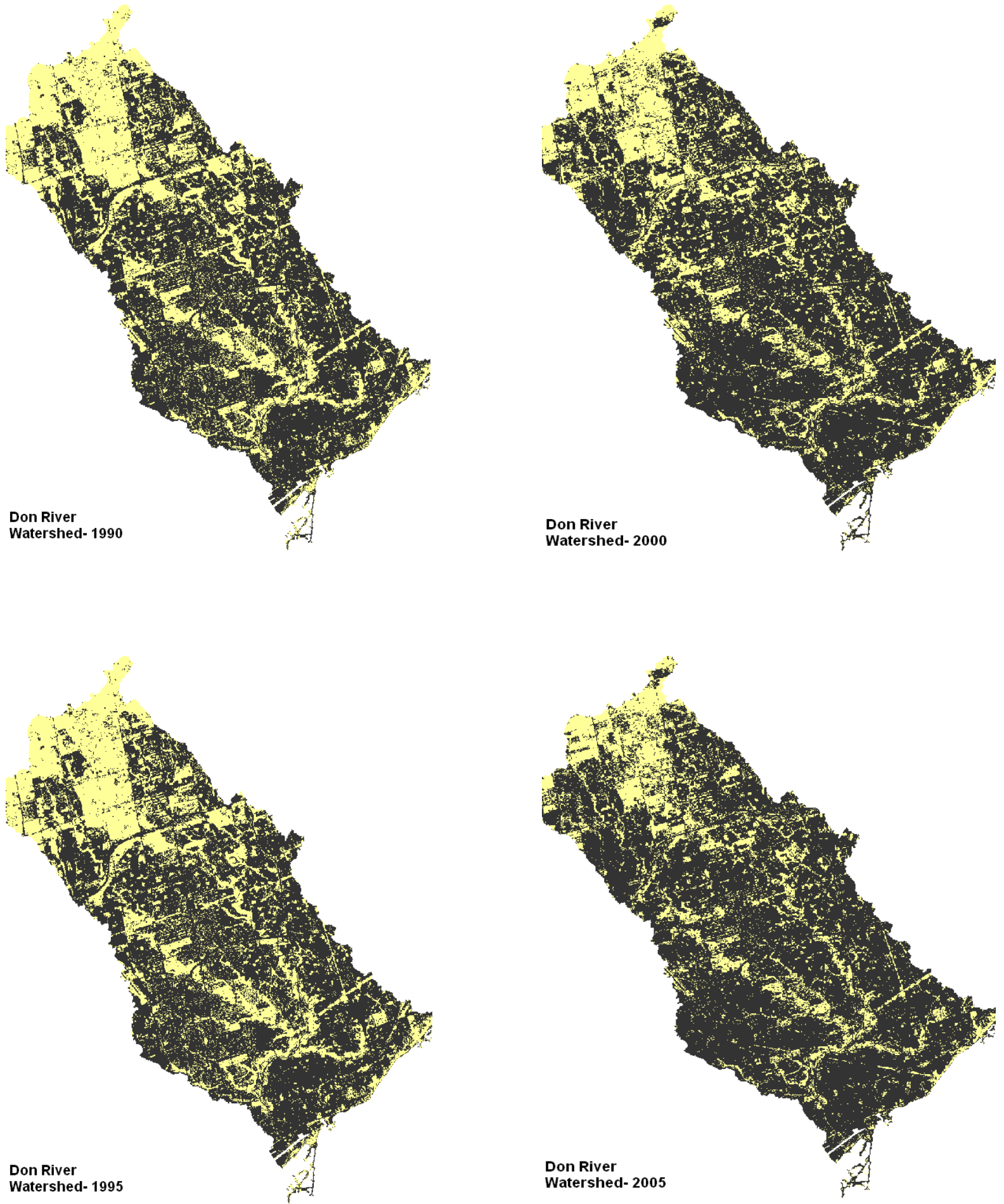

Figure 4.7 Impervious surface map of Don River watershed. 


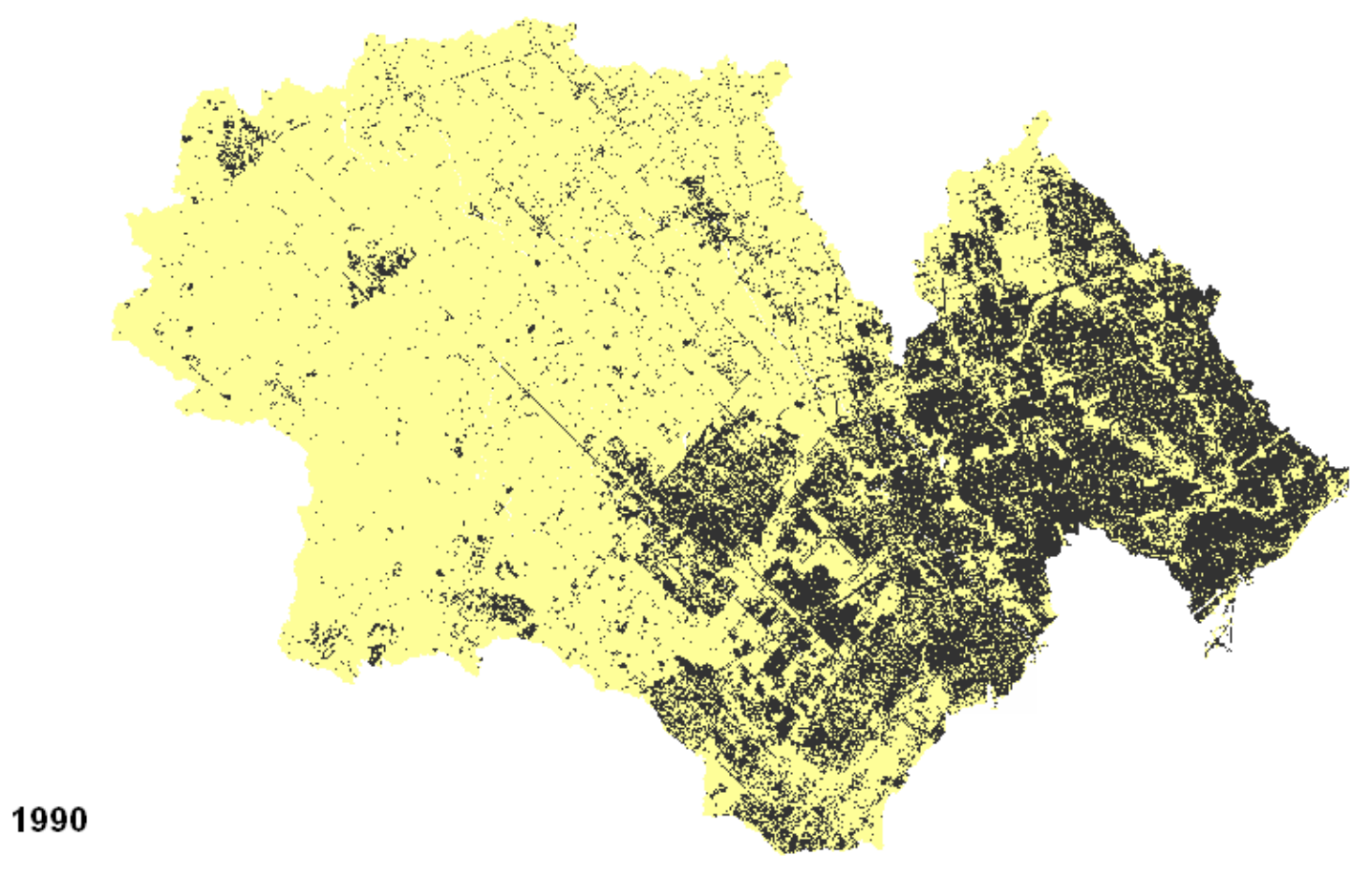

1995 

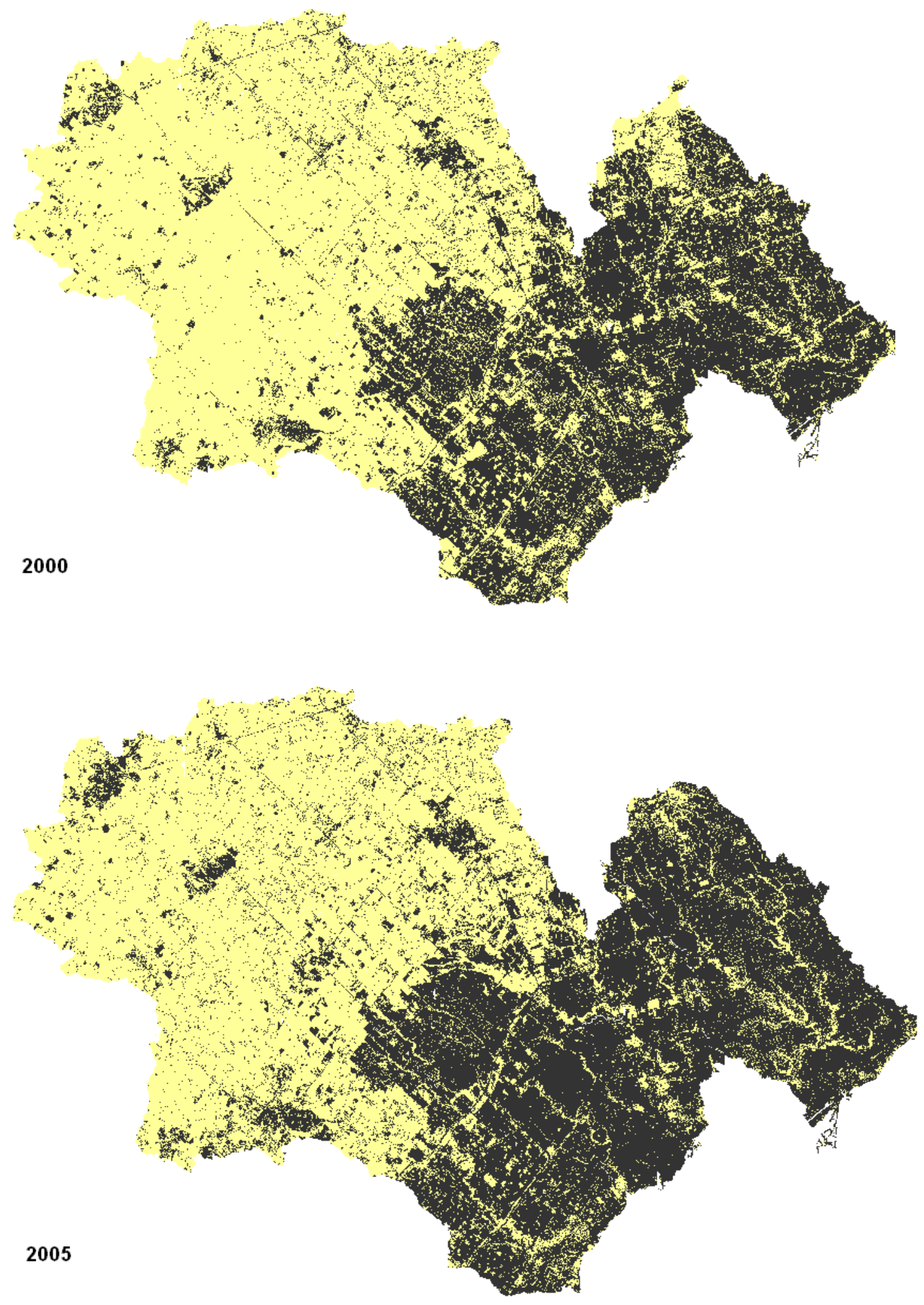

Figure 4.8 Impervious surface map of the entire study area watersheds. 
For each watershed, the percentage of impervious surfaces in 1990 is estimated and is compared to what was measured in the area 15 years later (5 year interval). The percentage of impervious surface growth in each watershed over time is listed in Table 4.1, while Figure 4.9 illustrates this growth visually in a graph. Through unsupervised classification, the substantial growth of impervious surfaces within the study area is even further distinguishable.

Table 4.1 Overall impervious surfaces in each watershed between 1990 and 2005.

\begin{tabular}{|l|l|l|l|l|c|}
\hline Watersheds & $\begin{array}{l}\mathbf{1 9 9 0} \\
(\mathbf{\%})\end{array}$ & $\begin{array}{l}\mathbf{1 9 9 5} \\
(\mathbf{\%})\end{array}$ & $\begin{array}{l}\mathbf{2 0 0 0} \\
(\mathbf{\%})\end{array}$ & $\begin{array}{l}\mathbf{2 0 0 5} \\
(\mathbf{\%})\end{array}$ & $\begin{array}{c}\text { Growth between } \\
\mathbf{1 9 9 0} \text { and 2005 (\%) }\end{array}$ \\
\hline West Humber & 12.06 & 17.86 & 19.47 & 23.95 & 11.89 \\
\hline Credit River & 17.18 & 21.94 & 23.96 & 27.61 & 10.43 \\
\hline Main Humber & 26.22 & 27.76 & 33.21 & 36.59 & 10.37 \\
\hline Etobicoke Creek & 40.32 & 48.52 & 52.67 & 56.95 & 16.36 \\
\hline Mimico Creek & 66.44 & 70.77 & 76.36 & 80.95 & 14.51 \\
\hline Don River & 69.56 & 73.46 & 77.76 & 83.57 & 14.01 \\
\hline
\end{tabular}

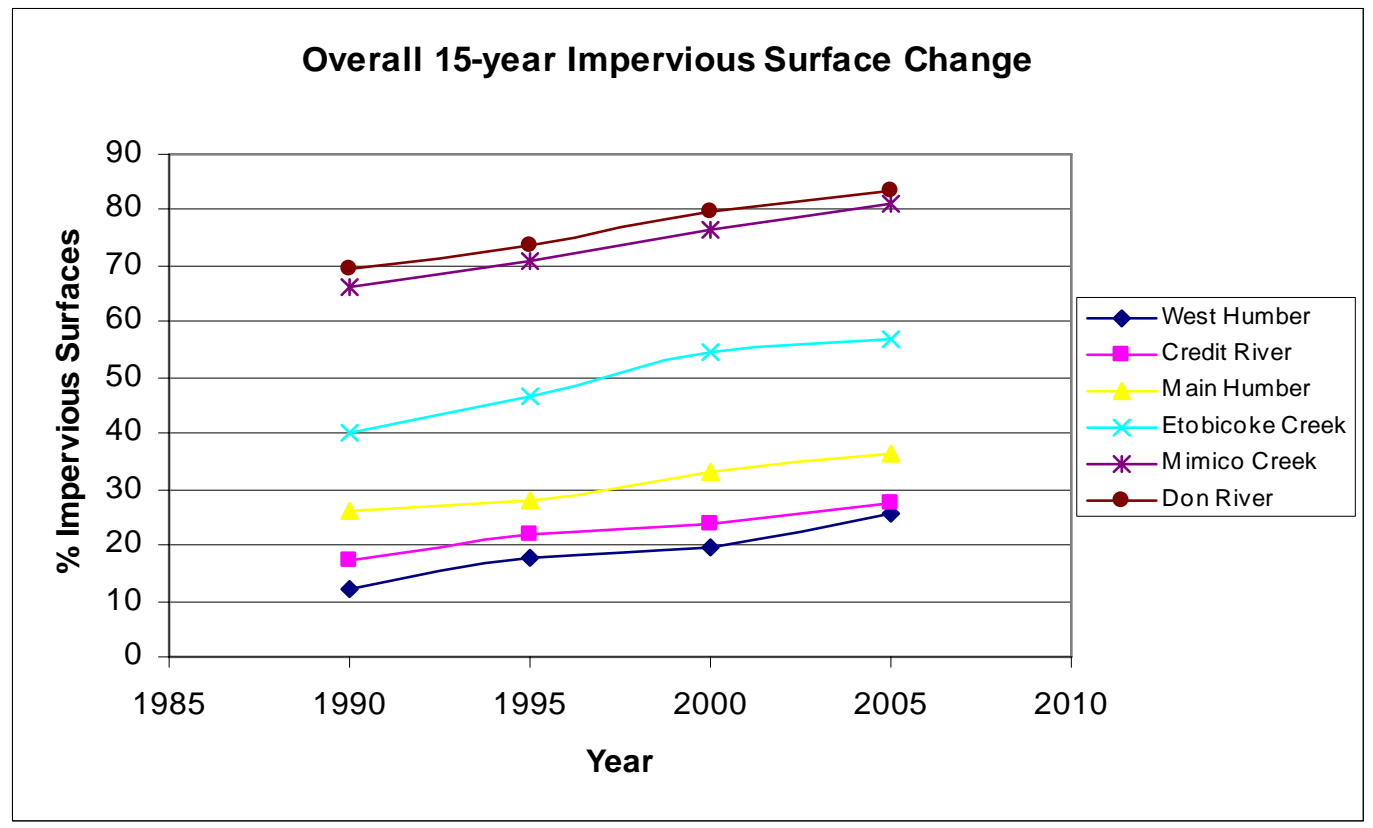

Figure 4.9 Overall impervious surface changes between 1990 and 2005. 


\subsubsection{Impervious Surface Growth Analysis}

The results from Table 4.1 and Figure 4.9 show steady growth rates throughout the different periods from 1990 to 2005. In West Humber watershed, the highest rate of urban growth occurred between 1990 and 1995, with a nearly 6\% increase in impervious surfaces. Most development took place in the lower half in the watershed. During this period, similar growth rates were seen in Credit River, Mimico and Don River watersheds. The Etobicoke Creek watershed, however, faced the highest amount of impervious surface growth of over $8 \%$ during this initial 5-year period, while the lowest increase, $1.5 \%$, occurred in Main Humber watershed. During the second 5-year period, between 1995 and 2000, Main Humber and Mimico Creek watersheds had the highest rate of impervious surfaces while the speed of new urban development slowed down in all the other watersheds. Different results were seen during the last 5-year period. Between 2000 and 2005, the highest impervious surface growth occurred in Don River watershed followed by a $4.50 \%$ increase in Mimico Creek watershed.

Overall, the results demonstrated an average of $12.92 \%$ increase in impervious surface coverage during a 15-year period in the entire study area. The highest overall growth occurs in the Etobicoke Creek Watershed. This increase, though small in number, is statistically a significant amount of developed land in an already densely populated area. The fastest urbanization areas are northward from the City of Brampton, west of the City of Mississauga as well as the Lower Zone of the Credit River watershed. The visual inspection of the region reveals that the entire lower half of the study area watersheds consists of impervious surfaces by 2005. 


\subsection{Accuracy Assessment of Classification}

For the 15-year land cover change analysis, the accuracy of the classified results was evaluated in terms of Landsat TM images. The classification accuracy of each watershed was evaluated using a stratified random sampling procedure where 50 samples were randomly selected and tested in each watershed for accuracy assessment. The results are presented in Table 4.2. The tables below report the producer's accuracy, the user's accuracy as well as the Kappa statistics for each watershed.

The producer's accuracy indicates how well training set pixels of the given cover type are classified. The user's accuracy is a measure of commission (inclusion) error and indicates the probability that a pixel classified into a given category actually represents that category on the ground. The Kappa Coefficient of Agreement on the other hand accounts for random chance in the accuracy assessment (Lillesand et al., 2004). An overall classification accuracy of over $91 \%$ and a kappa statistics over 0.88 are achieved, respectively.

Table 4.2 Accuracy Assessment Report.

\begin{tabular}{|c|c|c|c|c|c|}
\hline \multicolumn{6}{|c|}{1990 Classified Map- Credit River } \\
\hline \multirow[t]{2}{*}{ Classified data } & \multicolumn{3}{|c|}{ Reference data } & \multicolumn{2}{|l|}{ Classified Map } \\
\hline & Pervious & Impervious & Totals & Producer’s accuracy (\%) & $\begin{array}{l}\text { User's accuracy } \\
\text { (\%) }\end{array}$ \\
\hline Green & 30 & 4 & 34 & 96 & 88 \\
\hline Impervious & 1 & 15 & 16 & 87 & 93 \\
\hline \begin{tabular}{l|l} 
Total & \\
\end{tabular} & 31 & 19 & 50 & Overall accuracy_ $=90 \%$ & Kappa $=0.89$ \\
\hline \multicolumn{6}{|c|}{1995 Classified Map- Credit River } \\
\hline & \multicolumn{3}{|c|}{ Reference data } & \multicolumn{2}{|l|}{ Classified Map } \\
\hline Classified data & Pervious & Impervious & Totals & Producer’s accuracy (\%) & $\begin{array}{l}\text { User's accuracy } \\
\text { (\%) }\end{array}$ \\
\hline
\end{tabular}




\begin{tabular}{|c|c|c|c|c|c|}
\hline Green & 27 & 4 & 31 & 100 & 90 \\
\hline Impervious & 0 & 19 & 19 & 86 & 98 \\
\hline Totals & 27 & 23 & 50 & Overall accuracy_=94\% & Kappa $=0.87$ \\
\hline \multicolumn{6}{|c|}{2000 Classified Map- Credit River } \\
\hline & \multicolumn{3}{|c|}{ Reference data } & \multicolumn{2}{|l|}{ Classified Map } \\
\hline Classified data & Pervious & Impervious & Totals & Producer’s accuracy (\%) & $\begin{array}{l}\text { User’s accuracy } \\
\text { (\%) }\end{array}$ \\
\hline Green & 26 & 7 & 33 & 91 & 92 \\
\hline Impervious & 1 & 16 & 17 & 90 & 89 \\
\hline Total & 27 & 23 & 50 & Overall accuracy $=90 \%$ & Карра $=0.92$ \\
\hline \multicolumn{6}{|c|}{2005 Classified Map- Credit River } \\
\hline & \multicolumn{3}{|c|}{ Reference data } & \multicolumn{2}{|l|}{ Classified Map } \\
\hline Classified data & Pervious & Impervious & Totals & Producer’s accuracy (\%) & $\begin{array}{l}\text { User’s accuracy } \\
\text { (\%) }\end{array}$ \\
\hline Green & 27 & 6 & 33 & 96 & 90 \\
\hline Impervious & 1 & 16 & 17 & 86 & 89 \\
\hline Total & 28 & 22 & 50 & Overall accuracy $=92 \%$ & Карра $=0.89$ \\
\hline
\end{tabular}

\begin{tabular}{|c|c|c|c|c|c|}
\hline \multicolumn{6}{|c|}{1990 Classified Map- Etobicoke Creek } \\
\hline \multirow[t]{2}{*}{ Classified data } & \multicolumn{3}{|c|}{ Reference data } & \multicolumn{2}{|l|}{ Classified Map } \\
\hline & Pervious & Impervious & Totals & Producer’s accuracy (\%) & $\begin{array}{l}\text { User's accuracy } \\
\text { (\%) }\end{array}$ \\
\hline Green & 28 & 5 & 33 & 92 & 89 \\
\hline Impervious & 1 & 16 & 17 & 88 & 92 \\
\hline Total & 29 & 21 & 50 & Overall accuracy $=95 \%$ & Kappa $=0.90$ \\
\hline \multicolumn{6}{|c|}{1995 Classified Map- Etobicoke Creek } \\
\hline & \multicolumn{3}{|c|}{ Reference data } & \multicolumn{2}{|l|}{ Classified Map } \\
\hline Classified data & Pervious & Impervious & Totals & Producer's accuracy (\%) & $\begin{array}{l}\text { User's accuracy } \\
\text { (\%) }\end{array}$ \\
\hline Green & 26 & 2 & 28 & 98 & 90 \\
\hline Impervious & 1 & 21 & 22 & 86 & 98 \\
\hline Total & 27 & 23 & 50 & Overall accuracy = 95\% & Kappa $=0.90$ \\
\hline \multicolumn{6}{|c|}{2000 Classified Map- Etobicoke Creek } \\
\hline & \multicolumn{3}{|c|}{ Reference data } & \multicolumn{2}{|l|}{ Classified Map } \\
\hline Classified data & Pervious & Impervious & Totals & Producer's accuracy (\%) & $\begin{array}{l}\text { User's accuracy } \\
\text { (\%) }\end{array}$ \\
\hline Green & 27 & 7 & 34 & 90 & 92 \\
\hline Impervious & 1 & 15 & 16 & 91 & 89 \\
\hline Total & 28 & 22 & 50 & Overall accuracy = 90\% & Kappa $=0.91$ \\
\hline \multicolumn{6}{|c|}{2005 Classified Map- Etobicoke Creek } \\
\hline & \multicolumn{3}{|c|}{ Reference data } & \multicolumn{2}{|l|}{ Classified Map } \\
\hline Classified data & Pervious & Impervious & Totals & Producer's accuracy (\%) & $\begin{array}{l}\text { User's accuracy } \\
\text { (\%) }\end{array}$ \\
\hline
\end{tabular}




\begin{tabular}{|l|l|l|l|l|l|}
\hline Green & 24 & 6 & 30 & 96 & 90 \\
\hline Impervious & 1 & 19 & 20 & 86 & 89 \\
\hline Total & 25 & 25 & 50 & Overall accuracy $=92 \%$ & Kappa $=0.89$ \\
\hline
\end{tabular}

\begin{tabular}{|c|c|c|c|c|c|}
\hline \multicolumn{6}{|c|}{1990 Classified Map- Main Humber } \\
\hline \multirow[t]{2}{*}{ Classified data } & \multicolumn{3}{|c|}{ Reference data } & \multicolumn{2}{|l|}{ Classified Map } \\
\hline & Pervious & Impervious & Totals & Producer’s accuracy (\%) & \begin{tabular}{|l} 
User's accuracy \\
(\%)
\end{tabular} \\
\hline Green & 27 & 4 & 31 & 100 & 87 \\
\hline Impervious & 0 & 19 & 19 & 82 & 100 \\
\hline Total & 27 & 23 & 50 & Overall accuracy $=92 \%$ & Kappa $=0.83$ \\
\hline \multicolumn{6}{|c|}{1995 Classified Map- Main Humber } \\
\hline & \multicolumn{3}{|c|}{ Reference data } & \multicolumn{2}{|l|}{ Classified Map } \\
\hline Classified data & Pervious & Impervious & Totals & Producer’s accuracy (\%) & $\begin{array}{l}\text { User's accuracy } \\
\text { (\%) }\end{array}$ \\
\hline Green & 28 & 2 & 30 & 98 & 90 \\
\hline Impervious & 2 & 18 & 20 & 88 & 98 \\
\hline Total & 30 & 20 & 50 & Overall accuracy = 95\% & Kappa $=0.90$ \\
\hline \multicolumn{6}{|c|}{2000 Classified Map- Main Humber } \\
\hline & \multicolumn{3}{|c|}{ Reference data } & \multicolumn{2}{|l|}{ Classified Map } \\
\hline Classified data & Pervious & Impervious & Totals & Producer’s accuracy (\%) & $\begin{array}{l}\begin{array}{l}\text { User’s accuracy } \\
\text { (\%) }\end{array} \\
\end{array}$ \\
\hline Green & 29 & 4 & 33 & 89 & 92 \\
\hline Impervious & 2 & 15 & 17 & 91 & 89 \\
\hline Total & 31 & 19 & 50 & Overall accuracy = 91\% & Kappa $=0.89$ \\
\hline \multicolumn{6}{|c|}{2005 Classified Map- Main Humber } \\
\hline & \multicolumn{3}{|c|}{ Reference data } & \multicolumn{2}{|l|}{ Classified Map } \\
\hline Classified data & Pervious & Impervious & Totals & Producer’s accuracy (\%) & \begin{tabular}{|l}
$\begin{array}{l}\text { User's accuracy } \\
(\%)\end{array}$ \\
\end{tabular} \\
\hline Green & 28 & 3 & 31 & 96 & 90 \\
\hline Impervious & 0 & 19 & 19 & 86 & 89 \\
\hline Total & 28 & 22 & 50 & Overall accuracy = 92\% & Kappa $=0.90$ \\
\hline
\end{tabular}

\begin{tabular}{|l|l|l|l|l|l|}
\hline \multicolumn{6}{|c|}{1990 Classified Map- Mimico Creek } \\
\hline Classified data & \multicolumn{3}{|c|}{ Reference data } & \multicolumn{2}{c|}{ Classified Map } \\
\cline { 2 - 7 } & Pervious & Impervious & Totals & Producer’s accuracy (\%) & $\begin{array}{l}\text { User’s accuracy } \\
(\%)\end{array}$ \\
\hline Green & 17 & 3 & 20 & 91 & 89 \\
\hline Impervious & 0 & 27 & 27 & 89 & 92 \\
\hline Total & 17 & 33 & 50 & Overall accuracy $=91 \%$ & Kappa $=0.89$ \\
\hline
\end{tabular}




\begin{tabular}{|c|c|c|c|c|c|}
\hline \multicolumn{6}{|c|}{1995 Classified Map- Mimico Creek } \\
\hline & \multicolumn{3}{|c|}{ Reference data } & \multicolumn{2}{|l|}{ Classified Map } \\
\hline Classified data & Pervious & Impervious & Totals & Producer’s accuracy (\%) & $\begin{array}{l}\text { User's accuracy } \\
\text { (\%) }\end{array}$ \\
\hline Green & 20 & 3 & 23 & 95 & 87 \\
\hline Impervious & 3 & 24 & 27 & 82 & 98 \\
\hline Total & 23 & 27 & 50 & Overall accuracy $=93 \%$ & Kappa $=0.87$ \\
\hline \multicolumn{6}{|c|}{2000 Classified Map- Mimico Creek } \\
\hline & \multicolumn{3}{|c|}{ Reference data } & \multicolumn{2}{|l|}{ Classified Map } \\
\hline Classified data & Pervious & Impervious & Totals & Producer’s accuracy (\%) & $\begin{array}{l}\text { User's accuracy } \\
\text { (\%) }\end{array}$ \\
\hline Green & 17 & 2 & 19 & 90 & 92 \\
\hline Impervious & 1 & 30 & 31 & 91 & 89 \\
\hline Total & 18 & 32 & 50 & Overall accuracy $=90 \%$ & Kappa $=0.92$ \\
\hline \multicolumn{6}{|c|}{2005 Classified Map- Mimico Creek } \\
\hline & \multicolumn{3}{|c|}{ Reference data } & \multicolumn{2}{|l|}{ Classified Map } \\
\hline Classified data & Pervious & Impervious & Totals & Producer's accuracy (\%) & $\begin{array}{l}\text { User's accuracy } \\
\text { (\%) }\end{array}$ \\
\hline Green & 19 & 3 & 22 & 96 & 90 \\
\hline Impervious & 2 & 26 & 28 & 86 & 89 \\
\hline Total & 21 & 29 & 50 & Overall accuracy $=92 \%$ & Kappa $=0.89$ \\
\hline
\end{tabular}

\begin{tabular}{|c|c|c|c|c|c|}
\hline \multicolumn{6}{|c|}{1990 Classified Map- West Humber } \\
\hline \multirow[t]{2}{*}{ Classified data } & \multicolumn{3}{|c|}{ Reference data } & \multicolumn{2}{|l|}{ Classified Map } \\
\hline & Pervious & Impervious & Totals & Producer’s accuracy (\%) & $\begin{array}{l}\text { User’s accuracy } \\
\text { (\%) }\end{array}$ \\
\hline Green & 28 & 4 & 32 & 95 & 92 \\
\hline Impervious & 0 & 18 & 18 & 89 & 97 \\
\hline Total & 28 & 22 & 50 & Overall accuracy $=95 \%$ & Kappa $=0.91$ \\
\hline \multicolumn{6}{|c|}{1995 Classified Map- West Humber } \\
\hline & \multicolumn{3}{|c|}{ Reference data } & \multicolumn{2}{|l|}{ Classified Map } \\
\hline Classified data & Pervious & Impervious & Totals & Producer’s accuracy (\%) & $\begin{array}{l}\text { User’s accuracy } \\
\text { (\%) }\end{array}$ \\
\hline Green & 25 & 2 & 27 & 97 & 86 \\
\hline Impervious & 2 & 21 & 23 & 82 & 98 \\
\hline Total & 27 & 23 & 50 & Overall accuracy = 94\% & Kappa $=0.88$ \\
\hline \multicolumn{6}{|c|}{2000 Classified Map- West Humber } \\
\hline & \multicolumn{3}{|c|}{ Reference data } & \multicolumn{2}{|l|}{ Classified Map } \\
\hline Classified data & Pervious & Impervious & Totals & Producer’s accuracy (\%) & $\begin{array}{l}\text { User's accuracy } \\
(\%)\end{array}$ \\
\hline Green & 27 & 2 & 29 & 90 & 92 \\
\hline Impervious & 1 & 20 & 21 & 91 & 90 \\
\hline Total & 28 & 22 & 50 & Overall accuracy = 90\% & Kappa $=0.92$ \\
\hline
\end{tabular}




\begin{tabular}{|l|l|l|l|l|l|}
\hline \multicolumn{7}{|c|}{ 2005 Classified Map- West Humber } \\
\hline & \multicolumn{3}{|c|}{ Reference data } & \multicolumn{2}{c|}{ Classified Map } \\
\hline Classified data & Pervious & Impervious & Totals & Producer’s accuracy (\%) & $\begin{array}{l}\text { User's accuracy } \\
(\%)\end{array}$ \\
\hline Green & 26 & 0 & 26 & 96 & 87 \\
\hline Impervious & 2 & 22 & 24 & 86 & 90 \\
\hline Total & 28 & 22 & 50 & Overall accuracy $=89 \%$ & Kappa = 0.89 \\
\hline
\end{tabular}

\begin{tabular}{|c|c|c|c|c|c|}
\hline \multicolumn{6}{|c|}{1990 Classified Map- Don River } \\
\hline \multirow[t]{2}{*}{ Classified data } & \multicolumn{3}{|c|}{ Reference data } & \multicolumn{2}{|l|}{ Classified Map } \\
\hline & Pervious & Impervious & Totals & Producer’s accuracy (\%) & $\begin{array}{l}\text { User's accuracy } \\
\text { (\%) }\end{array}$ \\
\hline Green & 15 & 4 & 19 & 88 & 88 \\
\hline Impervious & 1 & 30 & 31 & 89 & 87 \\
\hline Total & 16 & 34 & 50 & Overall accuracy $=89 \%$ & Kappa $=0.89$ \\
\hline \multicolumn{6}{|c|}{1995 Classified Map- Don River } \\
\hline & \multicolumn{3}{|c|}{ Reference data } & \multicolumn{2}{|l|}{ Classified Map } \\
\hline Classified data & Pervious & Impervious & Totals & Producer’s accuracy (\%) & $\begin{array}{l}\text { User's accuracy } \\
\text { (\%) }\end{array}$ \\
\hline Green & 20 & 3 & 23 & 97 & 87 \\
\hline Impervious & 3 & 24 & 27 & 82 & 98 \\
\hline Total & 23 & 27 & 50 & Overall accuracy = 94\% & Kappa $=0.87$ \\
\hline \multicolumn{6}{|c|}{2000 Classified Map- Don River } \\
\hline & \multicolumn{3}{|c|}{ Reference data } & \multicolumn{2}{|l|}{ Classified Map } \\
\hline Classified data & Pervious & Impervious & Totals & Producer’s accuracy (\%) & $\begin{array}{l}\text { User's accuracy } \\
(\%)\end{array}$ \\
\hline Green & 16 & 0 & 16 & 90 & 89 \\
\hline Impervious & 2 & 32 & 34 & 91 & 89 \\
\hline Total & 18 & 32 & 50 & Overall accuracy $=90 \%$ & Kappa $=0.88$ \\
\hline \multicolumn{6}{|c|}{2005 Classified Map- Don River } \\
\hline & \multicolumn{3}{|c|}{ Reference data } & \multicolumn{2}{|l|}{ Classified Map } \\
\hline Classified data & Pervious & Impervious & Totals & Producer's accuracy (\%) & $\begin{array}{l}\text { User's accuracy } \\
\text { (\%) }\end{array}$ \\
\hline Green & 21 & 0 & 21 & 83 & 81 \\
\hline Impervious & 5 & 24 & 29 & 82 & 83 \\
\hline Total & 26 & 24 & 50 & Overall accuracy = 83\% & Kappa $=0.81$ \\
\hline
\end{tabular}




\subsection{Mapping of Chloride Concentrations}

\subsubsection{Spatial and Temporal Variations}

The total average and median chloride concentrations of samples collected from May to October (dry season) in 1990, 1995, 2000, and 2005, respectively, are illustrated in Figure 4.10, while Figure 4.11 shows the average and median chloride concentrations from samples collected between November and April (wet season). In mathematics and statistics, the total average is the sum of all the numbers divided by the number of samples in question, while a median (or middle value) is described as the number separating the higher half of a sample from the lower half (Witte, 1989).

Most water quality monitoring stations showed a gradual increase in chloride concentrations over the years. The most obvious increase between 1990 and 2005 was a three-fold increase in chloride concentrations which was observed in dry-season samples. A synthesis of scientific studies suggests a value of approximately $250 \mathrm{mg} / \mathrm{L}$ as a reasonable target for the protection of aquatic life. The $250 \mathrm{mg} / \mathrm{L}$ is also a federal threshold chosen by the government of Canada (Mayer et al., 1999). The results of dry-season chloride values demonstrated how this federal target was reached in 2000 and frequently exceeded in 2005. The wet-season values, however, show how this threshold was reached as early as in 1990.

In Sheridan Creek, a highly developed urban creek located in the Lower Zone of the Credit River watershed and bordering Lake Ontario, results showed average wet chloride concentrations increasing from 470 mg/L in 1990 to over 870 mg/L by 2005 . In the Don River in Toronto, concentrations of chloride increased to more than 860 $\mathrm{mg} / \mathrm{L}$ in winter with increases appearing to correspond with winter thaws. The dry 
season baseline chloride values in the Don River were $360 \mathrm{mg} / \mathrm{L}$ in 2005, while the same baseline values back in 1990 were $140 \mathrm{mg} / \mathrm{L}$. Similar baseline concentrations of chloride $(120 \mathrm{mg} / \mathrm{L})$ were seen in Etobicoke Creek, another highly urbanized watershed in the Peel Region. Chloride concentrations 3 times higher than baseline values were measured during the winter months in this creek.

In the Mimico Creek watershed, with over $80 \%$ impervious surface cover, average chloride concentrations exceeding $1102 \mathrm{mg} / \mathrm{L}$ were observed during winter months of January and Febuary with median concentrations of approximately 998 mg/L; lagging behind average values by only a few units. In general, a similar trend was found between average and median values in both wet and dry seasons, with median concentrations often being slightly lower than average concentrations.

Examination of the spatial distribution of chloride concentrations in surface waters within the study area watersheds also reflects the distribution of transportation related surfaces. In their 2006 study, Howard and Maier observed serious water quality degradation in the Don and Humber Rivers as they passed through the City of Toronto on their journey from headwaters in the Oak Ridges Moraine to Lake Ontario (Howard and Maier, 2006). Similar results were seen in this study.

Concentrations of chlorides in stations located in predominantly rural lands, i.e. Station Numbers 6008301802 and 6007601502, ranged from 25 to $50 \mathrm{mg} / \mathrm{L}$ whereas the more urbanized watersheds, such as the Mimico Creek and Don River, experienced higher chloride concentrations mainly due to the denser and more heavily used highways and road networks. Polluted runoff from major highways such as the 
Hwy 427 and Gardiner Expressways has the potential to influence the spatial pattern of chloride concentrations in the study area.

This further supports the importance of land use characteristics in the watersheds. Land use properties in each watershed are important in investigating correlation between water quality impacts and impervious surfaces because not only the degree of imperviousness but also the combination of the impervious surfaces and the type of land use upon which those impervious surfaces rest upon that can influence surface water quality. For example, it is possible to observe higher chloride concentrations in watersheds with higher amounts of industry, commercial enterprises, traffic congestion and primary roads.

With regards to temporal variations, research has shown that nonpoint source pollutant concentrations during wet weather are generally higher than during dry weather. Concentrations are often highest in the wet winter months since that is the time when de-icing salts are applied to roads and highways. During summer and fall months, the concentrations are reduced as most of the winter road salts had been washed off of surfaces by precipitation (TRCA, 1998; Snodgrass and D’Andrea, 1993).

The temporal variations between wet and dry weather chloride concentrations reflect differences in the source of flow during these two seasons. During dry summer months, the flows are generally small in volume and originate primarily from groundwater, which has already been filtered by riparian vegetation and soil. Summer base-flows are typically less contaminated than surface runoffs. By contrast, the 
majority of wet weather flows are larger in size and more polluted since they originate from impervious surfaces (Snodgrass and D’Andrea, 1993; Meyer, 2005).

Similar to previous research findings (Snodgrass and D’Andrea, 1993; Rose and Peters, 2001; Brandes et al., 2005; Howard and Maier, 2006), results obtained in this study show a strong seasonal variation. Aside from an obvious increase in chloride levels over time for each water quality monitoring station, Figures 4.12 and 4.13 demonstrate this marked temporal variation in chloride concentrations between baseflow and wet weather conditions, with wet season concentrations being noticeably higher (i.e. reaching over $1000 \mathrm{mg} / \mathrm{L}$ ) indicating peak inputs of road salts in winter. 

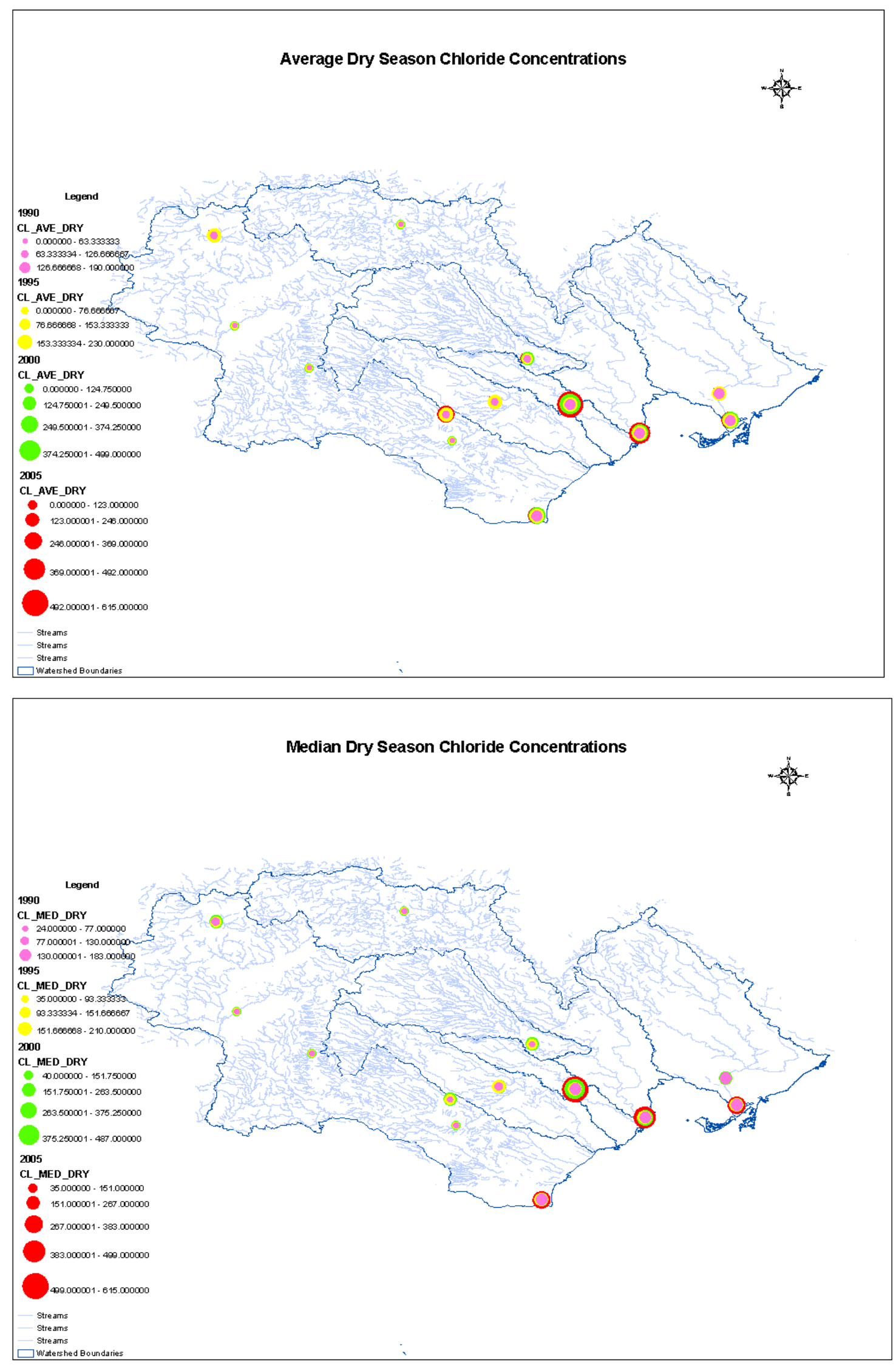

Figure 4.10 Average and median dry season chloride concentrations (mg/L) in the study area between 1990 and 2005. 

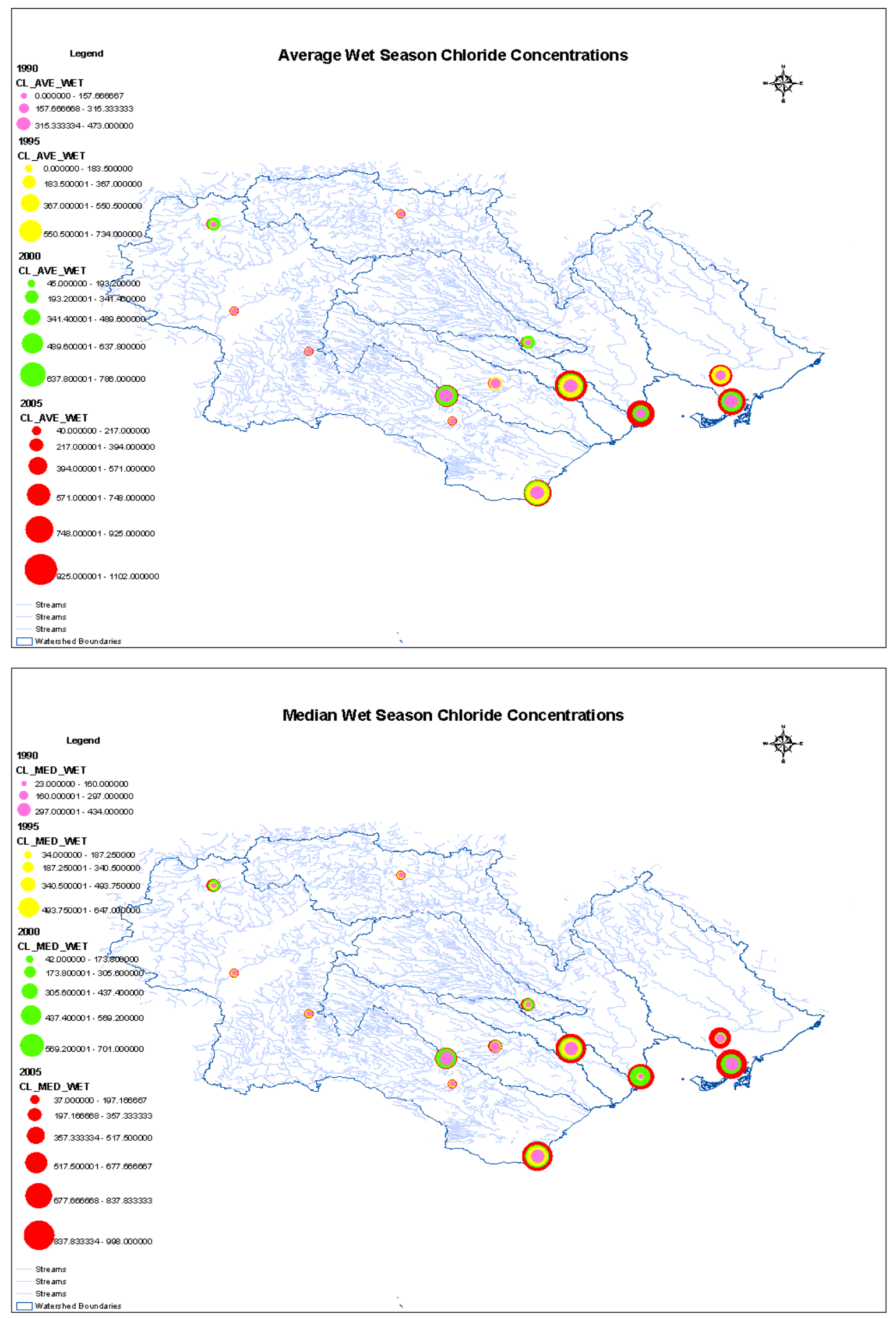

Figure 4.11 Average and median wet season chloride concentrations (mg/L) in the study area between 1990 and 2005. 


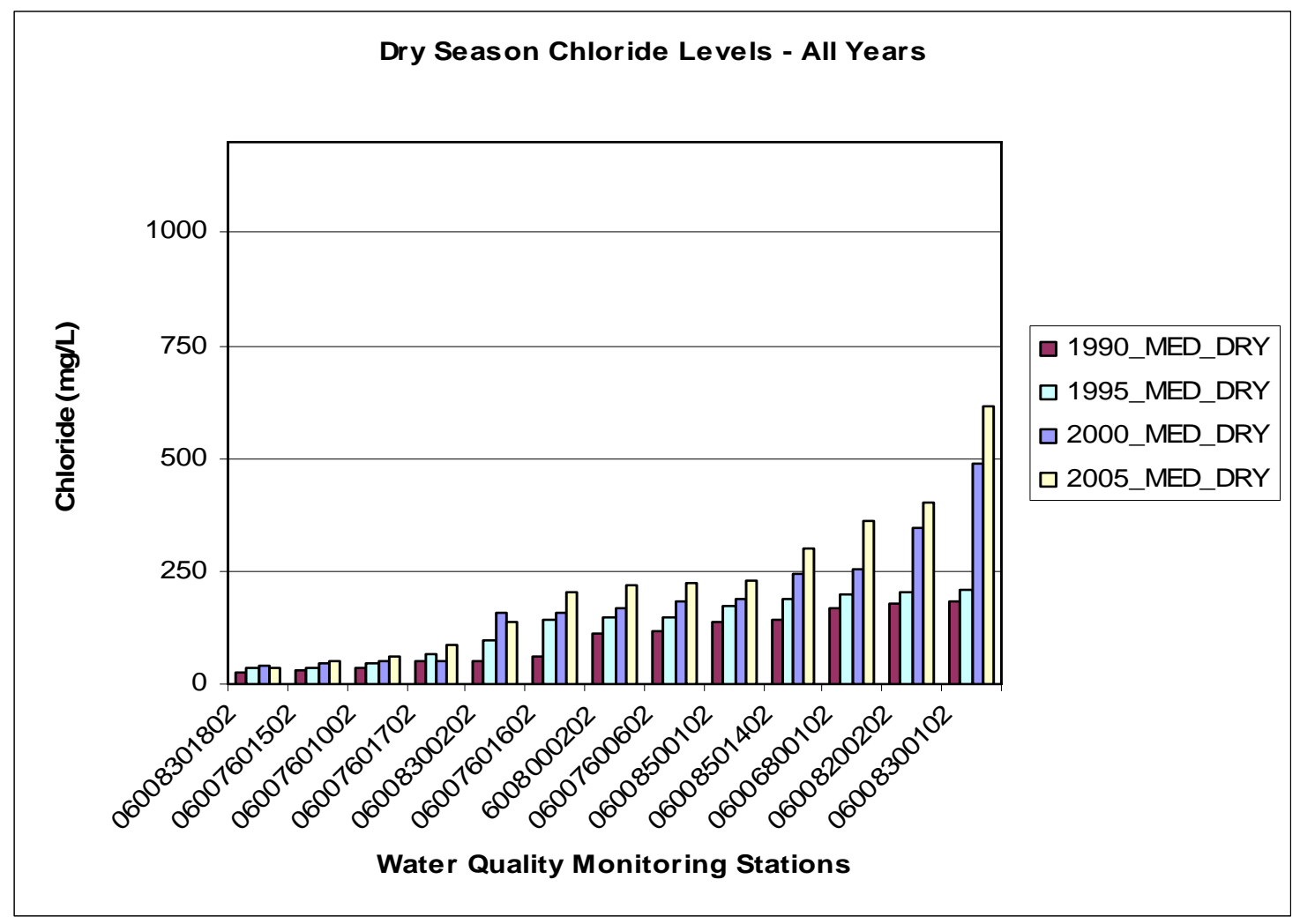

Figure 4.12 Temporal variations in chloride concentrations between base-flow and dry season conditions at each monitoring station.

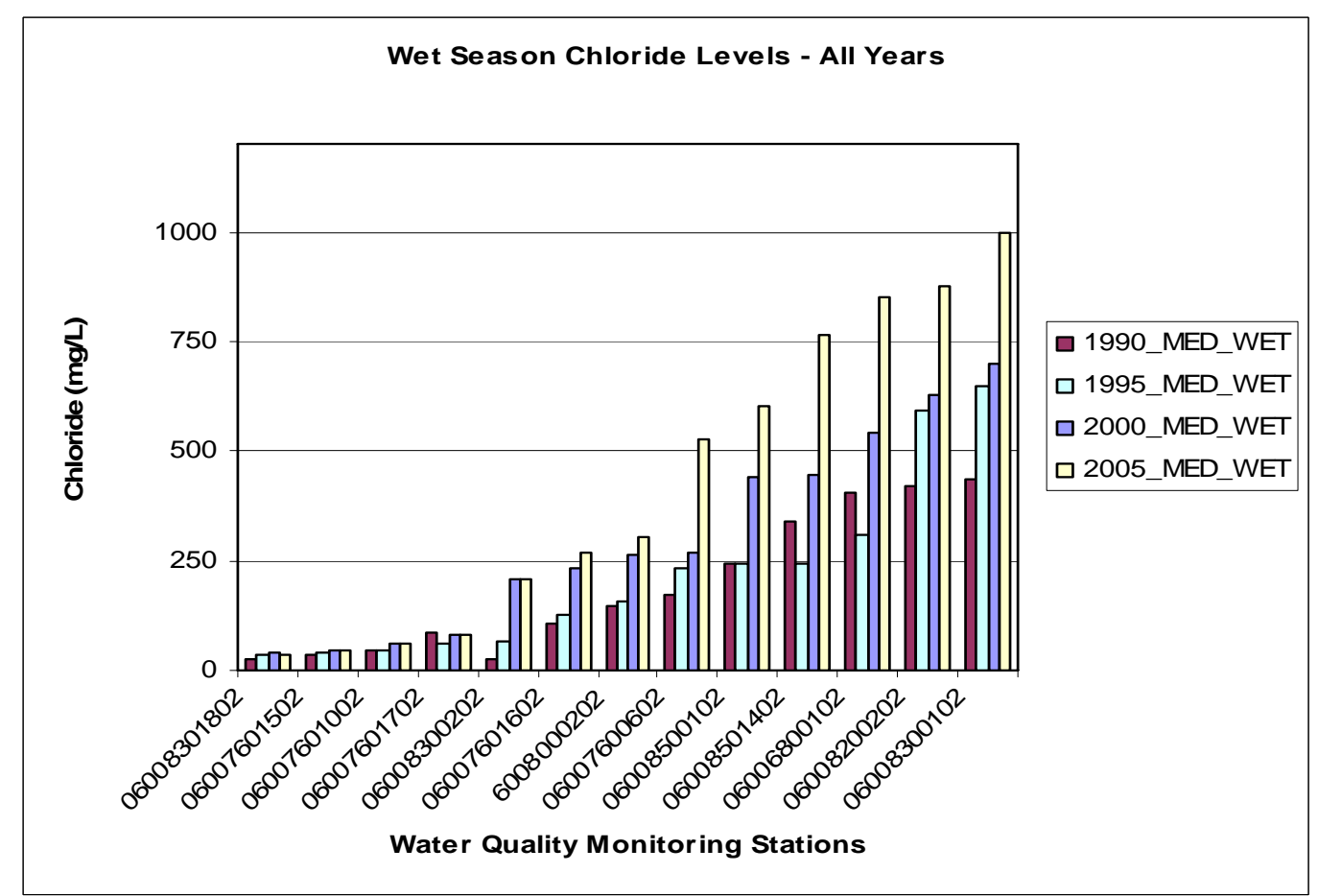

Figure 4.13 Temporal variations in chloride concentrations between base-flow and wet season conditions at each monitoring station. 


\subsubsection{The Role of Weather Conditions and Salt Usage on Chloride Concentrations}

This section addresses the role of snow fall amounts as well as municipality practices of salt usage on chloride concentrations in surface water. Table 4.3 shows the total salt usage per city in the study area, while Table 4.4 lists the total amounts of snow falls over the years. The limited data below indicates that from the period of 1990 through 2005 there has been a steady increase in the total amount of snowfall in the study area. However, there is no correlation between salt usage and snowfall in particular. This apparent inconsistency can be explained in several ways. First, this is based on very limited time scale data. Second, this data only reflects public's usage of salt and does not account for private residential and commercial usages. Third, the amount of snow is not the only factor in determining the salt usage. Other factors that can increase the salt usage include the frequency of freeze/thaw frost, snow, and freezing rain events. Sometimes a mild winter with few "big" events can actually lead to more salt usage (C. Marshall, personal communication, Oct 31, 2007).

Table 4.3 Total salt usage of cities. (Source: C. Morton and D. Morris, personal communication, Nov 2, 2007)

\begin{tabular}{|c|c|c|}
\hline City & Year & Salt Usage (tonnes) \\
\hline \multirow[t]{4}{*}{ Mississauga } & 1990 & N/A \\
\hline & 1995 & 46,799 \\
\hline & 2000 & 68,195 \\
\hline & 2005 & 65,666 \\
\hline \multirow[t]{4}{*}{ Brampton } & 1990 & N/A \\
\hline & 1995 & N/A \\
\hline & 2000 & N/A \\
\hline & 2005 & N/A \\
\hline \multirow[t]{4}{*}{ Caledon } & 1990 & *1,433 \\
\hline & 1995 & $* 2,298$ \\
\hline & 2000 & $* \mathrm{~N} / \mathrm{A}$ \\
\hline & 2005 & 5,600 \\
\hline
\end{tabular}




\begin{tabular}{|l|l|l|}
\hline \multirow{3}{*}{ Toronto } & 1990 & N/A \\
\cline { 2 - 3 } & 1995 & N/A \\
\cline { 2 - 3 } & 2000 & N/A \\
\cline { 2 - 3 } & 2005 & N/A \\
\hline
\end{tabular}

*Chloride deriving from calcium chloride ${ }^{1}$

Table 4.4 Total amount of snow fall in 1990, 1995, 2000 and 2005. (Source: Environment Canada, 2007)

\begin{tabular}{|l|l|l|l|l|}
\hline $\begin{array}{c}\text { Total Snow } \\
(\mathbf{c m})\end{array}$ & $\mathbf{1 9 9 0}$ & $\mathbf{1 9 9 5}$ & $\mathbf{2 0 0 0}$ & $\mathbf{2 0 0 5}$ \\
\hline November & 2 & 27 & 1 & 12 \\
\hline December & 28 & 30 & 63 & 41 \\
\hline January & 12 & 24 & 17 & 33 \\
\hline February & 26 & 14 & 39 & 33 \\
\hline March & 4 & 8 & 8 & 25 \\
\hline April & 2 & 5 & 8 & 16 \\
\hline Sum & 76 & 110 & 135 & 162 \\
\hline
\end{tabular}

\subsection{Results of Integrating Impervious Surface Estimates with Chloride Data}

For the purpose of data integration, "median-dry" chloride concentrations are chosen to be overlaid on top of impervious surface estimates, mainly for two reasons: "dry" season values are selected to be relatively consistent with the Landsat-5 TM data acquisition dates; and "median” values are selected to have a conservative estimate of the adverse effects of chloride concentrations in the study area watersheds.

When the two sets of maps are overlaid (see Figure 4.14), a corresponding trend was apparent over the years: the highest chloride concentrations occurred in areas with highest percentage of impervious surface area. In other words, the watersheds with moderate to low levels of development had the lowest chloride concentrations whereas the watersheds that were highly urbanized (i.e., Etobicoke, Mimico Creek

\footnotetext{
${ }^{1}$ Calcium chloride is being used in Caledon as a dust suppressant.
} 
and Don River) exhibited the highest chloride levels. The results of integrating remotely sensed data with chloride data successfully demonstrated a strong association between water quality as represented by chloride and urbanization that represents the percentage area occupied by impermeable surfaces.

The integrated maps demonstrated that concentrations tend to increase towards the river-lake boundary. Monitoring stations closest to the Lake Ontario exhibited the highest chloride concentration as the majority of salt applied during the winter months had not infiltrated into the soil, remained on the impervious surfaces, and eventually emptied into the lake via surface runoff. The surface water flow generally reflects the surface topography. In the study area watersheds, the overall direction of water flow is a south east direction moving towards the Lake Ontario.

Also, approximately three-quarters of the people who live in Ontario rely on water that is drawn from surface sources such as the Great Lakes (TRCA, 2007). As Lake Ontario becomes polluted, a primary source of drinking water for the region is potentially at risk. This can have adverse socio-economic impacts.

Again, the results here are consistent with the TRCA's study in 1998 where considerable water quality degradation had been observed in the Etobicoke Creek and Humber River watersheds as they passed through the Cities of Brampton and Mississauga on their journey from headwater springs in the Oak Ridges Moraine to Lake Ontario (TRCA, 1998). As a primary source of drinking water for the region should this trend continue over time, the resulting change can significantly stress the area. 


\section{Legend}

1990-Median Dry Chloride 1990_MED_D

- $24.000000-77.000000$

- $77.000001-130.000000$

- $130.000001-183.000000$

1990-A verage Dry Chloride

1990_AVE_D

- $0.000000-63.333333$

- $63.333334-126.666667$

- $126.666668-190.000000$

1990 -Median Wet Chloride 1990_MED_W

- 23.000000 - 107.000000

- $107.000001-245.000000$

245.000001-434.000000

1990-Average Wet Chloride

1990_AVE_W

- $0.000000-157.666667$

- $157.666668-315.333333$

$315.333334-473.000000$

obm_OBMUSER_waterseg_polysc_poly

Watershed Boundary

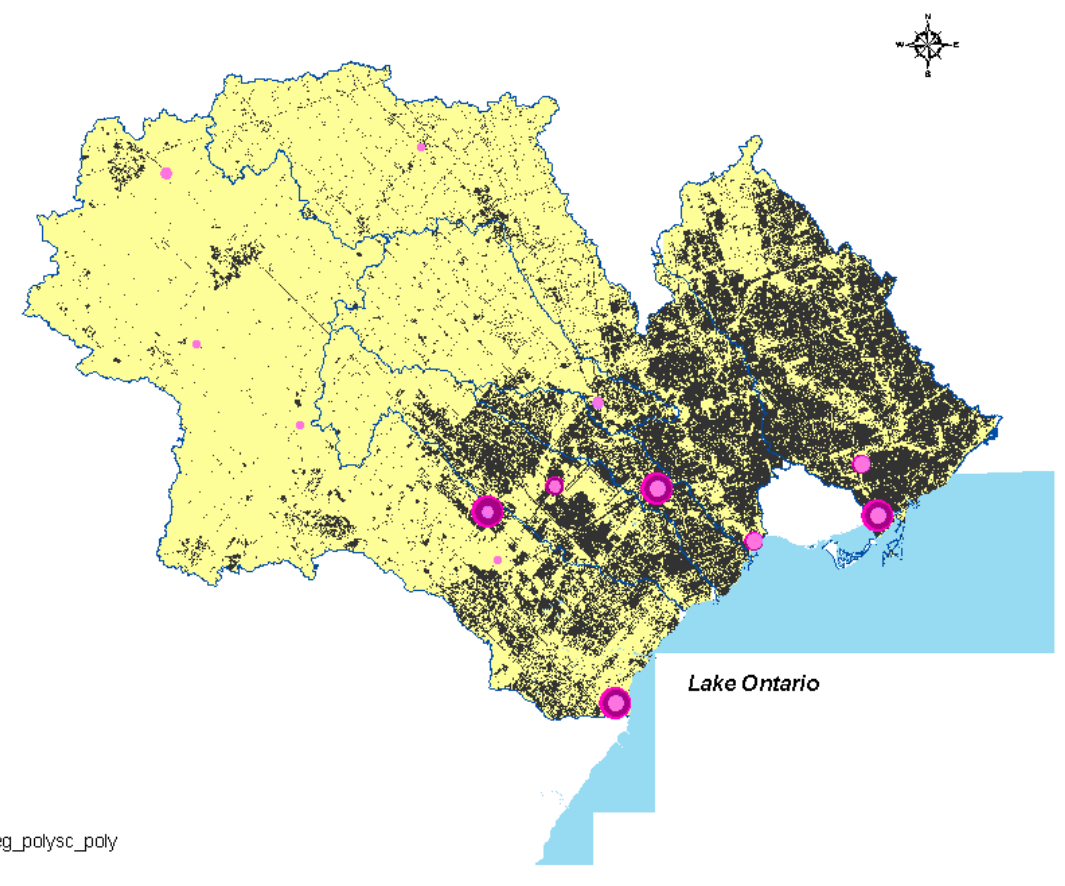

Integrated Chloride Map with Impervious Surface Map of 1995

Legend

1995-Median Dry Chloride 1995_MED_D

$35.000000-78.750000$ $78.750001-122.500000$

$122.500001-166.250000$

$166.250001-210.000000$

1995-Average Dry Chloride 1995_AVE_D

- $0.000000-57.500000$

- $57.500001-115.000000$

- $115.000001-172.500000$

$172.500001-230.000000$

1995-Median Wet Chloride

1995_MED_W

- $34.000000-187.250000$

$187.250001-340.500000$

$340.500001-493.750000$

493.750001 - 647.000000

1995-Average Wet Chloride

1995_AVE_W

$0.000000-183.500000$

183.500001 - 367.000000

367.000001 - 550.500000

$550.500001-734.000000$

obm_OBMUSER_waterseg_polysc_poly

Watershed Boundary

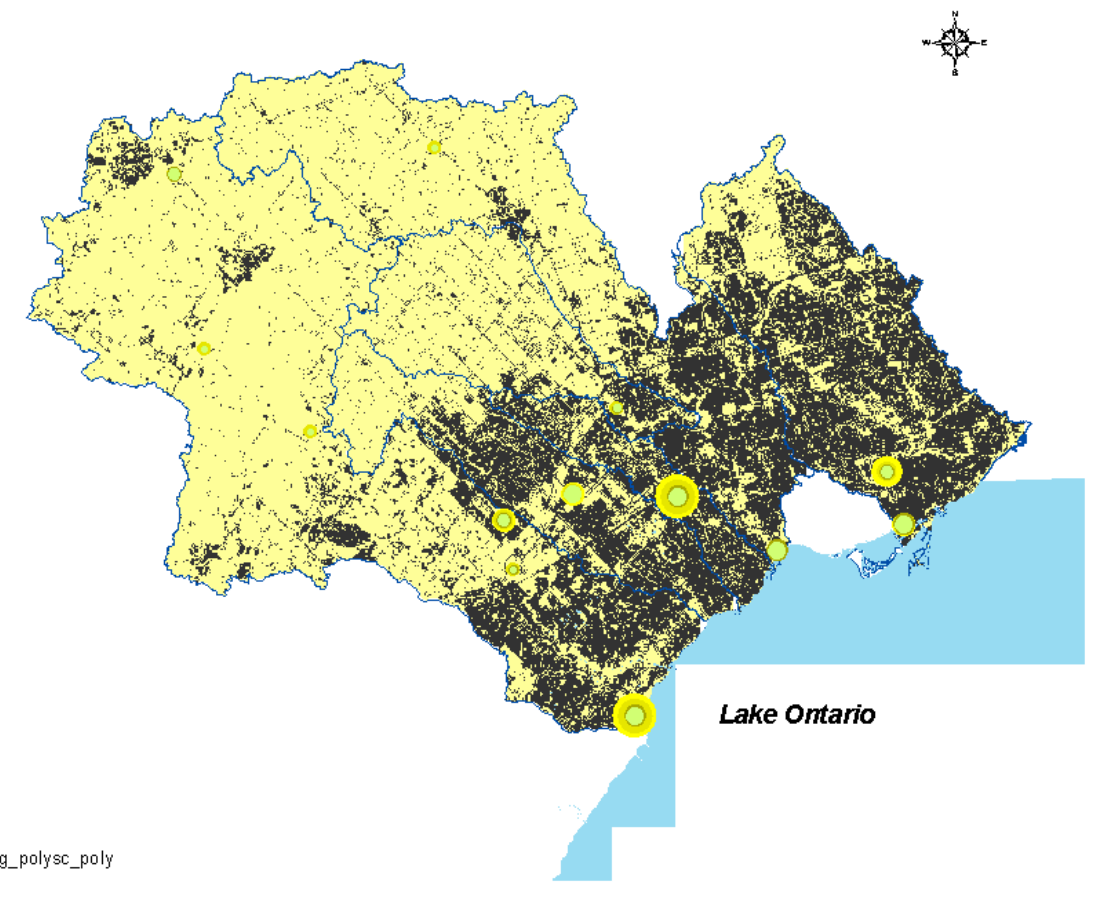



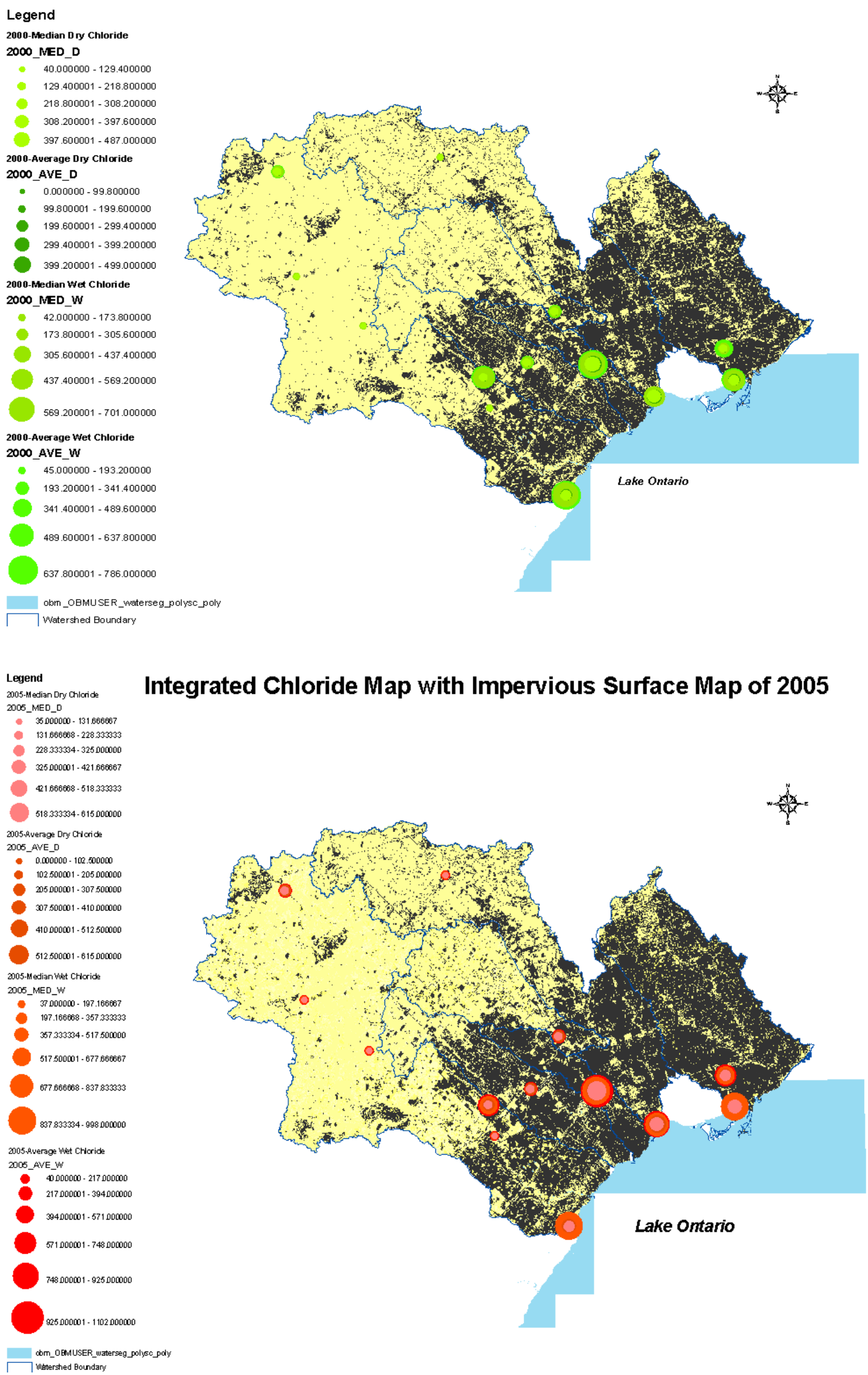

Figure 4.14 Chloride concentrations overlaid on impervious surface map of 1990, 1995, 2000 and 2005. 
Broadly speaking, a stressor (i.e. increased imperviousness) is defined as change that results in a response which disturbs the natural balance of an ecosystem. An indicator (increased chloride levels) is a characteristic of an ecosystem that provides clues as to when something is changing (Schmidt, 2004). Long-term study of indicators allows for a better understanding of the balance of natural environments as well as recognition of when this balance is disturbed by stressors such as urbanization (Jackson and Jobbagy, 2005). Land use change is one of the challenging issues that has the potential to significantly alter the ecosystem's health; particularly, the shift from a "green” to “impervious” landscape.

In the absence of human activity and anthropogenic sources, salt concentrations in surface waters are mainly related to the chemistry of the bedrock and watershed geology. In 2001, the Priority Substances List Assessment Report for Road Salts was released, indicating that the background salt concentrations of surface waters vary within the range $<1-5 \mathrm{mg} / \mathrm{L}$ (Environment Canada, 2001). However, chloride concentrations seen in this study were considerably higher than those reported background concentrations, reflecting the effects of urban sprawl and the consequent increase in the amount of constructed lands and therefore of road salt usage in this region. Impacts of high use of road salts were evident from the data, particularly in highly urbanized areas. Chloride concentrations of rural areas were among the lowest in the study area while a marked increase in chloride concentrations was noticeable in highly urbanized Mimico Creek and Don River watersheds. 


\subsection{Statistical Analysis}

In this section, the impervious surface estimates obtained in Section 4.1 and the chloride concentrations presented in Section 4.3 are combined and statistically tested for their degree of correlation. The best approach to validate the often-assumed adverse effects of impervious surfaces on water quality is by means of statistical examination. To investigate this assumption, linear regression lines of median dry season chloride concentrations are plotted against the impervious surface estimates for each date to determine if a pattern existed between chloride concentrations and amounts of impervious surfaces in the watersheds. These plots are presented in Figure 4.15. Also, the linear regression plot of chloride as a function of impervious surface for all four dates combined is presented in Figure 4.16. The coefficients of determination were calculated between percent impervious surfaces and chloride levels. The results are presented in Table 4.5.

While it is well recognized that impervious surface is associated with water quality impact (Moffett and Hasse, 2006), the study relied solely on impervious surface estimates as an indicator of water quality.

Another consideration is that comparison of chloride concentrations as a measure of water quality with percent impervious surfaces produces only a descriptive measure and not a predictive, causative measure. Accordingly, relationship discovered does not explain how, or even if, impervious surfaces adversely affect water quality, but rather that there is some quantifiable association between the two variables. 

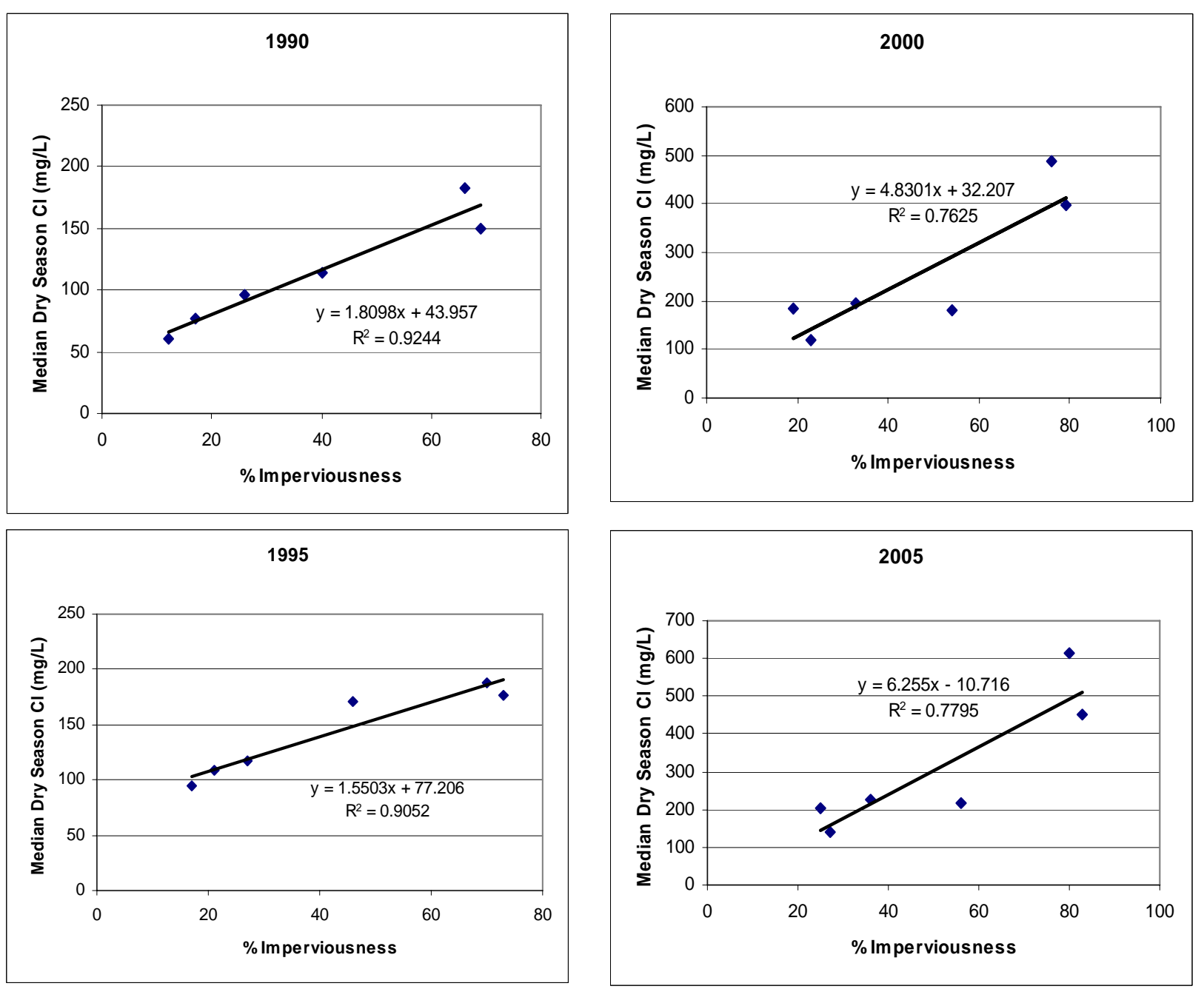

Figure 4.15 Linear regressions of chloride concentrations and impervious surfaces between 1990 and 2005.

According to statistical analyses based on individual dates, a correlation exists between impervious surfaces and chloride concentrations over the years. The findings demonstrate that urbanization and the resultant increase in imperviousness do generate higher chloride concentrations. Correspondingly, the higher levels of chloride can potentially degrade quality of surface waters in the study area. However, when all dates were combined, the correlation was no longer linear (Figure 4.16). This can be explained by an uneven increase in chloride concentrations with respect to impervious surface growth. While impervious surfaces are increasing steadily over 
the years, there is an uneven increase in chloride concentrations in some watersheds, depending on the characteristics of the watershed as well as climatic conditions, resulting in a non-linear correlation between chloride and imperviousness.

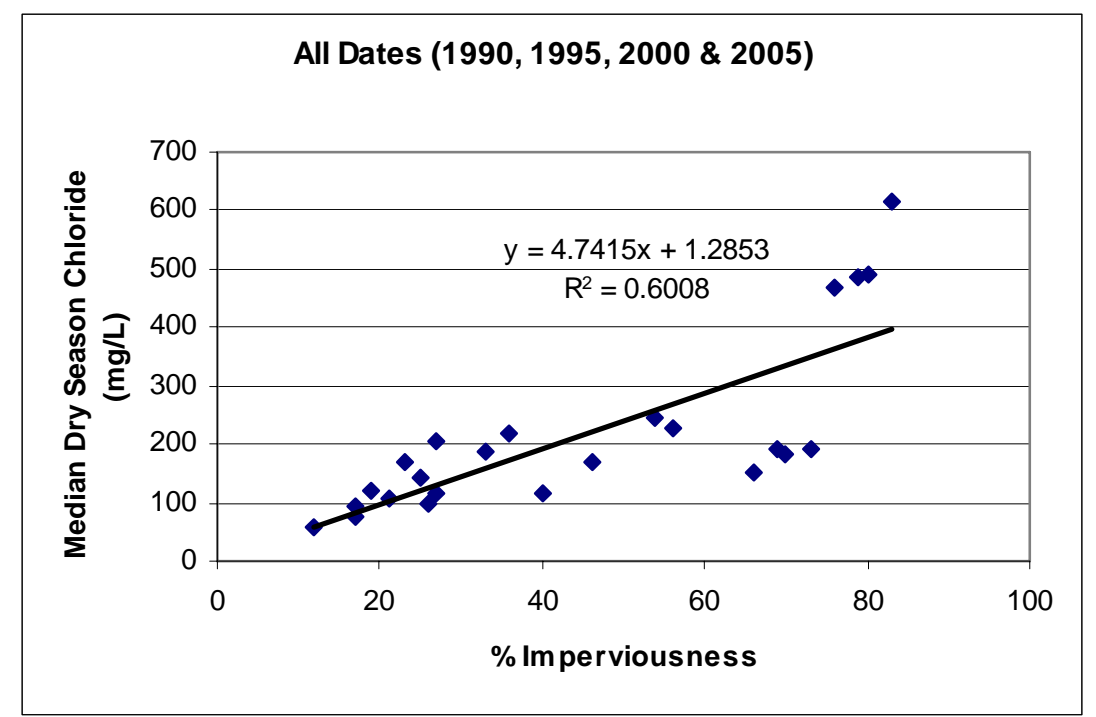

Figure 4.16 Linear regression plot of chloride as a function of impervious surfaces for all four dates combined.

Table 4.5 Linear regressions between chloride (dry season) and impervious surfaces by year.

\begin{tabular}{|l|c|c|c|c|c|}
\hline Water Quality Measure & \multicolumn{5}{|c|}{ \% Impervious Surfaces } \\
\cline { 2 - 6 } & $\mathbf{1 9 9 0}$ & $\mathbf{1 9 9 5}$ & $\mathbf{2 0 0 0}$ & $\mathbf{2 0 0 5}$ & All dates combined \\
\cline { 2 - 6 } & $\mathrm{R}^{2}$ & $\mathrm{R}^{2}$ & $\mathrm{R}^{2}$ & $\mathrm{R}^{2}$ & $\mathrm{R}^{2}$ \\
\hline Median Dry Chloride & 0.92 & 0.90 & 0.76 & 0.77 & 0.60 \\
\hline
\end{tabular}

Figure 4.17, below, further illustrates the degree of association between the two variables, representing impervious growth of each watershed as it relates to increases in chloride concentrations from 1990 to 2005. Overall, as the amount of impervious surfaces increase in each watershed over the years, chloride concentrations also increase, with the exception of Don River watershed where chloride concentrations slightly decrease with increasing impervious surfaces. 
Also, while impervious surfaces increase at a relatively constant rate over the years, there is a dramatic increase (i.e. three fold increase) in chloride concentrations in Mimico Creek and Don River watersheds particularly in 2000 and 2005.

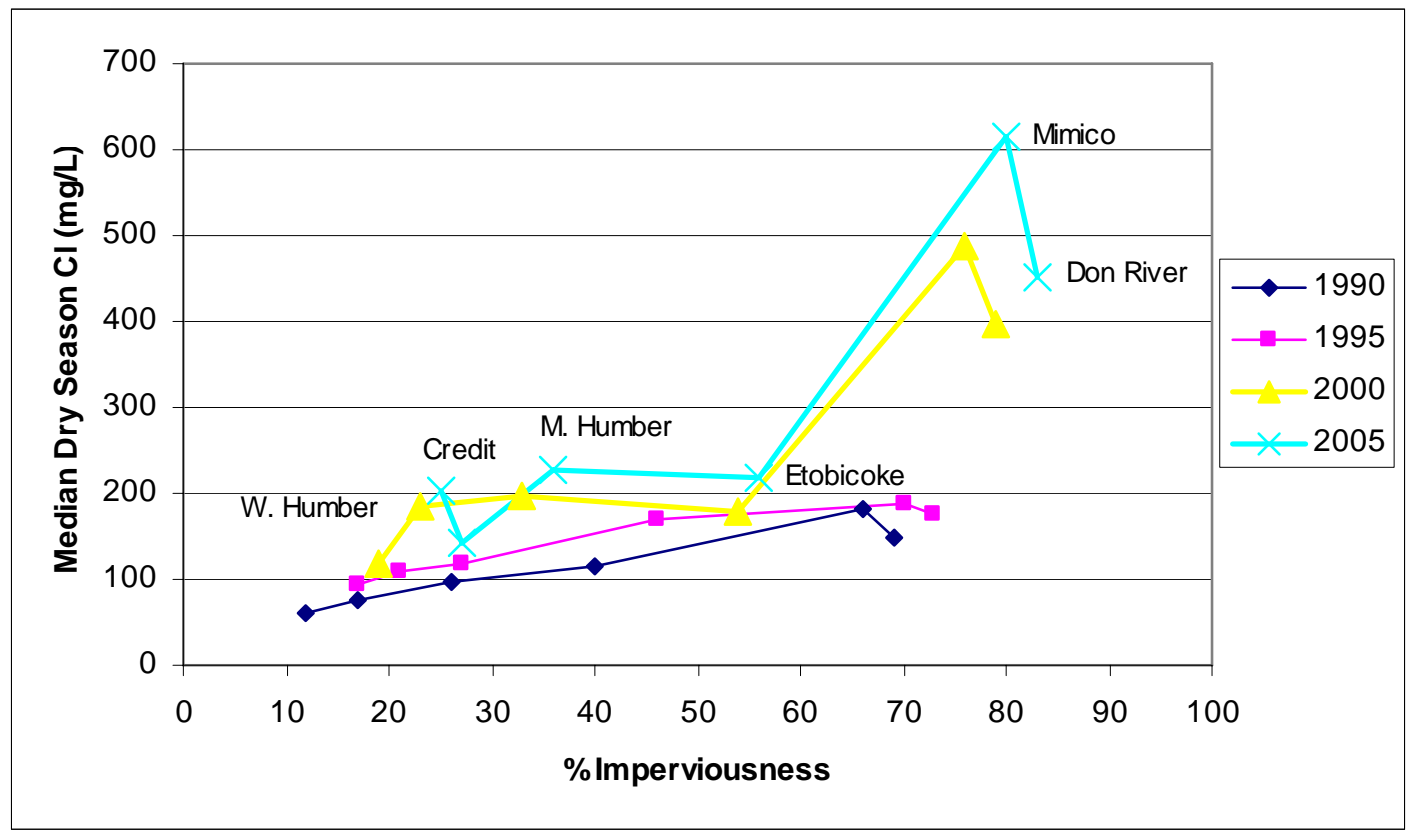

Figure 4.17 Non-linear correlation between chloride (dry season) and impervious surfaces in six selected watersheds by year.

\subsection{Chapter Summary}

Overall, the integration of remotely sensed impervious surfaces with surface water chloride concentrations revealed how closely these two variables are correlated. The value of this correlation is that both chloride concentrations and the degree of imperviousness in a watershed may serve as a preliminary indicator parameter in environmental monitoring programs. Therefore, very fast, simple and inexpensive outlined map of surface water chloride concentrations in conjunction with impervious surface areas using remote sensing techniques could indicate the relative degradation of different stream segments or document long-term watershed degradation related to gradual urban sprawl. 


\section{CHAPTER 5}

\section{CONCLUTIONS AND RECOMMENDATIONS}

This chapter begins by a brief overview of the main study objective and how successful the research was in meeting this objective. Section 5.1 draws the conclusions of the major achievements and findings. This is followed by summary of the limiting factors found in the results (Section 5.2). In Section 5.3 several recommendations are made on how the study can help municipalities as well as local and regional water resource planners to make informed decisions. Finally, suggestions for future research are provided in Section 5.4.

\subsection{Conclusions}

In this research, spatial as well as temporal analysis of chloride levels as a function of impervious surfaces was carried out in the selected GTA watersheds. The main objective of this study was to relate the percentage of impervious surfaces to chloride which is a nonpoint source pollutant as well as a water quality indicator. This objective came from the knowledge that water bodies around the GTA are impaired as a result of nonpoint source pollution, and that developed lands contribute to that pollution.

With urbanization, the amount of impervious surfaces and in particular transportation related surfaces such as roads, highways, sidewalks, and parking spaces increase. Due to the region's cold climate and heavy snow precipitation in winter, road maintenance practices require the usage of salt in order to ensure roads are free of ice and snow. This is required to provide safe transportation conditions. Thus, as cities and 
municipalities expand and the area covered by impervious surfaces expands, the area on which the salt is applied also increases. Impervious surfaces prohibit the infiltration of water. When the salt covered snow melts during winter and spring thaw, polluted runoff is transported into receiving surface waters which eventually reach the Lake Ontario.

The results demonstrated an average of $12.9 \%$ increase in impervious surfaces and a corresponding three-fold increase in chloride levels from 1990 to 2005. The Mimico Creek and Don River watersheds, two of the most urbanized watersheds in the GTA, exhibited the highest amounts of chloride concentrations. Overall, through an innovative integrated remote sensing approach, the empirical evidence collected in this study was successful in demonstrating a strong relationship between increases in impervious surface areas and chloride levels over time as well as identifying areas most vulnerable to surface water quality degradation by road salts.

With the direct correlation between imperviousness and chloride, an obvious benefit of remotely sensed impervious surfaces is that this type of data alone can provide clues as to which areas are more prone to water quality degradation. In areas where up-to-date and accurate chloride data is unavailable, continuous spatially explicit remotely sensed impervious data may provide equally beneficial coverage of areas under stress.

\subsection{Limitations of the Study}

Due to cost and availability restrictions associated with Landsat-5 TM images, the study only examined the relationship between chloride and impervious surfaces in a 
five year interval between 1990 and 2005. Instead of a five year interval, the annual classification of impervious surfaces could provide officials with more detailed information on the patterns of urban sprawl and could offer more constructive recommendations to urban planners for their future practices in the region. Also, to get a better understanding of the cumulative results of chloride salts, a detailed annual investigation of salt usage, private (residential and commercial) usages, as well as frequency of extreme storm events could provide more definitive correlations.

This study found a steady increase in the amount of impervious surfaces over the years as well as a steady increase in chloride levels in surface waters over the years. For this reason it was expected that there would also be an increase in salt usage by the municipalities. However no such correlation was observed. This lack of correlation is primarily attributed to the lack of comprehensive public salt usage data. Gathering salt usage data from the municipality officials proved very challenging mainly because they were not responsive to the request of information. Their unwillingness to share data proved a serious challenge to obtaining comprehensive data sets. This was an insurmountable obstacle because the municipalities were the sole proprietors of public salt usage data. In addition to their reluctance in sharing data the City of Brampton and the City of Mississauga did not retain historical data on salt purchases for more than seven years.

Chloride, by nature, persists in the environment and thus has residual impacts. Therefore, it was difficult to establish whether the increase in surface water chloride concentrations were exclusively attributed to annual usage of salt as a function of new developments or whether it is attributed to the persistent nature of the chloride and the residual effect of chloride from previous years. 
At last, the major issue that limited the scope of this research is that although the results presented in this study indicate a correlation does exist between the level of imperviousness and chloride levels, due to lack of funding, steady historic chloride data were missing for a significant number of monitoring stations within the study area watersheds. Not to mention the uneven distribution of water quality monitoring stations. Therefore, not enough sample sites could be included in the investigation to provide a truly quantitative and statistically robust analysis. The relationships reported here are strictly qualitative, they warrant further investigation and quantification.

\subsection{Recommendations for Water Resource Planners}

Urban nonpoint source pollution represents one of the most complex environmental challenges facing the Great Lakes Basin. Watershed and urban planners constantly look for ways to reduce nonpoint source pollution. One way to reduce nonpoint source pollution is to reduce imperviousness. In recent years, impervious surfaces have emerged as a water quality indicator. Understanding the spatial and temporal relationship between imperviousness and water quality would allow for informed land use management decisions (Clausen et al., 2003; Moore and Palmer, 2005).

Use of imperviousness as a water quality indicator is valuable for a number of reasons. First, although impervious surfaces do not generate pollution directly, they are a key component of the land-uses that do generate pollution. Impervious covers prohibit natural interception and filtration of pollutants by soil and vegetation, serve as a system transporting pollutants into the waterways, and therefore are a critical contributor to the hydrologic changes that pollute water resources (Arnold and Gibbons, 1996). It is not surprising, then, that research from the past two decades 
consistently shows a strong correlation between the imperviousness of a watershed and the quality of its streams and rivers.

The second reason that makes imperviousness such an ideal factor to be used in regional water resource planning is that it is quantifiable. For this reason, it has an enhanced ability to be utilized in planning and policy applications. Estimate of the degrees of imperviousness enables city officials and municipalities to look into the future of their cities, and indirectly to the health of their local water resources.

The long-term nature of this study suggests an increasing trend in both chloride levels and impervious surfaces in the coming years. The next step would be for the urban planners and decision makers in the Peel Region and City of Toronto to reverse the adverse effects caused by impervious surfaces and road salts. Minimizing the negative effects of chloride on the environment can be achieved through regulatory approaches, utilization of Best Management Practices (BMP), public education, and more importantly, considerable reduction in use of inorganic salts through use of alternative product. These are briefly discussed in the following paragraphs.

Recent studies show that Scandinavian countries are currently studying alternatives to traditional road salts, including mixing it with sand or sugar and replacing it with other chemicals, such as potassium (Jackson and Jobbagy, 2005). While there is ongoing research into the use of alternatives, salt continues to be the most costeffective and widely used de-icing agent across Canada. 
In April 2004, Environment Canada released a Code of Practice for the Environmental Management of Road Salts. Since then, the Municipality of Metropolitan Toronto as well as the Regional Municipality of Peel have developed a Salt Management Plan to minimize the amount of salt entering the environment by including best salt handling practices, and using new technologies. The Code of Practice is a voluntary pollution control tool for road authorities using more than 500 tonnes of road salts per year. It is proposed that unless mandatory requirements are put in place by regulatory authorities, no effective method of salt management, storage, application or disposal could be achieved and no major reduction in usage could be implemented (Hounsell et al., 2006).

As well as Salt Management Plans, other urban Best Management Practices can be implemented to decrease the urban impacts by road salts. These practices include: grassed waterways, porous pavement, green roofs, nutrient and chemical management, detention basins, infiltration facilities, catch basins, wetlands, and buffer strips (Brabec et al., 2002; Groffman et al., 2004, VanWoert et al., 2005). It is important to note that these practices have limitations, therefore the effectiveness of these BMPs in the study area watersheds grants further examination. Within the Greater Toronto Area, one region that has always been the focus of local and regional planners is the ORM. A study by Bowen and Hinton (1998) revealed that upstream areas within the ORM dilute chloride concentrations (and other nonpoint source pollutants) in downstream urban areas (Bowen and Hinton, 1998). Proper management and conservation of ORM should be continued to ensure a healthy environment in the region. 


\subsection{Directions for Future Research}

This study was an exploratory study and it enabled the identification of other issues that merit examination. Some directions for future research are provided below:

While the results presented in this study provide a consistent set of impervious surface estimates over a 15-year period, continued examination of object-oriented classification as well as other classification approaches such as pixel-based classification might serve to increase classification accuracy results.

Chloride was the only water quality parameter that was tested in relation to the degree of imperviousness in this study. Another area that can be explored in the future is the comparison of other water quality parameters such as total suspended solids, $\mathrm{pH}$ level, nitrogen, phosphorus, calcium, sodium, and carbon with impervious surfaces.

To represent the study in a more comprehensive and statistically strong manner, one possible future scenario to examine would be to monitor the effects of chloride on a large number of streams with watersheds that contain a variety of impervious surfaces. This would allow for a better assessment of the impact of impervious surfaces on stream health over a broader range of impervious surface levels as well as varying land-use types. Therefore, it is important to recognize that some impervious areas are completely surrounded by pervious areas and therefore have less of an impact on water resources. On this note, it would be interesting to examine the quality of watersheds without headwaters in the Oak Ridges Moraine compared to the ones surrounded by large areas covered by riparian forest. 
As demonstrated in the results, water quality degradation is attributed to the amount of impervious surface coverage, but more than likely it is a combination of the impervious surface coverage and the land use upon which those impervious surfaces rest that affect water quality. Thus, it is important to include land use information such as the amount of industry, commercial enterprises, traffic congestion and roads (primary and secondary) in future studies.

In this study, the entire watershed from the location of the monitoring station was included in the calculation of percent impervious surface assuming that any nonpoint source pollutant would eventually reach the monitoring station's location. However, it is important to test the impact of impervious surfaces that are far from the water quality monitoring station versus those that are close. It is possible to see different results when taking into consideration far-range effects of impervious surfaces compared to near-range effects of imperviousness.

The advantage of impervious surfaces as an environmental indicator is that it primarily signifies the direct impact of road salts (chloride) on surface water quality. It also can provide some indirect measure of other effects that are not directly related to road salts but are often associated with imperviousness, such as population density or urban climate change. Future studies can demonstrate whether imperviousness could serve as an indicator for effects related to agricultural and rural practices that can also significantly affect stream water quality. Therefore, impervious surfaces cannot serve as a universal indicator of surface water health but may serve as one of many indicators that could be used in environmental and ecological monitoring. 


\section{REFERENCES}

Arnold, C.L and C.J. Gibbons. 1996. Impervious Surface Coverage: The Emergence of a Key Environmental Indicator. Journal of the American Planning Association. 62(2): 3243-258.

Barnes, K. B., J.M. Morgan, and M.C. Roberge, 2001. Impervious Surfaces and the Quality of Natural and Built Environments. Baltimore, MD: Department of Geography and Environmental Planning, Towson University.

Bauer, M. E., J.K. Doyle, and N.J. Heinert, 2002. Impervious Surface Mapping Using Satellite Remote Sensing. Proceedings, IEEE Geoscience and Remote Sensing Symposium, 24-28 June, Toronto, Canada, Unpaginated CD ROM.

Booth, D.B., and L.E. Reinfelt, 1993. Consequences of Urbanization on Aquatic Systems - Measured Effects, Degradation Thresholds, and Corrective Strategies. Proceedings of Watershed 1993: A National Conference on Watershed Management. March 21-24, Alexandria, VA. pp. 545-550.

Bowen, G.S. and M.J. Hinton, 1998. The Temporal and Spatial Impacts of Road Salt on Streams Draining the Greater Toronto Area. Proceedings of the Groundwater in A Watershed Context Symposium, December 2-4, 1998. Canadian Water Resources Association.

Boyd, D., 1999. Assessment of Six Tributary Discharges to the Toronto Area Waterfront. Volume 1: Project Synopsis and Selected Results. Ontario Ministry of the Environment. Prepared for the Toronto and Region Remedial Action Plan.

Boyer, E.W., C.L. Goodale, N.A. Jaworsk, and R.W. Howarth. 2002. Anthropogenic Nitrogen Sources and Relationships to Riverine Nitrogen Export in the Northeastern USA. Biogeochemistry. 57(1): 137-169.

Brandes, D., G.J. Cavallo, and M.L. Nilson, 2005. Base-flow and Trends in Urbanizing Watersheds of the Delaware River Basin. Journal of American Water Resource Association, 41(6): 1377-1391.

Brabec, E., S. Schulte, and P.L. Richards, 2002. Impervious Surfaces and Water Quality: A Review of Current Literature and Its Implications for Watershed Planning, Journal of Planning Literature, 16(4):499-514.

Campbell, J.B., 2002. Introduction to Remote Sensing, 3/e. The Guilford Press, New York, NY, 620p.

Canadian Council of Ministers of the Environment, 1998. Guidelines for Canadian Drinking water Quality. Environment Canada, Ottawa, Ontario.

Clausen, J.C., G. Warner, D. Civco and M. Hood. 2003. Nonpoint Education for Municipal Officials Impervious Surface Research: Final Report. Connecticut DEP. 18p. 
Corwin, D.L., and R.J. Wagenet, 1996. Applications of GIS to the Modeling of Nonpoint Source Pollutants in the Vadose Zone: A Conference Overview. Journal of Environmental Quality, 25(3):403-410.

Coulter, C.B., Kolka, R.K., and J.A. Thompson, 2004. Water Quality in Agricultural, Urban and Mixed Land Use Watersheds. Journal of American water resources association. 40(6): 1593-1601.

Credit Valley Conservation, 2005. Watershed Report Card: A Detailed Summary on the Ecosystem Health of the Credit River Watershed. 23p. URL:

http://www.creditvalleycons.com/bulletin/downloads/WRCard-Detailed.pdf (Last date accessed: Nov 15, 2007)

CRISP, 2007. Centre for Remote Imaging, Sensing and Imaging. SPOT, France, URL: http://www.crisp.nus.edu.sg/ research/tutorial/spot.htm (last date accessed: Oct 2, 2007)

City of Toronto, 2007. Toronto Facts. Canada. URL: http://www.toronto.ca/toronto_facts/diversity.htm (Last accessed Nov. 16, 2007)

D'Andrea and R. Anderton, 1996. Assessment of Tributary Discharges Along the Metropolitan Toronto Waterfront. In Proceedings of the Watershed Management Symposium, Canadian Water Resources Association. ISBN 1-896513-06-9.

Donnay, J.P., M.J. Barnsley and P.A. Longley, 2001. Remote Sensing and Urban Analysis. Remote Sensing and Urban Analysis. (J.P. Donnay, M.J. Barnsley and P.A. Longley, editors), Taylor \& Francis, London, pp. 1-18.

Environment Canada, 2001. Priority Substances List Assessment Report: Road Salts. Environment Canada and Health Canada. Prepared for the Canadian Environmental Protection Act, 1999 Priority Substances List. Internet Publication. http://www.hcsc.gc.ca/ewhsemt/alt_formats/hecssesc/pdf/pubs/contaminants/psl2l sp2/road_salt_sels_voirie/road_salt_sels_voirie_e.pdf (Last date accessed: Dec 1, 2007)

Environment Canada, 2007. Canadian Climate Normals. Monthly Data Report for the Pearson International Airport Weather Station. URL: http://www.climate.weatheroffice.ec.gc.ca/climate_normals/stnselect_e.html (Last date accessed: Dec 1, 2007)

Environmental Protection Agency, 2002. National Water Quality Inventory. 2000 Report. EPA-841-R-02-001. Office of Water. Washington D.C. 20460.

Flanagan, M. and D.L. Civco, 2001. Subpixel Impervious Surface Mapping. Proceedings of 2001 ASPRS Annual Convention. 23-27 April. St. Louis. Missouri (American Society for Photogrammetry and Remote Sensing, Bethesda. Maryland). Unpaginated CD-ROM.

Forsythe, K.W. and P. Du, 2006. Development Patterns in Canada’s Largest Urban 
Agglomeration: Four Decades of Evolution. Proceedings of the 1st International Workshop of the EARSeL Special Interest Group Urban Remote Sensing (SIGURS) “Challenges and Solutions”. March 2-3, 2006. Berlin, GERMANY. (CDROM).

Frost, L. R., S. J. Pollock, and R. F. Wakelee, 1981. Hydrogeologic Effects of Highway De-icing Chemicals in Massachusetts. U.S. Geological Survey, Report 81-209, 56p.

GeoCommunity, 2007. Sensor Description...QuickBird. URL: http://imaging.geocomm.com/features/sensor/quickbird/ (last date accessed: Nov 20, 2007).

Gerber, R., and K.H. Howard, 1997. Groundwater to the Oak Ridges Moraine, St. John’s, Newfoundland, Geological Association of Canada. pp.173-192.

Gibson, R.J., R.L. Haedrich, and C.M. Wernerheim, 2005. Loss of Fish Habitat as a Consequence of Inappropriately Constructed Stream Crossings. Fisheries 30(1): 10-17.

Groffman, P.M., N.L. Law, K.T. Belt, L.E. Band, and G.T. Fisher, 2004. Nitrogen Fluxes and Retention in Urban Watershed Ecosystems. Ecosystems 7: 393-403.

Hall, M.J., 1984. Urban Hydrology, Elsevier Applied Science Publishers, Northern Ireland. 299p.

Herlihy, A.T., J.L. Stoddard, and C.B. Johnson, 1998. The Relationship Between Stream Chemistry and Watershed Land Cover Data in the Mid Atlantic Region, U.S. Water Air and Soil Pollution. 105 (1-2): 377-386.

Hounsell, J., A. Lintner, and K. Mercer, 2006. Low-salt Diet for Ontario’s Roads and Rivers. Current State of Regulation and Policy, the Ecosystem, Socio-Economic and Health Implications, and Alternative Substances for Winter Road Maintenance. RiverSides Stewardship Alliance and Sierra Legal Defense Fund. URL:

http://www.riversides.org/websitefiles/riversides_road_salts_report_final.pdf (Last date accessed: Dec 1, 2007)

Howard, K.W.F. and S. Livingstone, 2000. Transport of Urban Contaminants into Lake Ontario via Sub-surface Flow. Journal of Urban Water, 2: 183-195.

Howard, W.F. and H. Maier, 2006. Road De-Icing Salt as a Potential Constraint on Urban Growth in the Greater Toronto Area, Canada. Journal of Contaminant Hydrology, 91:146-170.

Hurd, J.D. and D.L. Civco, 2004. Surface Water Quality and Impervious Surface Quantity: a Preliminary Study. Technical Project Completion Report, Project NOAA NA16OC2673NOAA, Coastal Services Center, Charleston, SC. 57p. 
Jackson, R.B. and E.G. Jobbagy, 2005. From Icy Roads to Salty Streams. PNAS, 102 (41): 14487-14488.

Jensen, J.R., 2005. Introductory Digital Image Processing: a Remote Sensing Perspective, 3/e. Prentice-Hall, Upper Saddle River, New Jersey.

Johnson, G.D. and P.B. Kauss, 1991. Tributary Contaminant Inputs on the St. Clair and Detroit Rivers and Lake St. Clair 1984-1985. Water Resources Branch, Ontario Ministry of the Environment, Toronto, Ontario.

Kaushal, S.S., P.M. Groffman, G.E. Likens, K.T. Belt, W.P. Stack, V.R. Kelly, L.E. Band, and G.T. Fisher, 2005. Increased Salinization of Fresh Water in the Northeastern United States, Proceedings of the National Academy of Sciences of the United States of America, 102 (2005):13517-13520.

Krause, C.W., B. Lockard, T.J. Newcomb, D. Kibler, V. Lohani, and D.J. Orth, 2004. Predicting Influences of Urban Development on Thermal Habitat in a Warm Water Stream. Journal of American Water Resource Association, 40(6): 16451658.

Lillesand, T.M., R.W. Kiefer and J.W. Chipman, 2004. Remote Sensing and Image Interpretation, 5/e, John Wiley \& Sons, New York, NY, 763p.

Lillesand, T.M. and R.W. Kiefer, 2000. Remote Sensing and Image Interpretation, 4/e, John Wiley \& Sons, New York, NY, 208p.

Loague, K., D.L. Corwin, and T.R. Ellsworth, 1998. The Challenge of Predicting Nonpoint Source Pollution: GIS Can Assess Soil and Groundwater Contamination by Pollutans, But Uncertainties Must be Quantified. Environmental Science \& Technology, 32(5):130-133.

Locat, J., and P. Gelinas, 1989. Infiltration of Deicing Road Salts in Aquifers: The Trois-Rivieres-Ouest Case Study, Quebec, Canada. Canadian Journal of Earth Sciences, 26(11): 2186-2193.

Lunetta, R.S., and C.D. Elvidge, 1998. Applications, Project Formulation, and Analytical Approach, Remote Sensing Change Detection: Environmental Monitoring Methods and Applications (R.S. Lunetta and C.D. Elvidge, editors), Taylor \& Francis, London. pp. 1-19.

Mayer, T., W.J. Snodgrass and D. Morin, 1999. Spatial Characterization of the Occurrence of Road Salts and Their Environmental Concentrations as Chlorides in Canadian Surface Waters and Benthic Sediments. Water Quality Resources Journal of Canada, 34(4): 545-574.

Meyer, S.C., 2005. Analysis of Base-flow Trends in Urban Streams, Northeastern Illinois, USA. Journal of Hydrogeology, 13: 871-885. 
Mokken, R.J., 1995. Remote Sensing, Statistics and Artificial Neural Networks Some R \& D Perspectives. Proceedings of the International Symposium on Spectral Sensing Research '95 (ISSSR), Theme: Crisis Support. 26 November - 1 December 1995, Melbourne, Victoria, Australia. CD-ROM.

Moffett, D., and J. Hasse, 2006. Looking for the Relationship Between Sprawl and Water Quality: A Case Study of Gloucester County, NJ. Middle States Geographer, 39: 26-33.

Moore, A.A., and M.A. Palmer, 2005. Invertebrate Biodiversiy in Agricultural and Urban Headwater Streams: Implications for Conservation and Management. Ecological Applications, 15(4): 1169-1177.

Ontario Ministry of Environment, 2007. Provincial Water Quality Monitoring Network. Government of Ontario. Queen's Printer for Ontario. URL: http://www.ene.gov.on.ca/envision/news/2005/051602mb.htm (Last date accessed: Nov 18, 2007).

Oruc, M., A.M. Marangoz, and G. Buyuksalih, 2004. Comparison of Pixel-Based and Object-Oriented Classification Approaches Using Landsat-7 ETM Spectral Bands. Proceedings of the ISRPS 2004 Annual Conference, Istanbul, Turkey. July 19-23.

Paine, L., 1979. Chlorides in the Don River Watershed Resulting from Road De-Icing Salt, Technical Report Working Paper Pub. No. SIC-3, University of Toronto, Institute of Environmental Studies Snow and Ice Working Group.

Perchanok, M.S., D.G. Manning and J.J. Armstrong, 1991. Highway Deicers:

Standards, Practice and Research in the Province of Ontario. Research and Development Branch, Ontario Ministry of Transportation, Downsview, Ontario. 53 pp. (MAT-91-13).

Pilon, P. and K.W.F. Howard, 1987. Origins of Elevated Chloride Concentrations in Groundwater Systems. Ontario Ministry of the Environment Technology Transfer Conference No. 7, Toronto, December, pp. 376-398 (ISSN 0-825-4591).

Pollock, S., 1992. Remediating Highway De-Icing salt Contamination of Public and Private Water Supplies in Massachusetts. Resources, Conservation and Recycling, 7: 7-24.

Qiu, F., K.L. Woller and R. Briggs, 2003. Modeling Urban Population Growth from Remotely Sensed Imagery and TIGER GIS Road Data. Photogrammetric Engineering and Remote Sensing, 69 (9): 1031-1042.

Qian, J., Q. Zhou and Q. Hou, 2007. Comparison of Pixel-Based and Object-Oriented Classification Methods for Extracting Built-up Areas in Arid Zones. Proceedings of ISPRS Workshop on Updating Geo-spatial Databases with Imagery \& The 5th ISPRS Workshop on DMGISs, 1(2007):163-171. 
Region of Peel, 2007. Peel data centre. 2006 Census. URL:

http://www.region.peel.on.ca/planning/pdc/data/census/census-tables-2006.htm

Rose, S., and N.E. Peters, 2001. Effects of Urbanization on Streamflow in the Atlanta Area (Georgia, USA): A Comparative Hydrological Approach. Hydrological Processes, 15: 1441-1457.

Roy, H.A., D.A. Rosemond, J.M. Paul, D.S. Leign, and B.J. Wallace. 2003. Stream Macroinvertebrate Response to Catchment Urbanization. Freashwater Biology, 48:329-346.

Satellite Imaging Corporation, 2007. Characterization of Satellite Remote Sensing Systems. URL: http://www.satimagingcorp.com/satellite-sensors.html (Last date accessed: Oct 21, 2007)

Shuster, W.D, J. Bonta, H. Thurston, E. Warnemuende, and D.R. Smith. 2005. Impact of Impervious Surface on Watershed Hydrology. Urban Water Journal, 2(4):263275.

Sibul, U., K.T. Wang, and D. Vallery, 1977. Ground Water Resources of the Duffins Creek- Rouge River Drainage Basins. Ministry of the Environment, Water Resources Report, 8, 109p.

Schmidt, C., 2004. Sprawl: The New Manifest Destiny? Environmental Health Perspectives. 112: A621-A627.

Schueler, T.R., 1994. The Importance of Imperviousness. Watershed Protection Techniques, 1(3): 100-111.

Snodgrass, W. and M. D’Andrea, 1993. Dry Weather Discharges to the Metropolitan Toronto Waterfront. A Report Prepared for the Toronto Remedial Action Plan, Queen's Printer of Ontario, Toronto.

Sonzogni, W.C., W. Richardson, P. Rodgers and T.J. Monteith. 1983. Chloride Pollution of the Great Lakes. Journal of Water Pollution Control, 55: 513-521.

Soil and Water Conservation Society- Ontario Chapter, 2007. Adapting to Impacts on Soil and Water from Higher Intensity Rains with Climate Change in the Great Lakes Basin. Final Report.

Stocker, J. 1998. Methods for Measuring and Estimating Impervious Surface Coverage. NEMO Technical Paper No.3, University of Connecticut, Haddam Cooperative Extension Center.

Stocker, J.W., C. Arnold, S. Prisloe and D. Civco, 1999. Putting Geospatial Information into the Hands of the "Real" Natural Resource Managers. Proceedings of the 1999 ASPRS Annual Convention, Portland, Oregon. pp. 10701076. 
Todd, D.A., P.B. Bedient, J.F. Hassbeek, and N. Joel, 1989. Impact of Land Use and NPS Loads on Lake Quality. Journal of Environmental Engineering. 115(3): 633649.

Toronto and Region Conservation Authority, 2007a. Drinking Water Source Protection. URL: http://www.ctcswp.ca/index.shtml, (Last date accessed: Nov 3, 2007).

Toronto and Region Conservation Authority, 2006a. Turning Over a New Leaf: The Etobicoke and Mimico Creek Watersheds Report Card 2006. 51p.

Toronto and Region Conservation Authority, 2006b. Forging a New Deal for the Don: the 2006 Don Watershed Progress Report. URL:

http://www.trca.on.ca/Website/TRCA/Website.nsf/WebPage/trca_water_protecti on strategies_don_don?OpenDocument\#healthy (Last date accessed: Nov 4, 2007).

Toronto and Region Conservation Authority, 1998. 1990 to 1996 Water Quality Data from the Toronto RAP Watershed; Based on Data from the Ontario Ministry of the Environment's Provincial Water Quality Monitoring Network. Toronto, Ontario.

Toronto and Region Conservation Authority, 2007b. HumberRiver Watershed Plan 2007: Draft, June 11, 2007. TRCA, Toronto, Ontario. 13p.

VanWoert, N.D., D.B. Rowe, J.A. Andresen, C.L. Rugh, R.T. Fernandez, and L. Xiao, 2005. Green roof stormwater retention: Effects of Roof Surface, Slope, and Media Depth. Journal of Environmental Quality, 34: 1036-1044.

Wang, Y.Q., Zhang, X., and Lampa, W. 2000. Improvement of Spatial Accuracy in Natural Resources Mapping Using Multisensor Remote Sensing and Multisource Spatial Data. In Proceedings of the 4th International Symposium on Spatial Accuracy Assessment in Natural Resources and Environmental Sciences, 12-14 July 2000, Amsterdam, The Netherlands. Edited by G.B.M. Heuvelink and M.J.P. Lemmens. Delft University Press, Delft, The Netherlands. pp. 723-730.

Weng, Q.H., 2001. Modeling Urban Growth Effects on Surface Runoff with the Integration of Remote Sensing and GIS. Environmental Management. 28(6): 737748.

Williams, D.D., N.E. Williams and Y. Cao, 2000. Road Salt Contamination of Groundwater in a Major Metropolitan Area and Development of a Biological Index to Monitor its Impact. Water Resources, 34(1): 127-138.

Witte, R.S., 1989. Statistics. 3/e. Holt, Rinehart and Winston Inc., New York.

Wu, C., and A.T. Murray, 2003. Estimating Impervious Surface Distribution by Spectral Mixture Analysis. Remote Sensing of Environment, 84(4): 493-505. 